\title{
End-tital inspiratory activity and asthma : an experimental study in animals and humans
}

Citation for published version (APA):

Meessen, N. E. L. (1996). End-tital inspiratory activity and asthma : an experimental study in animals and humans. [Doctoral Thesis, Maastricht University]. Maastricht University. https://doi.org/10.26481/dis.19960619nm

Document status and date:

Published: 01/01/1996

DOI:

10.26481/dis.19960619nm

Document Version:

Publisher's PDF, also known as Version of record

\section{Please check the document version of this publication:}

- A submitted manuscript is the version of the article upon submission and before peer-review. There can be important differences between the submitted version and the official published version of record.

People interested in the research are advised to contact the author for the final version of the publication, or visit the DOI to the publisher's website.

- The final author version and the galley proof are versions of the publication after peer review.

- The final published version features the final layout of the paper including the volume, issue and page numbers.

Link to publication

\footnotetext{
General rights rights.

- You may freely distribute the URL identifying the publication in the public portal. please follow below link for the End User Agreement:

www.umlib.nl/taverne-license

Take down policy

If you believe that this document breaches copyright please contact us at:

repository@maastrichtuniversity.nl

providing details and we will investigate your claim.
}

Copyright and moral rights for the publications made accessible in the public portal are retained by the authors and/or other copyright owners and it is a condition of accessing publications that users recognise and abide by the legal requirements associated with these

- Users may download and print one copy of any publication from the public portal for the purpose of private study or research.

- You may not further distribute the material or use it for any profit-making activity or commercial gain

If the publication is distributed under the terms of Article $25 \mathrm{fa}$ of the Dutch Copyright Act, indicated by the "Taverne" license above, 
END-TIDAL INSPIRATORY ACTIVITY AND ASTHMA An experimental study in animals and humans 
N N.E.L. Meessen, Heteren 1996

End-tidal inspiratory activity and asthma- An experimental study in animals and humans.

Thesis, Rijksuniversiteit Limburg, The Netherlands ISBN 90-9009531-4

Datawyse | Universitaire Pers, Maastricht 


\section{END-TIDAL INSPIRATORY ACTIVITY AND ASTHMA}

An experimental study in animals and humans

\section{PROEFSCHRIFT}

ter verkrijging van de graad van doctor

aan de Rijksuniversiteit Limburg te Maastricht,

op gezag van de Rector Magnificus, Prof.mr. M.J. Cohen, volgens het besluit van het College van Decanen, in het openbaar te verdedigen

op woensdag 19 juni 1996 om 12.00 uur

door

Nicolaas Emile Leo Meessen 
PROMOTORES

Prof.dr. S.C.M. Luijendijk

Prof.dr. H.Th.M. Folgering (Katholieke Universiteit Nijmegen)

CO-PROMOTOR

Dr.ir.C.P.M. van der Grinten

BEOORDELINGSCOMIMISSIE

Prof.dr. C.E. Blanco, voorzitter

Prof.dr. Ph.H. Quanjer (Rijksuniversiteit Leiden)

Prof.dr. F. Spaans

The studies presented in this thesis were performed at:

Department of Pulmonology

University Hospital Maastricht

The Netherlands

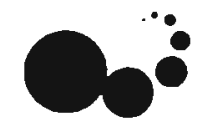

Department of Pulmonary Diseases

University Hospital Nijmegen, Dekkerswald

The Netherlands

The studies were granted by The Netherlands Asthma Foundation.

Publication of this thesis was financially supported by SmithKline Beecham Farma b.v. and The Netherlands Asthma Foundation. 
aan Juleck en Marylla

voor Paulus, Marte-Sophie en Sonja 



\section{CONTENTS}

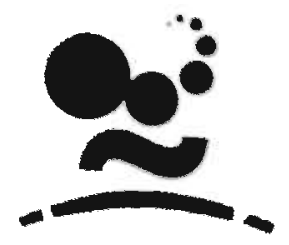

List of abbreviations

1 General introduction

2 Tonic activity in inspiratory muscles during continuous negative airway pressure in cats

3 Histamine-induced end-tidal inspiratory activity and lung receptors in cats

4 Continuous negative airway pressure increases tonic activity in diaphragm and intercostal muscles

5 Histamine-induced bronchoconstriction and end-tidal inspiratory activity in man

6 Breathing pattern during bronchial challenge in humans

7 General discussion

8 Summary

9 Samenvatting

Dankwoord

Curriculum vitae 


\section{Abbreviations}

\begin{tabular}{|c|c|}
\hline $\mathrm{BHR}^{+}$ & bronchial hyperresponsiveness \\
\hline $\mathrm{BHR}^{-}$ & no bronchial hyperresponsiveness (='normal') \\
\hline BL & baseline \\
\hline CNAP & continuous negative airway pressure \\
\hline CPAP & continuous positive airway pressure \\
\hline CL,dyn & dynamic compliance of the lung \\
\hline CTRL & control \\
\hline EMG & electromyogram \\
\hline EMGdi & EMG of the diaphragm \\
\hline EMGet & EMG; end-tidal value \\
\hline EMGICM & EMG of parastemal intercostal muscles \\
\hline EMGphas & phasic inspiratory EMG activity \\
\hline EMGphasene & phasic inspiratory EMG activity during control breaths \\
\hline EMGpk & peak inspiratory EMG activity \\
\hline $\mathrm{EMGpk}_{\mathrm{cTRL}}$ & peak inspiratory EMG activity during control breaths \\
\hline $\mathrm{EMGpk}_{\text {HIST }}$ & peak inspiratory EMG activity after administration of histamine \\
\hline ETIA & end-tidal inspiratory activity \\
\hline ETIAdi & end-tidal inspiratory activity obtained from EMG of diaphragm \\
\hline ETIAICM & end-tidal inspiratory activity obtained from EMG of ICM \\
\hline $\mathrm{FEV}_{1}$ & forced expiratory volume in $1 \mathrm{sec}$ \\
\hline $\mathrm{f}$ & respiratory frequency \\
\hline FRC & functional residual capacity \\
\hline FVC & forced vital capacity \\
\hline ICM & parasternal intercostal muscles \\
\hline $\mathrm{kPa}$ & kilo Pascal; $1 \mathrm{kPa} \approx 10 \mathrm{~cm} \mathrm{H}_{2} \mathrm{O}$ \\
\hline Páo & pressure at airway opening \\
\hline Pol & arterial blood pressure \\
\hline \multirow[t]{2}{*}{$\mathrm{PC}_{20}$} & provocative concentration of histamine causing a fall of $20 \%$ \\
\hline & in $\mathrm{FEV}_{1}$ relative to control \\
\hline $\mathrm{PetCO}_{2}$ & partial pressure of carbon dioxide in end-tidal air \\
\hline$P_{p}$ & transpulmonary pressure \\
\hline
\end{tabular}




$\begin{array}{ll}\text { Pur } & \text { tracheal pressure } \\ \text { RAR } & \text { rapidly adapting pulmonary stretch receptor } \\ \text { RL } & \text { lung resistance } \\ \text { RL,in } & \text { lung resistance during inspiration } \\ \text { RL,ex } & \text { lung resistance during expiration } \\ \text { Rrs } & \text { resistance of respiratory system } \\ R_{r_{6}} & \text { Rrs determined at } 6 \mathrm{~Hz} \text { by forced oscillation technique } \\ \text { SAR } & \text { slowly adapting pulmonary stretch receptor } \\ \text { SE } & \text { standard error of the mean } \\ \tau & \text { time constant of decay of inspiratory activity during expiration } \\ \text { UI } & \text { duration of inspiration } \\ \text { tE } & \text { duration of expiration } \\ \text { TIA } & \text { tonic inspiratory activity } \\ \text { Tvg } & \text { temperature of vagus nerves in cooling device } \\ \dot{V} & \text { airflow } \\ \dot{V} E & \text { minute ventilation } \\ \text { VT } & \text { tidal volume }\end{array}$



1

General Introduction 


\subsection{INTRODUCTION}

Important characteristics of acute asthma are bronchoconstriction and hyperinflation ${ }^{52}$. It has been shown that end-tidal lung volume is increased during histamine-induced bronchoconstriction ${ }^{26}$. Bronchoconstriction and hyperinflation have often been induced by histamine to study the aforementioned characteristics of asthma ${ }^{27.34}$.

Inspiratory muscles are not always fully inactive during expiration. In the literature, the end-tidal electrical activity of inspiratory muscles, just prior to the phasic increase in inspiratory activity, is mostly called tonic inspiratory activity ${ }^{34}$. Martin et al. ${ }^{27}$ have shown that during histamine-induced hyperinflation the end-tidal pleural pressure was lower than the predicted chest wall relaxation pressure at the corresponding end-tidal lung volume, indicating end-tidal activity of inspiratory muscles. End-tidal inspiratory activity (ETIA) is considered as one of the causes of hyperinflation ${ }^{26,27}$. ETIA has been observed in human subjects during exacerbations of asthma and after administration of histamine both in man and animals ${ }^{3.4 .35}$. These studies have further shown a significant correlation between the increase in thoracic gas volume and the increase in ETIA. Recent studies in rabbits and cats have shown that lowering tracheal pressure can also evoke ETIA ${ }^{19.37}$. Although histamine-induced ETIA is absent after vagotomy ${ }^{3.19}$, the physiological mechanisms causing ETIA were largely unknown when we started this study. Therefore, we performed experiments in cats and humans to evaluate the precise role of pulmonary receptors in generating ETIA. Further, the contribution of ETIA to histamine-induced hyperinflation in humans was evaluated.

\subsection{PULMONARY RECEPTORS}

In 1868 Hering and Breuer presented the results of their investigations concerning the role of the vagus nerve in the control of respiration ${ }^{721}$. Briefly, Breuer observed in animals that if the tracheal cannula was occluded at the end of an expiration, the next inspiration was already markedly prolonged and also more forceful, whereas connection to oxygen-free air at the end of expiration did not immediately produce these effects. In addition, if the tracheal cannula was occluded at the end of an inspiration, the duration of the subsequent expiration was increased. These reflexes are now known as the Breuer-Hering inflation and deflation reflexes. Breuer and Hering concluded that the degree of distension of the lung has a modifying influence on the pattern of breathing. where the degree of lung distension is mediated to the central respiratory centres through pulmonary afferents running in the vagus nerve. Receptors involved in the aforementioned reflexes have been originally called pulmonary stretch receptors. Inflation of the lung enhances the afferent impulses of these 
receptors causing inspiratory off-switch, and their continuing discharge during expiration lengthens the expiratory pause. Adrian ${ }^{1}$ developed techniques for recording activity from single fibres of the vagus nerve and identified pulmonary stretch receptors on the basis of their pattern of activity. The discharge frequency of these receptors is enhanced by lung inflation and adapts slowly when this stimulus is maintained. Therefore, these receptors are now called slowly adapting pulmonary stretch receptors (SARs)،

Since, exploration of afferent pathways from the lower respiratory tract has been continued ${ }^{24,48}$. It has been shown that a second group of receptors of the trachea and larger bronchi are sensitive to mechanical stimulation and to inhaled chemical irritants and reflexly induce cough. These 'irritant' receptors have been renamed rapidly adapting pulmonary stretch receptors (RARs) because these receptors adapt rapidly when stimulated by inflation ${ }^{24}$. Although the terms irritant receptors and RARs are used interchangeably, the latter appears to be more appropriate.

Many studies have been performed on pulmonary receptors and their respiratory reflexes $2,11,36,38,42,4751$. The vagus nerve is considered to contain three types of pulmonary afferent fibres: myelinated fibres originating from SARs and RARs, and unmyelinated fibres from so called $\mathrm{C}$-fibre endings. The importance of the vagal afferent innervation of these receptors in modifying the breathing pattern can be demonstrated by blockade of their afferent fibres or by vagotomy, which results in alterations in the breathing pattem and in the loss of reaction to (noxious) stimuli.

In the studies presented in this thesis, pulmonary receptors play a prominent role in the discussion about the mechanisms underlying the end-tidal activity of inspiratory muscles. In the next paragraphs the three types of pulmonary receptors will be characterised in more detail.

\subsubsection{SLOWLY ADAPIING PULMONARY STRETCH RECEPTORS}

Slowly adapting pulmonary stretch receptors (SARs) are responsible for the BreuerHering inflation reflex. In addition, stimulation of SARs causes the tracheobronchial smooth muscles to relax, resulting in airway dilatation ${ }^{51}$. SARs are closely associated with airway smooth muscles. Branches end as free terminals bound to connective tissue elements between the lamina propria and the smooth muscle layer. Afferent activity from SARs appears to increase as the tension in the airway wall increases, and is made up of a dynamic and a static component ${ }^{8}$. When a given lung inflation is imposed and maintained, SARs characteristically show a long-lasting discharge with an immediate rapid rise that slows progressively into a sustained firing rate ${ }^{4,6,9,41}$ : SARs cannot be distinguished from RARs by their adaptation rate alone. They can be further identified as SARs by the remarkable regularity of the interspike interval, 
reflecting their steady discharge. Conduction velocities of impulses through vagal (myelinated) fibres of SARs have been found to be relatively high as compared to those in afferents of RARs and C-fibre endings ${ }^{4 i}$. A wide range of conduction velocities have been found for afferents of SARs. Conduction velocities in afferents of SARs, however, are consistently higher than those in afferents of RARs ${ }^{41}$.

Few chemicals are known to excite SARs, and none are known to stimulate them selectively. In rabbits high concentrations of $\mathrm{SO}_{2}$ abolish receptor discharge selectively, an effect utilized in this species to assess the respective contributions of SARs and RARs to the deflation reflex ${ }^{10}$. In other species (i.e. in cats) $\mathrm{SO}_{2}$ does not appear to abolish SAR discharge ${ }^{20,49}$. Because of differences in conduction velocities impulses in afferents of SARs and RARs can be blocked selectively by cooling the vagus nerves to an appropriate temperature ${ }^{23,39}$.

\subsubsection{RAPIDLY ADAPTING PULMONARY STRETCH RECEPTORS}

Knowlton and Larrabee ${ }^{24}$ identified RARs as receptors with myelinated fibres that were stimulated by lung inflation but differed from SARs in having a more rapid adaptation of their firing rate to sustained inflations, and a more irregular pattern of discharge. According to their report, most of these receptors show a brief irregular burst of impulses during lung inflation, the frequency of which decreases rapidly at maintained inflation.

The term irritant receptor is also used for these receptors because of their response to inhaled agents such as ammonia, dust, and cigarette smoke $e^{33.44}$. Further, RARs can be stimulated by forced deflations ${ }^{2,42,43,48}$. Thus, deflation increases the input from RARs to the brain-stem and reduces that from SARs ${ }^{1}$. RARs concentrated at the carina and in the primary bronchi are believed to mediate the cough reflex ${ }^{49}$.

Thus, RARs are sensitive to mechanical and chemical stimuli and reflexly give rise to several defense reflexes. The reflex actions of RARs include cough and bronchoconstriction, and probably also hyperpnoea ${ }^{50}$.

RARs are believed to have epithelial nerve endings in the tracheobronchial submucosa. Degeneration experiments have confirmed that these intra-epithelial terminals have vagal afferents.

Histamine is a natural drug that is often used to activate RARs ${ }^{40}$. A major difficulty in investigating the reflexes of RARs is that histamine (and other naturally occurring chemicals) known to stimulate RARs are themselves powerful bronchoconstrictors. Of particular interest, therefore, is the question how much of the reflex effects of RARs can be ascribed to mechanical stimulation and how much to direct chemical stimulation of the nerve endings ${ }^{16,46}$. 


\subsubsection{C-FIBRE ENDINGS}

Formerly, C-fibre endings have been called deflation receptors because deflation was thought to be their natural stimulus ${ }^{8}$. As it was subsequently found that these receptors were relatively insensitive to deflations ${ }^{2}$, they were renamed juxta-pulmonary capillary receptors (J-receptors) because of their location near pulmonary capillaries ${ }^{36}$. The terms pulmonary and bronchial $\mathrm{C}$-fibres refer to the blood supply of the endings and thus to their general locations, close to the pulmonary and bronchial circulations respectively ${ }^{14}, \mathrm{~J}$-receptor is equivalent to pulmonary $\mathrm{C}$-fibre. In the face of their relative insensitivity to deflations C-fibre endings differ markedly from RARs. It has been shown that $\mathrm{C}$-fibre endings can to some extent be stimulated by inflation ${ }^{2}$. However, C-fibre endings are vigorously stimulated by pulmonary congestion ${ }^{36}$. Phenyl diguanide and capsaicin, two chemicals known to stimulate C-fibre endings, are regularly used to study reflex effects of these receptors. Conduction velocities of impulses in the unmyelinated afferents of $\mathbf{C}$-fibre endings are much lower than in the myelinated afferents of SARs and RARs ${ }^{41}$. Due to these electrophysiological properties, reflex effects of myelinated and unmyelinated afferents have been studied by selectively cooling the vagus nerves. At temperatures below $6{ }^{\circ} \mathrm{C}$ the conduction in myelinated fibres is markedly diminished, whereas conduction in C-fibres is still largely intact ${ }^{21,39}$.

Reflex actions of C-fibre endings include apnoea followed by rapid shallow breathing. It is generally believed that $\mathbf{C}$-fibre endings are nociceptive endings which are primarily activated by tissue damage, the accumulation of interstitial fluid and the release of mediators. During intrapulmonary sederna, a strong stimulus for C-fibre endings, lungs, are more stiff, and rapid shallow breathing appears ergonomically favourable.

In summary: SARs can be stimulated by inflation (e.g. continuous positive airway pressure, CPAP). RARs can be stimulated by histamine, by deflation (e.g. continuous negative airway pressure, CNAP) and by hyperinflation. Histamine acts in two ways on RARs: 1) indirectly by mechanical stimulation due to bronchoconstriction, 2) directly by chemical stimulation. Further, histamine evokes bronchoconstriction in two ways: a) by a vagal reflex due to stimulation of RARs, b) by direct stimulation of bronchial smooth muscles. Reflex effects of the three different pulmonary receptors can be studied by selective cooling of the vagus nerves ${ }^{18}$. Below $6{ }^{\circ} \mathrm{C}$ conduction in afferents of myelinated fibres (of SARs and RARs) is markedly reduced, whereas that in C-fibres is still largely intact. Conduction of impulses in afferents of RARs appears to be diminished at lower temperatures than conduction in afferents of SARs. Thus, when cooling the vagus nerves from $37{ }^{\circ} \mathrm{C}$ down to $0{ }^{\circ} \mathrm{C}$ the conduction in the afferents of SARs is affected first, followed by that in RARs and finally that in Cfibres. 


\subsection{HYPERINFLATION AND RESPIRATORY MUSCLES}

Pulmonary hyperinflation can be defined as an increase in end-tidal lung volume above functional residual capacity which is determined by the equilibrium of passive elastic forces of the lung and thoracic wall. Hyperinflation has a static and a dynamic component. In normal subjects the end-tidal lung volume during tidal breathing corresponds to the relaxed lung volume of the total respiratory system. In patients with emphysema, the elastic recoil of the lung is diminished, which results in a marked increase in the relaxed lung volume. This and/or transformed passive elastic characteristics of the chest wall are responsible for the static component of hyperinflation. In asthmatics, hyperinflation is also substantially determined by dynamic factors. In conditions of bronchoconstriction, expiration is impaired by high airway resistance with concomitant expiratory flow limitation. When the duration of expiration is too short to fully exhale, hyperinflation develops.

Increased end-tidal lung volume is a well known feature of acute bronchoconstriction in response to inhalation of histamine in asthmatic patients ${ }^{52}$. It has been found that the increases in end-tidal lung volume do not parallel the magnitude of intrapulmonary gas trapping due to bronchoconstriction ${ }^{27}$. Hyperinflation, associated with histamine-induced bronchoconstriction in normal and asthmatic subjects, is also determined by another active component, as has been shown by EMG reoordings of inspiratory muscles ${ }^{34,35}$. These changes are reversible by administration of bronchodilators. Another contributor to hyperinflation is persisting activity of inspiratory muscles at the end of expiration ${ }^{2628,34}$. If inspiratory muscles are not completely relaxed at end of expiration, end-tidal lung volume will be increased.

The pathophysiological effects of hyperinflation are beneficial as well as detrimental ${ }^{15}$. Hyperinflation improves the distribution of inspired air over the lung ${ }^{25}$ and lowers airway resistances. In general, however, hyperinflation is considered to be disadvantageous to inspiratory muscle function ${ }^{12}$. Hyperinflation causes an unfavourable shift on the pressure-volume curve; i.e. the elastic recoil of the lungs is increased. The efficiency of the diaphragm is decreased due to a shift on its length-tension curve and a flattening of its curvature. Muscle fibres of the costal part of the diaphragm, which are apposed to the thorax, may no longer be at more or less right angles to the tibres of the crural part of the diaphragm. Hence, during hyperinflation the zone of apposition is decreased and its fibres are more or less in series with the crural fibres. This explains why in patients with severe hyperinflation the lower part of the rib cage moves inward during inspiration, which implies that the diaphragm functions as a fixator of the thoracic basis rather than as a major agonist of inspiration. The mechanical disadvantages of hyperinflation for the parastemal intercostal muscles (ICM) are much less ${ }^{12,13,22}$. 


\subsection{AIMS AND OUTLINE OF THE STUDIES}

The aims of our studies were to analyze the origin and consequences of ETIA. To address the question of the origin of ETIA, experiments were performed in animals. ETIA had already been shown in rabbits ${ }^{3.37}$ and cats $^{19}$. The roles of the three groups of pulmonary receptors, RARs, SARs and C-fibre endings, in the generation of ETIA were studied in anaesthetized spontaneously breathing cats. EMGs from the diaphragm and the parasternal intercostal muscles (ICM) were recorded under several conditions. To differentiate between the reflex effects of the different pulmonary receptors, the experiments were performed at different temperatures of the vagus nerves and after vagotomy. It has been shown that ETIA can be induced in cats by application of $\mathrm{CNAP}^{19}$. Further, it is known that CNAP stimulates RARs mechanically. Thus, we applied CNAP to evaluate the effects of mechanical stimulation of RARs on ETIA. Results of these experiments are presented in chapter 2. RARs can also be stimulated by histamine $e^{2,4}$. Administration of histamine will stimulate RARs chemically and mechanically due to the associated bronchoconstriction. Therefore, we also studied the effects of intravenous administration of histamine on ETIA. Additionally, SARs were stimulated by application of CPAP. Results of administration of histamine and application of CPAP are presented in chapter 3.

The experiments conducted in cats showed that ETIA is increased by stimulation of RARs, and that stimulation of SARs decreases ETIA, while C-fibre endings are not involved in the generation of ETIA.

The consequences of ETIA for breathing were evaluated in studies performed in humans while extrapolating the above-mentioned mechanism of the generation of ETIA obtained from our studies in animals. Accordingly, the increase in ETIA was quantified in response to mechanical stimulation of RARs by application of CNAP. Results are presented in chapter 4. Further, histamine was administered to evaluate the contribution of mechanical and chemical stimulation of RARs to ETIA. Histamine-induced increase in end-tidal lung volume and the relative contributions of ETIA and of bronchoconstriction to the increased end-tidal lung volume were quantified. To that end, humans were challenged with histamine, both before and after administration of bronchodilators. EMGs of the diaphragm and ICM were: recorded simultaneously. Changes in bronchoconstriction, ETIA and end-tidal lung volume were determined. The results of this study are presented in chapter 5 .

It is known that vagal afferents are involved in the control of breathing ${ }^{17.32,45}$. We analyzed the effects of inhalation of histamine on the breathing pattern in humans. Results of these experiments are presented in chapter 6. 
Initially, in the publications ${ }^{29.31}$ reproduced in chapters 2 and 4 , we used the term 'tonic inspiratory activity' which we adoptecl from the literature ${ }^{2734}$. 'Tonic' refers to inspiratory activity present at the end of expiration just prior to the onset of phasic inspiratory activity. In the publications ${ }^{30}$ reproduced in chapters 3 and 5 , we preferred to use the term ETIA because we think that 'tonic' does not reflect the nature of ETIA properly (see chapters 3 and 7). Hence, in this thesis both terms 'tonic inspiratory activity and ETIA are used.

\subsection{REFERENCES}

1. Adrian ED (1933). Afferent impulses in the vagus and their effect on respiration. J Physiol (Lond) 79: 332-358.

2. Armstrong DJ and Luck JC (1974). A comparative study of irritant and type J receptors in the cat. Respir Physiol 21: 47-60.

3. Badier M, Jammes $Y$, Romero-Colomer P and Lemerre C (1989). Tonic activity in inspiratory muscles and phrenic motoneurons by stimulation of vagal afferents. J Appl Physiol 66: 1613-1619.

4. Barlett D,Jr. and St.John WM (1979). Adaptation of pulmonary stretch receptors in different mammalian species. Respir Physiol 37: 303-312.

5. Bouhuys A. Pressure-flow relations. In: The physiology of breathing, edited by Bouhuys A. New York: Grune and Stratton, 1977, p. 173-201.

6. Bradley GW and Scheurmier N (1977). The transduction of tracheal stretch receptors in vitro. Respir Physiol 31: 365-375.

7. Breuer J (1868). Die Selbststeuerung der Athmung durch den Nervus vagus. Sitrungsber Akad Wiss Wien 58: 909-937.

8. Coleridge HM and Coleridge JCG. Reflexes evoked from tracheobronchial tree and lungs. In: Handbook of Physiology. The Respiratory System. Control of Breathing, Vol. II, edited by Cherniack NS and Widdicombe JG. Bethesda, MD: American Physiological Society, 1986, p. 395-429.

9. Davenport PW, Sant'Ambrogio FB and Sant'Ambrogio G (1981). Adaptation of tracheal stretch receptors. Respii Phiysiol 44: 339-349.

10. Davies A. Dixon M, Callanan D, Huszczuk A, Widdicombe JG and Wise JCM (1978). Lung reflexes in rabbits during pulmonary stretch receptor block by sulphur dioxide. Respir Physiol 34: 83-101.

11. Davies A and Roumy M (1986). A role of pulmonary rapidly adapting receptors in control of breathing. Aust J Exp Bio! Med Sci 64: 67-78.

12. Decramer $\mathbf{M}$ (1989). Effects of hyperinflation on the respiratory muscles. Eur Respir $\mathbf{J}$ 2: 299-302.

13. Decramer M. Effects of hyperinflation on respiratory muscle function. In: Chronic pulmonary hyperinflation, edited by Grassino A, Rampulla C, Ambrosino $\mathrm{N}$ and Fracchia C. London: Springer-Verlag, 1991, p. 83-89. 
14. Delpierre S, Grimaud C, Jammes $\mathrm{Y}$ and Mei N (1981). Changes in activity of vagal bronchopulmonary $\mathrm{C}$ fibres by chemical and physical stimuli in the cat. J Physiol (Lond) 316: $61-74$.

15. Demedts M (1990). Mechanisms and consequences of hyperinflation. Eur Respir J 3: 617-618.

16. Dixon M, Jackson DM and Richards IM (1979). The effects of histamine, acetylcholine and 5-hydroxytryptamine on lung mechanics and irritant receptors in the dog. J Physiol (Lond) 287: 393-403.

17. Fanelli A, Duranti R, Gorini M, Spinelli A, Giglioti F and Scano G (1994). Histamine-induced changes in breathing pattern may precede bronchoconstriction in selected patients with bronchial asthma. Thorax 49: 639-643.

18. Grinten van der CPM, Meessen NEL and Luijendijk SCM. Vagal cooling and the origin of pulmonary reflexes in cats. In: Modelling and control of ventilation, edited by Semple SJG and Adams L. New York: Plenum, 1995, p. 67-72.

19. Grinten van der CPM, Vries de WR and Luijendijk SCM (1992). Vagally mediated modification of inspiratory activity by changes in airway pressure. Respir Physiol 90: 159-172.

20. Grunstein MM, Hazucha J, Sorli J and Milic-Emili J (1977). Effects of SO2 on control of breathing in anesthetized cats. J Appl Physiol : Respirat Environ Exercise Physiol 43: 844-851.

21. Hering $\mathbf{E}$ and Breuer $\mathbb{J}$ (1868). Die Selbststeuerung der Athmung durch den Nervus vagus. Sitzungsber Akad Wiss Wien 57: 672-677.

22. Jiang TX, Deschepper K, Demedts $\mathbf{M}$ and Decramer M (1989). Effects of acute hyperinflation on the mechanica! effectiveness of the parasternal intercostals. Am Rev Respir Dis 139: 522-528.

23. Jonzon A, Pisarri TE, Roberts AM, Coleridge JCG and Coleridge HM (1988). Attenuation of pulmonary afferent input by vagal cooling in dogs. Respir Physiol 72: 19-34.

24. Knowlton GC and Larrabee MG (1946). A unitary analysis of pulmonary volume receptors. Am J Physiol 147: 100-114.

25. Macklem PT (1984). Hyperinflation. Am Rev Respir Dis 129: 1-2.

26. Martin JG, Habib M and Engel LA (1980). Inspiratory muscle activity during induced hyperinflation. Respir Physiol 39: 303-313.

27. Martin JG, Powell E, Shore SA, Emrich J and Engel LA (1980). The role of respiratory muscles in the hyperinflation of bronchial asthma. Am Rev Respir Dis 121: 441-447.

28. Martin JG, Shore SA and Engel LA (1983). Mechanical load and inspiratory muscle action during induced asthma. Am Rev Respir Diș 128: 455-460.

29. Meessen NEL, Grinten van der CPM, Folgering HTM and Luijendijk SCM (1993). Tonic activity in inspiratory muscles during continuous negative airway pressure. Respir Physiol 92: 15!-166.

30. Meessen NEL, Grinten van der CPM, Folgering HTM and Luijendijk SCM (1995). Histamine-induced end-tidal inspiratory activity and lung receptors in cats. Eur Respir J 8: 2094-2103.

31. Meessen NEL, Grinten van der CPM, Luijendijk SCM and Folgering HTM (1994). Continuous negative airway pressure increases tonic activity in the diaphragm and intercostal muscles in humans. J Appl Physiol 77: 1256-1262.

32. Millman RP, Silage DA, Peterson DD and Pack AI (1982). Effect of aerosolized histamine on occlusion pressure and ventilation in humans. J Appl Physiol 53: 690-697. 
33. Mills JE, Sellick H and Widdicombe JG (1969). Activity of lung irritant receptors in pulmonary microembolism, anaphylaxis and drug-induced bronchoconstrictions. J Physiol (Lond) 203: 337-357.

34. Muller N, Bryan AC and Zamel N (1980). Tonic inspiratory muscle activity as a cause of hyperinflation in histamine-induced asthma. J Appl Physiol : Respirat Environ Exercise Physiol 49: 869-874.

35. Muller N, Bryan AC and Zamel N (1981). Tonic inspiratory muscle activity as a cause of hyperinflation in asthma. I Appl Physiol : Respirat Environ Exercise Physiol 50: 279-282.

36. Paintal AS (1969). Mechanisms of stimulation of type J pulmonary receptors. J Physio! (Lond) 203: 511-532.

37. Patberg WR (1983). Effect of graded vagal blockade and pulmonary volume on tonic inspiratory activity in rabbits. Pflügers Arch 398: 88-92.

38. Pisarri TE, Jonzon A, Coleridge HM and Coleridge JCG (1992). Vagal afferent and reflex responses to changes in surface osmolarity in lower airways of dogs. J Appl Physiol 73: 2305-2313.

39. Pisarri TE, Yu J, Coleridge HM and Coleridge JCG (1986). Background activity in pulmonary vagal C-fibers and its effects on breathing. Respir Fhysiol 64: 29-43.

40. Ravi K, Singh M and Julka DB (1995). Properties of rapidly adapting receptors of the airways in monkeys (Macaca mulatta). Respir Physiol 99: 51-62.

41. Sant'Ambrogio G (1982). Information arising from the tracheobronchial tree of mammals. Physiol Rev 62: 531-569.

42. Sellick $H$ and Widdicombe JG (1969). The activity of lung irritant receptors during pneumothorax, hyperpnoea and pulmonary vascular congestion. J Physiol (Lond) 203: 359-381,

43. Sellick H and Widdicombe JG (1970). Vagal deflation and inflation reflexes mediated by lung irritant receptors. Q J Exp Physiol 55: 153-163.

44. Sellick H and Widdicombe JG (1971). Stimulation of lung irritant receptors by cigarette smoke, carbon dust, and histamine aerosol. J Appl Physiol : Respirat Environ Exercise Physiol 31: 15-19.

45. Strumberg NOT and Gustatsson PM (1993). Ventilatory pattern during hronchial histamine challenge in aschmatics. Eur Respir J 6: 1126-1131.

46. Vilruk FH, Hahin HL. Nadel JA and Sampson SR (1977). Mechanisms by which histamine stimulates rapidly adapting receptors in dog lungs. J Appl Physiōl : Respirat Environ Fxercise Physiol 43: 397-402.

47. Von Euler $\mathrm{C}$. Herrero $\overrightarrow{\mathrm{F}}$ and Wexler $\mathrm{I}(1970)$ ). Control mechanisms determining rate and depth of respiratory movements. Respir Physiol 10: 93-108.

48. Widdiconbe JG (1954). Receptors in the trachea and bronchi of the cat. J Physiol (Lond) 123: 71-104.

49. Widdicombe JG (1954). Respiratory reflexes from the trachea and bronchi of the cal. J Physiol (Lond) 123: 55-70.

50. Widdicomle JG. Nervous receptors in the respiratory tract and lungs. In: Lung Biology in Health and Disease, Regulation of breathing. Vol. 17, part I, edited by Hombein T. New York: Dekker, 1981, p. 429-472.

51. Widdicombe JG and Nadel IA (1963). Reflex effects of lung inflation on tracheal volume. J Appi Physio! i8: 681-686.

52. Woolcock A, Rebuck AS, Cade JF and Read J (1971). Lung volume changes in asthma measured concurrently by two methods. Ann Rev Respir Dis 104: 703-709. 


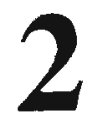

Tonic activity in inspiratory muscles during continuous negative airway pressure in cats 


\subsection{ABSTRACT}

We studied tonic inspiratory activity (TIA) induced by continuous negative airway pressure (CNAP) in anaesthetized, spontaneously breathing cats. TIA in the diaphragm and parasternal intercostal muscles (ICM) was quantified in response to tracheal pressure $(\mathbb{P r})=-0.3$ to $-1.2 \mathrm{kPa}$. To differentiate between reflexes from rapidly adapting receptors (RARs), slowly adapting receptors (SARs) and C-fibre endings different temperatures of the vagus nerves ( $T \mathrm{vg}$ ) were used between 4 and $37{ }^{\circ} \mathrm{C}$. At Ptr $=-1.2 \mathrm{kPa}$ mean TIA values were $41 \%$ and $62 \%$ of peak inspiratory EMG activity of controll breaths for the diaphragm and ICM, respectively. After vagotomy and for Tvg $<6{ }^{\circ} \mathrm{C}$ CNAP did not induce TIA any more. Changes in. duration of inspiration and duration of expiration during vagal cooling down to $4{ }^{\circ} \mathrm{C}$ confirmed the selective block of conductance in vagal afferents of the three types of lung receptors. We conclude that CNAP-induced TIA results from stimulation of RARs. Our data strongly indicate that stimulation of SARs suppresses TIA, whereas C-fibre endings are not involved in TIA at all. The results suggest that part of the hyperinflation in bronchial asthma may be caused by TIA in response to mechanical stimulation of RARs.

\subsection{INTRODUCTION}

Inspiratory muscles are not always fully inactive in expiration. The electrical activity observed in the electromyogram (EMG) of inspiratory muscles at the end of expiration- just prior to the phasic increase in inspiratory activity- is called tonic inspiratory activity (TIA). TIA enhances functional residual capacity and has been observed in human subjects during an exacerbation of asthma and after administration of histamine in both man and animals ${ }^{2.19}$. Recently, we have shown in cats that histamine-induced TIA can be considered as the net result of excitation of inspiratory activity by rapidly adapting pulmonary stretch receptors (RARs) and of inhibition of inspiratory activity by slowly adapting pulmonary stretch receptors (SARs) ${ }^{16}$.

In previous studies it has been shown that histamine stimulates RARs both by a direct chemical effect and by an indirect mechanical effect resulting from bronchoconstric$\operatorname{tion}^{23.25}$. It is likely, therefone, that histamine-induced TIA is the result of both effects. In both rabbits and cats phrenic activity and electrical activity of inspiratory intercostal muscles have been observed in late expiration during mechanical stimulation of lung receptors by decreasing tracheal pressure $(\mathrm{Ptr})$ or by deflating the lungs $\mathrm{s}^{\mathrm{I}, 20}$. Activity in the afferents of RARs has been shown to increase instantaneously after deflating the lungs of rabbits ${ }^{18,22}$. Comparable effects have been observed in cars'. Although 
these studies have been useful in describing qualitative effects of mechanical stimulation of lung receptors, they have not yielded adequate information concerning the magnitude of TIA in response to mechanical stimulation of RARs.

The aim of the present investigation in anaesthetized, spontaneously breathing cats. was to quantify TIA evoked by mechanical stimulation of RARs. Continuous negative airway pressure (CNAP) was applied to stimulate RARs. In order to differentiate between the reflex effects of the different types of lung receptors (RARs, SARs and C-fibre endings) the experiments were performed at different temperatures of the cervical vagus nerves. This method has been applied before by several authors ${ }^{14,21}$. To quantify TIA in response to decreased Pr EMGs were recorded from both the diaphragm and the parasternal intercostal muscles (ICM). Several other respiratory variables were also analyzed.

\subsection{METHODS}

\subsubsection{ANIMALS AND ANAESTHESIA}

Experiments were performed on 20 adult cats of either sex, weighing between 3.8 and $7.0 \mathrm{~kg}$. They were sedated with ketamine-hydrochloride $(10 \mathrm{mg} / \mathrm{kg}$ body weight, i.m.) and anaesthetized by intravenous injection of a chloralose-urethane mixture (12.5 mg/kg and $62.5 \mathrm{mg} / \mathrm{kg}$, respectively). Supplemental doses of the anaesthetic mixture, $5 \%$ of the initial dose, were given if needed to maintain surgical anaesthesia. The cats were placed in the supine position on an operating table and breathed spontaneously. Arterial blood pressure (Pol), heart rate, breathing frequency (f) and the partial pressure of carbon dioxide in end-tidal air $\left(\mathrm{PerCO}_{2}\right)$ were continuously monitored.

\subsubsection{MEASUREMENTS}

Catheters were inserted into the left femoral artery and vein for monitoring Pol and for intravenous administration of fluids. Pol was measured with a differential pressure transducer (Statham P23). The trachea was exposed in the neck and a cannula (7 mm O.D., $40 \mathrm{~mm}$ long) was inserted just below the cricoid cartilage. The tracheal cannula was connected to a flow-pressure transducer (Fleisch no. 0) of a pneumotachograph (Gould) by which airflow (V) could be measured. The other end of the Fleisch head was connected to a main tube by means of a T-piece. Tracheal pressure (Ptr), relative to that of room air, was obtained from a side arm of the T-piece (Figure 2.1). An oesophageal balloon was used to measure oesophageal pressure. Transpulmonary pressure ( $\left.\mathrm{P}_{\mathrm{t}}\right)$ was obtained from the difference between $\mathrm{P} t \mathrm{t}$ and oesophageal pressure. To verify the proper operation of the oesophageal balloon an inspiratory 
effort against an occluded tracheal cannula was performed. Ptp should then remain unchanged during the effort. Ptr and Ptp were measured with differential pressure transducers (Statham PM131TC).

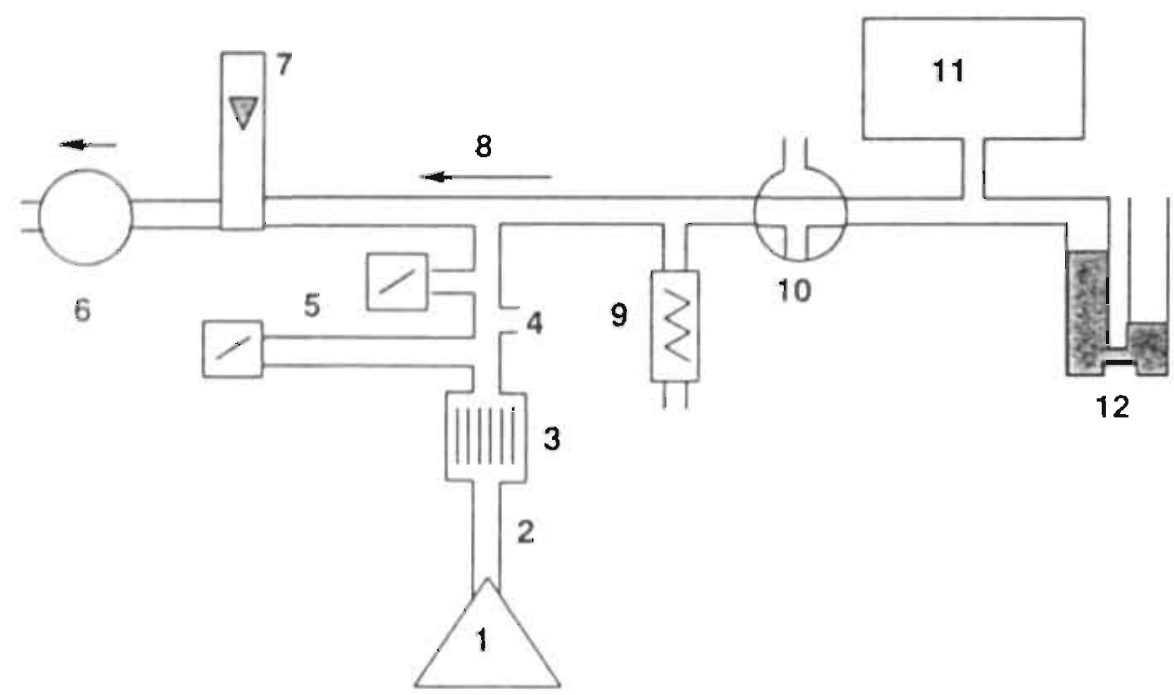

Figure 2.1 Diagram of breathing circuir.

1. cat. 2. tracheal cainula, 3. Fleisch head, 4. port for measuring CO2, 5. ports for measuring tracheal and transpulmonary pressure, 6. vacuum pump, 7. flow meter, 8. direction of bias flow, 9. adjustable flow resistance, 10. 3-way tap, 11. bottle $(50 \mathrm{l})$, 12. water manometer. With tap in position, as shown, airway pressure is negative.

A vacuum pump was used to maintain a constant bias flow of about $18 \mathrm{l} \cdot \mathrm{min}^{-1}$ in the main tube, which was sufficient to prevent rebreathing of expired gas. By turning a 3way tap, the free connection to room air was occluded and the bias flow was then directed through an adjustable flow resistance (Figure 2.1). At the same time the connection to the water manometer was accomplished. With the help of this manometer and the adjustable flow resistance a certain value of Pr was preset. During an experimental run a preset negative Pur could be established almost instantaneously by rapidly turning the tap. A large bottle filled with air $(50 \mathrm{i})$ and a water manometer with wide tubes (diam $9 \mathrm{~cm}$ ) were used to minimize pressure fluctuations in the main tube due to breathing by the cat.

The electric conductance in vagal afferents could be blocked by cooling both cervical vagus nerves. The vagi were exposed in the mid neck and freed from the carotid sheaths, and the two nerves were placed in the gold coated grooves of two cooling devices. The grooves were $13 \mathrm{~mm}$ long, $2 \mathrm{~mm}$ deep and $1 \mathrm{~mm}$ wide. In each device a Peltier element (cooling) and a transistors (heating) were used to achieve the 
required temperature. The temperature of the vagus nerves ( $\mathrm{Tvg}_{\mathrm{vg}}$ could be adjusted between 37 and $0{ }^{\circ} \mathrm{C}$ with a precision of $0.1{ }^{\circ} \mathrm{C}$. To protect the vagi from drying and deterioration both nerves were immersed in oxygenated paraffin oil.

At the end of the experimental protocol bilateral section of the cervical vagi was performed to eliminate all output from lung receptors through vagal afferents to central respiratory centres. Temperature of both proximal ends of the cut vagi were then maintained at $0{ }^{\circ} \mathrm{C}$ to prevent spontaneous excitations.

Hooked needle electrodes were used to obtain EMGs from inspiratory muscles. After a small abdominal incision had been made just below the ribcage, a pair of electrodes was inserted into the costal part of the diaphragm. Further, a second pair of electrodes was inserted parasternally into the intercostal muscles approximately $1 \mathrm{~cm}$ lateral to the sternum in the third or fourth intercostal space.

The electric activity of the diaphragm (EMGdi) and of ICM (EMGICM) were amplified, filtered (low frequency cutoff at $150 \mathrm{~Hz}$ and high frequency cutoff at 3000 $\mathrm{Hz}$ ), rectified and fed into a leaky integrator with a time constant of $50 \mathrm{~ms}$ (Neurolog, Digitimer). $\mathrm{PerCO}_{2}$ was measured by a capnograph (Nellcor $\mathrm{N}-1000$ ). Body temperature was taken from the rectum and maintained between $36-38{ }^{\circ} \mathrm{C}$ by heating the operating table.

Signals representing EMGdi, EMGicm, V. Ptp, $\mathrm{Ptr}, \mathrm{Pet}_{\mathrm{CO}}$, Pbl, rectal temperature and $\mathrm{T}_{\mathrm{vg}}$ (from both vagi) were monitored continuously and were further sampled $(50 \mathrm{~Hz})$ for off-line analysis.

\subsubsection{EXPERIMENTAL PROTOCOL}

We studied the effects of CNAP on TIA, at normal Tvg and at decreased Tvg. The effect of stimulation of $\mathrm{C}$-fibre endings was studied in 4 animals. To that end a dose of capsaicin $(50 \mu \mathrm{g} / \mathrm{kg})$ was administered by intravenous injection at three values of Tvg (37, 10, and $\left.4{ }^{\circ} \mathrm{C}\right)$. In the final part of the experiment we studied the effect of $\mathrm{Pur}=-0.9 \mathrm{kPa}$ on TIA after vagotomy.

a) CNAP-induced TIA at normal temperature of the cervical vagi.

After 10 control breaths had been recorded at normal Ptr, airway pressure was decreased to $-0.3,-0.6,-0.9$ or $-1.2 \mathrm{kPa}$ in a steplike fashion during an expiration, maintained at the adjusted level for at least 10 breaths and restored again to control during an inspiration. Thus, altogether about 30 breaths were recorded. Between two consecutive trials a recovery period of at least 3 minutes was allowed.

b) CNAP-induced TLA at different temperatures of the cervical vagi.

Before starting the recordings $T_{\mathrm{vg}}$ was maintained at the selected value for at least 2 minutes. For all temperatures the same level of CNAP $(-0.9 \mathrm{kPa})$ was ised. Further, the experimental protocol was the same as the one described above. The following values for Tvg were used: $37,22,14,12,10,8,6$ and $4{ }^{\circ} \mathrm{C}$. 


\subsubsection{DATA ANALYSIS}

From the recordings we determined end-tidal EMG activity (EMGet) and peak inspiratory EMG activity compared to the electrical zero levell from both the diaphragm and ICM. In order to eliminate the effects of instrumental, inter-animal and intra-animal scatter in the measured EMG activity we quantified TIA as the ratio of EMGet to the mean peak inspiratory EMG activity $\left(\overline{\mathrm{EMG}} \overline{\mathrm{pk}}_{\mathrm{C} \mathrm{Nu}}\right)$ obtained from at least 5 control breaths of the same recording.

In formula: $\mathrm{TIA}=\mathrm{EMGet} / \overline{\mathrm{EM}} \overline{\mathrm{G}}_{\mathrm{pk}} \mathrm{c} \times 100 \%$.

Ratios were calculated and then averaged for at least 5 controll breaths and for at least 5 breaths during CNAP. Next, the mean value of TIA for the control breaths was compared to the mean value of TIA for the breaths during CNAP. For the selected breaths several other parameters were also calculated and averaged in the same way. This was done for duration of inspiration and expiration ( $\mathrm{U}$ and $\mathrm{tE}$ respectively) as obtained from the flow signal, $f$ (calculated as $60 /(t+\mathrm{tE})$ ), $\mathrm{P} t \mathrm{p}, \mathrm{P}_{\mathrm{tr}}, \mathrm{PerCO}_{2}$, tidal volume (VT; by integration of flow), mean anterial blood pressure ( $\left(\bar{P}_{b l}\right)$ and minute ventilation (VंE; calculated as VT.f). Total lung resistance (RL) and dynamic compliance $(\mathrm{CL}, \mathrm{dyn})$ were calculated by a modification of the method of Mead and Whittenberger ${ }^{15}$. RL. was calculated separately for the inspiratory and expiratory phase of the breathing cycle ( $R L$, in, $R L$,ex). The resistance of the equipment dead space was the sarne in all experiments and was not subtracted.

All values reported are means \pm standard error (SE). Differences were evaluated for statistical significance by using the $t$-test for paired observations.

\subsection{RESULTS}

Figure 2.2 shows original recordings of integrated EMG activity obtained from inspiratory muscles before, during and after application of CNAP. After about 10 control breaths Ptr was decreased in a step-like fashion for about 20 breaths and thereafter Pur was restored (trace 3). This figure demonstrates that immediately after the onset of CNAP the end-tidal levels of the integrated EMGdi and EMGICM activities are elevated (trace 1 and trace 2, respectively). End-tidal values of $P_{t}$ changed in accordance with the changes in Ptr (trace 5). Further this figure demonstrates the increase in $\mathrm{f}$ due to CNAP.

\subsubsection{EFFECTS OF DIFFERENT LEVELS OF CNAP ON TLA}

Eight out of 19 cats showed no TIA at Ptr $\geq-1.2 \mathrm{kPa}$. To limit the magnitude of the applied airway pressure the results for TIA presented in this paper refer to the remaining 'responders'. Average responses of TIA to decreasing levels of Prr are 
shown in Figure 2.3. The increase in TIA in response to Pur $\leq-0.6 \mathrm{kPa}$ was statistically significant $(p<0.05)$ for both the diaphragm and ICM. For all 11 animals together, at Pur $=-1.2 \mathrm{kPa}$ TLA ranged up to $67 \%$ and $86 \%$ of $\overline{\mathrm{EM}} \overline{\mathrm{G}}_{\mathrm{pk}} \mathrm{cm}$ in the diaphragm and ICM, respectively. Mean ( \pm SE) CNAP-induced TIA levels were about $41 \% \pm 4.3$ and $62 \% \pm 3.7$ for the diaphragm and. ICM, respectively (Figure 2.3). One cat showed TIA in the diaphragm only at $P$ tr $=-1.2 \mathrm{kPa}$, whereas in ICM TIA was already observed at $\mathrm{Ptr}=-0.3 \mathrm{kPa}$. In two animals airway pressures down to $-1.2 \mathrm{kPa}$ hardly evoked TIA in the diaphragm although $\mathrm{P}$ rr $=-1.2 \mathrm{kPa}$ did induce TIA

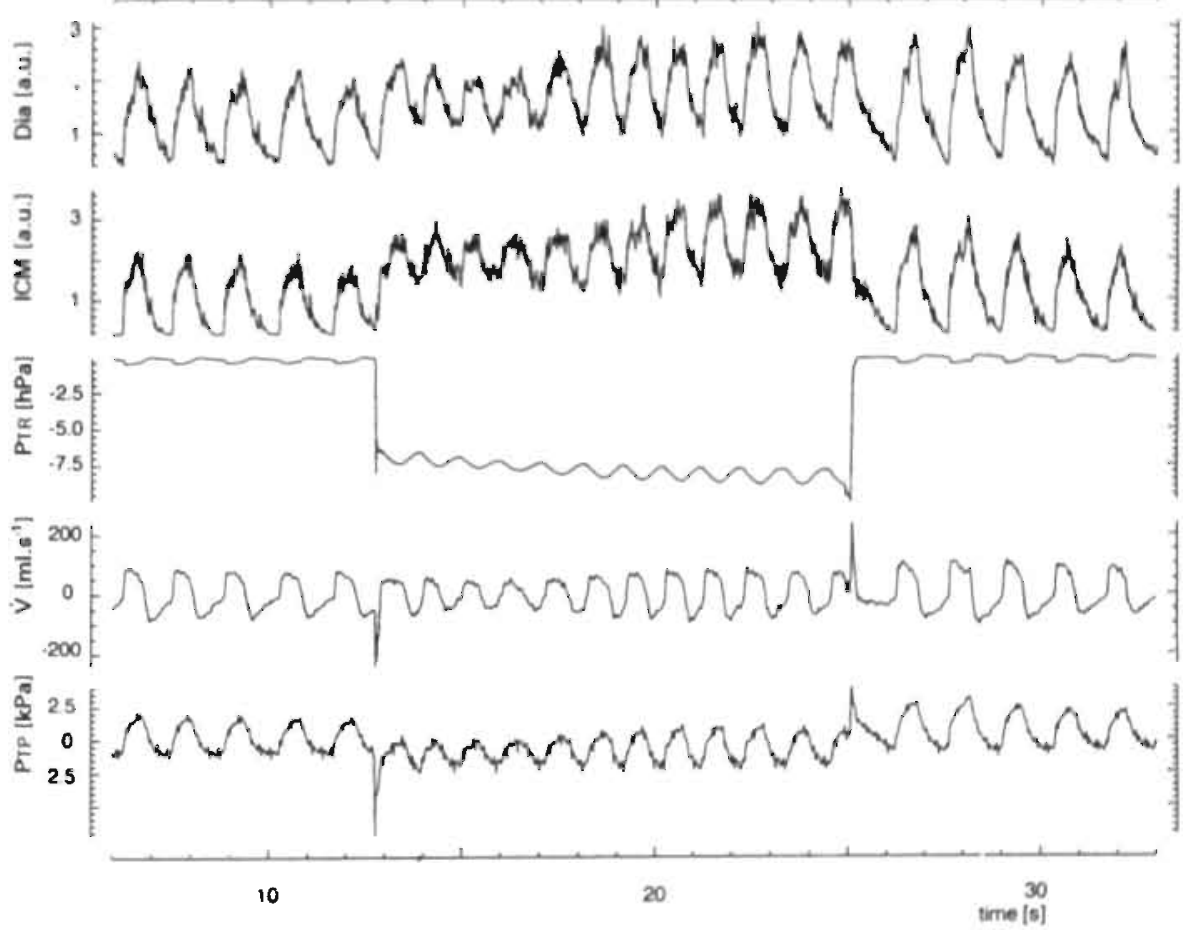

Figure 2.2 Recording diring changes in tracheal pressure. From top to bottom, integrated EMG of diaphragm (EMGdi), integrated EMG of ICM (EMGICM), tracheal pressure (Pir), airflow $(V)$ and trasspulmonary pressure $\left(P_{t p}\right)$. Note instantaneous, onset of tonic inspiratory activity after application of CNAP $\left(P_{t r}=-0.9 \mathrm{kPa}\right)$, and similarly its immediate disappearance after return to control. Temperature of cervical vagi was $37^{\circ} \mathrm{C}$. 

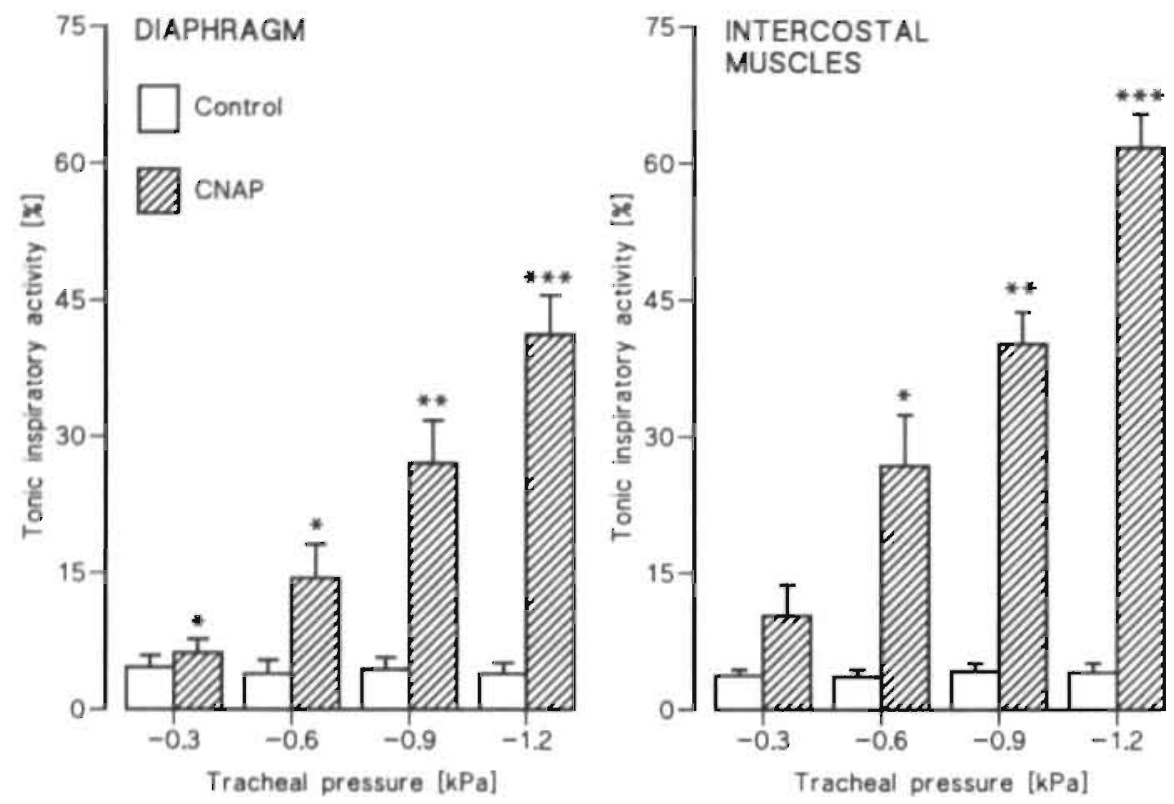

Figure 2.3 Effects of different levels of CNAP on tonic inspiratory activity (TIA) in diaphragm.

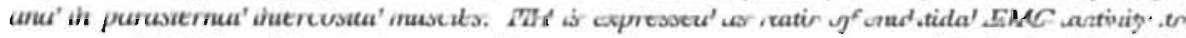
mean peak EMG activity during control breaths. Data represent means \pm SE obtained from 11 anaesthetized, spontaneously breathing cats. Temperature of cervical vagi was $37{ }^{\circ} \mathrm{C}$. Asterisks indicate statistically significant differences compared to control $\left(^{* * *} p<0.001 ;{ }^{* *} p<0.01\right.$; ${ }^{*} p<0.05$ ).

in ICM. Mean differences in TIA between CNAP and control ( $\triangle$ TIA) were larger for ICM than for the diaphragm at all values of Pr.

EFFECTS OF DIFEERENT LEVELS OF CNAP ON OTHER RESPIRATORY VARLABLES

As a result of CNAP tI, tE and VT decreased significantly relative to control values. The increases in $\mathrm{f}$ and $\dot{V} \mathrm{E}$ were significant for airway pressures below $-0.6 \mathrm{kPa}$ (Table 2.1). The net result of changes in $f$ and VT accounted for the increased VE. Although tI decreased significantly at a higher level of CNAP (-1.2 kPa), the increase in $f$ was mainly caused by shortening of tE. There was no significant change in $\bar{P} b$ as a result of CNAP (Table 2.1).

$\mathrm{CL}$,dyn decreased significantly with decreasing $\mathrm{Pur}$ (Table 2.1). A negative correlation was obtained between the decrease in CL,dyn evoked by CNAP and $\triangle T$ TIA, both for the diaphragm. and ICM (Figure 2.4). As compared to control RL,ex increased significantly in response to airway pressures of -0.3 down to $-1.2 \mathrm{kPa}$ (Table 2.1). 

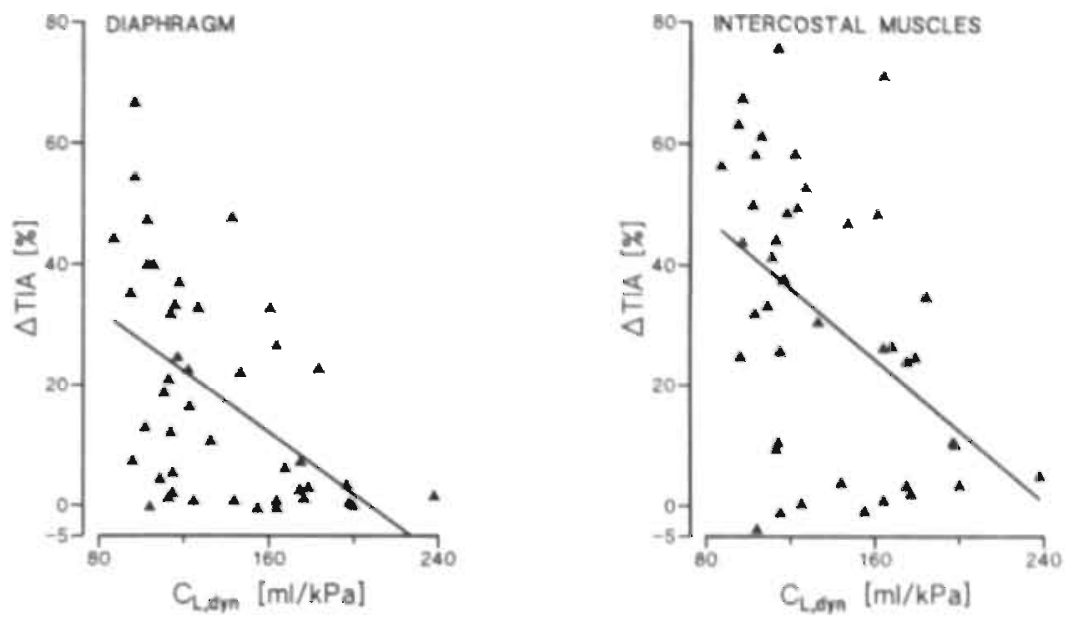

Figure 2.4 Relationship between increase in tonic inspiratory activity $(\triangle T Z A)$ in diaphragm and intercostal muscles and decrease in dynamic lung compliance (CLdyn) evoked by CNAP. Data points were obtained from 11 anaesthetized, spontaneously breathing cats, Regression lines through data points are shown, $r=-0.507(p<0.001)$ and $0.464(p<0.01)$ for diaphragm and intercostal muscles, respectively.

Table 2.1 Effects of continuous negative airway pressure on respiratory and circulatory variables.

\begin{tabular}{|c|c|c|c|c|c|}
\hline $\mathrm{P}_{t r}[\mathrm{kPa}]$ & control & -0.3 & -0.6 & -0.9 & -1.2 \\
\hline$V_{T}[\mathrm{ml}]$ & $41.0(0.8)$ & $39.2(2.2)$ & $37.5(2.6)^{\circ}$ & $34.4(2.5)^{\circ}$ & $21.6(2.2)^{\cdots}$ \\
\hline$f\left[\min ^{-1}\right]$ & $29.3(1.2)$ & $32.6(4.3)$ & $42.8(7.2)^{\circ}$ & $47.0(7.6)^{* *}$ & $54.5(7.4)^{*}$ \\
\hline$\dot{V} E\left[I . m^{-1}\right]$ & $1.18(0.04)$ & $1.20(0.11)$ & $1.44(0.15)^{\circ}$ & $1.46(0.16)^{*}$ & $1.58(0.15)^{*}$ \\
\hline $\mathrm{t} \mid \mathrm{s}]$ & $1.20(0.06)$ & $1.30(0.19)$ & $1.18(0.21)$ & $1.05(0.17)$ & $0.87(0.13)^{*}$ \\
\hline $\mathrm{tE}[\mathrm{s}]$ & $1.01(0.04)$ & $0.90(0.10)^{*}$ & $0.69(0.11)^{\cdots}$ & $0.63(0.13)^{\cdots}$ & $0.48(0.07)^{\cdots}$ \\
\hline $\mathrm{Pet} \mathrm{CO}_{2}[\mathrm{kPa}]$ & $4.7(0.06)$ & $4.7(0.13)$ & $4.4(0.16)$ & $4.0(0.27)^{\circ}$ & $3.7(0.38)^{\circ}$ \\
\hline$\overline{\mathrm{P}} \mathrm{b}[\mathrm{kPa}]$ & $20.0(0.27)$ & $20.0(0.51)$ & $20.0(0.52)$ & $20.2(0.69)$ & $20.1(0.65)$ \\
\hline $\mathrm{Cl}_{\text {dyn }}\left[\mathrm{mi}, \mathrm{kPa}^{-1}\right]$ & $170(7)$ & $152(14)^{* *}$ & $140(10)^{\cdots *}$ & $137(8)^{*}$ & $116(8)^{\cdots}$ \\
\hline $\mathrm{RL}_{\text {in }}$ [kPa. $\left.\left.\right|^{-1} . \mathrm{s}\right]$ & $1.51(0.06)$ & $1.84(0.17)$ & $1.76(0.26)$ & $2.00(0.36)$ & $2.05(0.41)$ \\
\hline RLex $\left[\mathrm{kPa} .\left.\right|^{-1}, \mathrm{~s}\right]$ & $1.62(0.07)$ & $2.77(0.25)^{\circ}$ & $2.32(0.22)^{*}$ & $2.35(0.20)^{\prime \prime}$ & $2.84(0.40)^{\prime \prime}$ \\
\hline
\end{tabular}

Values, obtained from 11 anaesthetized, spontaneously breathing cats are means $\pm S E$ of control breaths and of breaths during different levels of CNAP.

$P t r$, tracheal pressure; $V T$, tidal volume; $f$, breathing frequency; $V_{E}$, minute ventilation; $t$, duration of inspiration; $t E$, duration of expiration; $\mathrm{PaCO}_{2}$, end-tidal $\mathrm{PCO}_{3}, \overline{\mathrm{P}} b$, mean arterial blood pressure; $C L, d y n$, dynamic lung compliance; $R L$, in and $R L, a$, lung resistance derived from inspiratory and expiratory phases of breathing cycle. Temperature of vagi was $37^{\circ} \mathrm{C}$. Control values for each Ptr are averaged $(n=44)$. Symbols refer to statistical comparison between $C N A P$ and control from same recording by t-test for paired observations $(* * * p<0.001$; ** $p<0.01 ; * p<0.05)$. 


\subsubsection{EFFECTS OF VAGAL COOLING ON TIA}

Results for TIA in the diaphragm and ICM at different Tvg for control breaths and for CNAP are presented in Figure 2.5. Between 37 and $12{ }^{\circ} \mathrm{C}$ CNAP-induced TIA was comparable in magnitude. Between 10 and $4{ }^{\circ} \mathrm{C}$ we observed an attenuation of
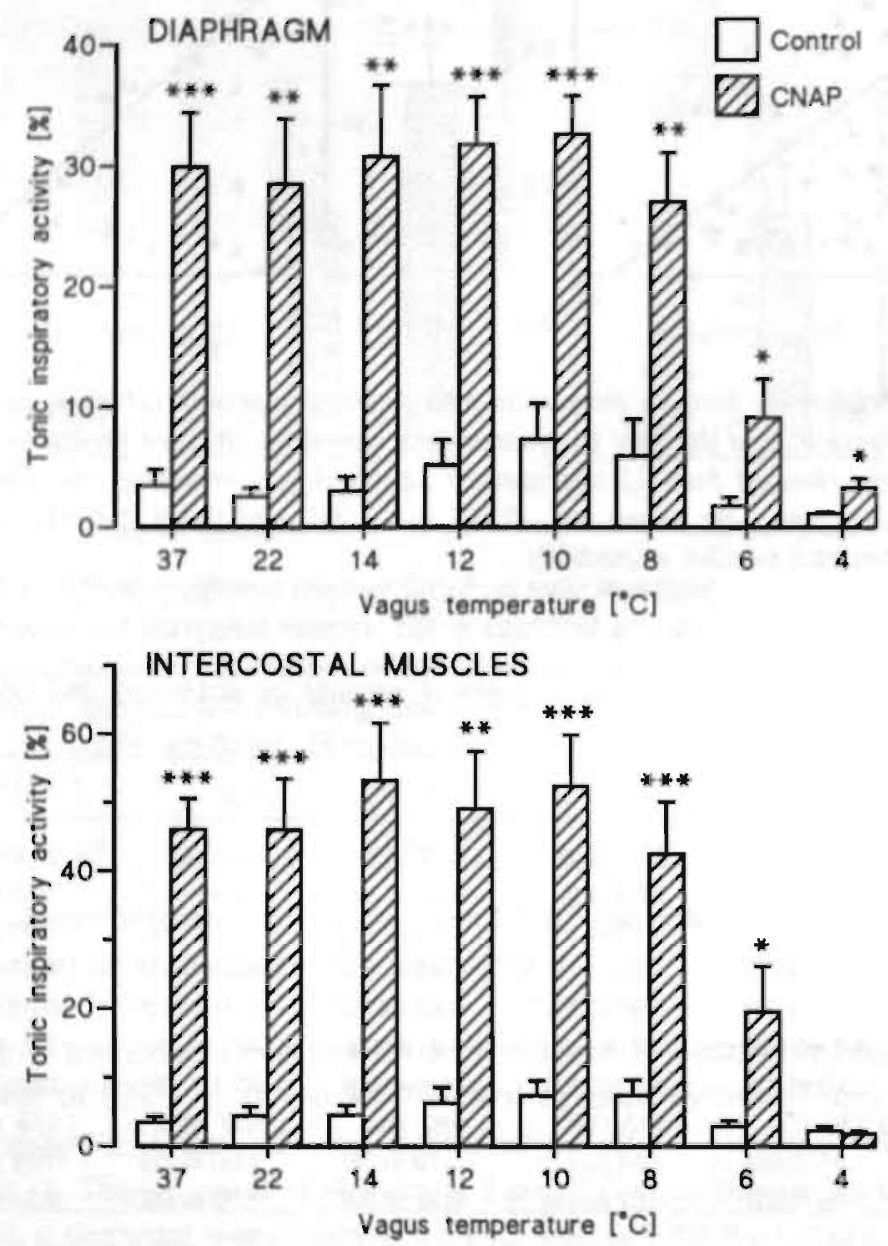

Figure 2.5 Effects of vagal cooling on tonic inspiratory activity (TLA) in diaphragm and in intercostal muscles. $7 Z A$ was induced by CNAP $\left(P_{t r}=-0.9 \mathrm{kPa}\right)$. TIA is expressed as ratio of end-tidal EMG activity to mean peak EMG activity during control breaths. Data represent means $\pm S E$ obtained from 9 anaesthetized, spontaneously breathing cats. Note that scalings of panels differ. Increase in TIA at $4^{\circ} \mathrm{C}$ in diaphragm between CNAP and control is less than highest control value. Asterisks indicate statistically significant differences compared to control at same temperature $\left({ }^{* * *} p<0.001 ; * * p<0.01 ; * p<0.05\right)$. 

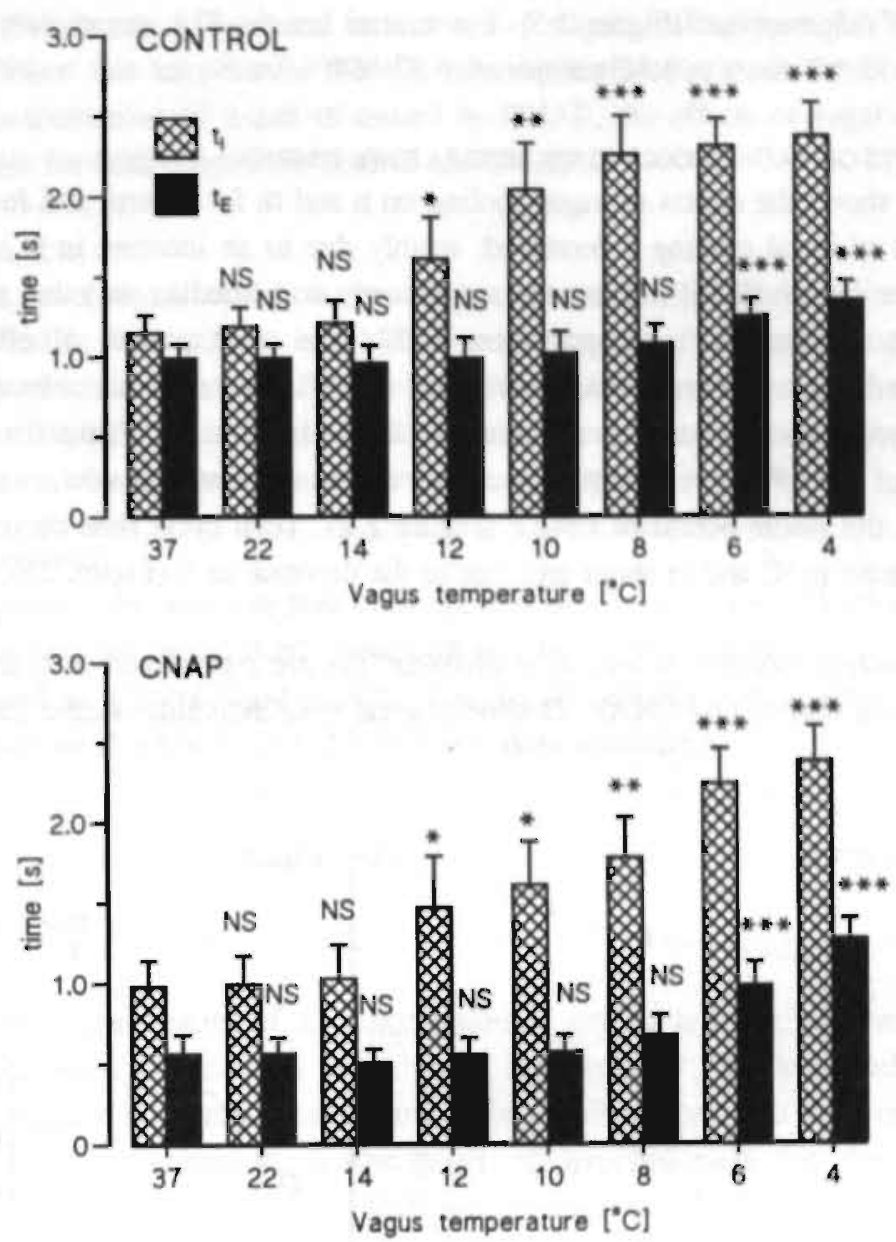

Figure 2.6 Effects of vagal cooling on duration of inspiration (II) and expiration (IE) of control breaths and during CNAP. Data represent means $\pm S E$ of 11 anaesthetized, spontaneously breathing cats. Note that during cooling $u$ increases significantly from a vagus temperature of $12{ }^{\circ} \mathrm{C}$, whereas $t E$ increases from a temperature of $6^{\circ} \mathrm{C}$. Asterisks indicate statistically significant differences compared to values at $37^{\circ} \mathrm{C}\left({ }^{* * *} p<0.001\right.$; ** $p<0.01$; * $p<0.05$; NS not significant).

CNAP-induced TIA for both the diaphragm and ICM. Below temperatures of $6{ }^{\circ} \mathrm{C}$ tonic discharges in inspiratory muscles induced by CNAP virtually disappeared being less than the highest control value.

As we mentioned for the experiments with different levels of CNAP, TIA values for ICM were significantly higher than those for the diaphragm within the whole 
temperature range applied (Figure 2.5). For control breaths TIA was slightly elevated at a Trg of $12{ }^{\circ} \mathrm{C}$ down to $8{ }^{\circ} \mathrm{C}$ compared to $37^{\circ} \mathrm{C}$.

\subsubsection{EFFECTS OF VAGAL COOLING ON RESPIRATORY TIMING}

Figure 2.6 shows the effects of vagal cooling on $\mathrm{u}$ and $\mathrm{tE}$ for control and for CNAP. As a result of vagal cooling $f$ decreased, mainly due to an increase in $u$. At vagus temperatures below $12{ }^{\circ} \mathrm{C}$ u increased significantly compared to its value at $37^{\circ} \mathrm{C}$, whereas $\mathrm{EE}$ significantly increased below $6{ }^{\circ} \mathrm{C}$. The same pattern of effects was demonstrated for both conditions, control and CNAP. The different responses of $\mathrm{u}$ and $t E$ to vagal cooling suggest different causal mechanisms. Immediately after the on-switch of CNAP (Prr $=-0.9 \mathrm{kPa}$ ) we observed an increase in $\mathrm{f}$ which maintained throughout the whole period of CNAP (Figure 2.2). Total cycle time decreased due to the decrease in $\mathrm{tE}$ and in lesser part due to the decrease in tu (Figure 2.6, $\mathrm{Tvg}=37$ $\left.{ }^{\circ} \mathrm{C}\right)$.

The relationships between $\mathrm{tI}$ and $\mathrm{tE}$ at different $\mathbf{T} \mathrm{vg}$ are represented as tI- $\mathrm{EE}$ plots in Figure 2.7 for control and CNAP. Despite of great inter-individual scatter these plots
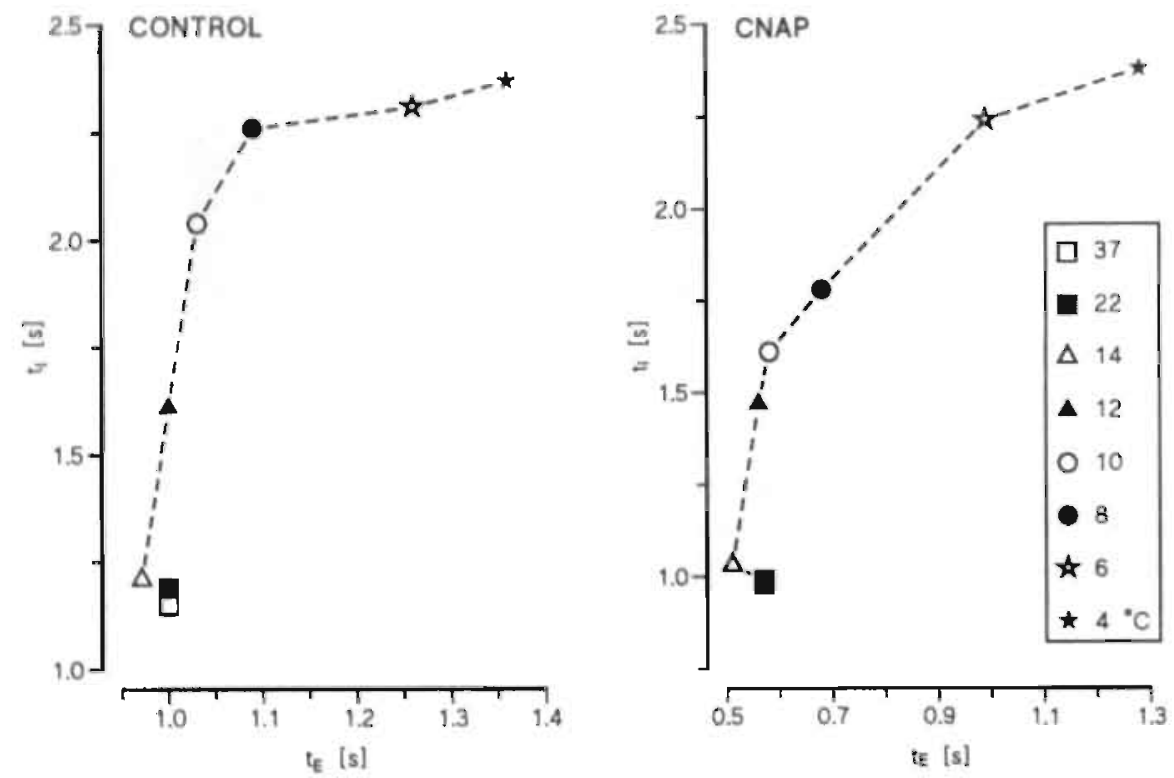

Figure 2.7 Relationship between duration of inspiration (tt) and expiration (IE) at different temperatures of the vagus nerves during control and CNAP. Data presented are means of 11 anaesthetized, spontaneously breathing cats. Note that both $t I$ and $I E$ increase by cooling the vagi down to $4^{\circ} \mathrm{C}$, but this occurs earlier for $t \mathrm{t}$ than for $\mathbb{E}$. 
indicate that mainly $\mathrm{u}$ increased as a result of vagal cooling from $37{ }^{\circ} \mathrm{C}$ down to $10^{\circ} \mathrm{C}$. Below this temperature there is also an increase in IE. In spite of the shift towards a shortening of $\mathrm{u}$ and $\mathrm{EE}$ caused by CNAP, the effects of vagal cooling are comparable for both conditions, control and CNAP.

\subsubsection{CAPSAICIN}

Capsaicin, a chemical which is known to activate C-fibre endings in cats', was administered in four animals in which it evoked apnoea followed by rapid shallow breathing which is a normal response. No TIA was observed, however, at the three values for $\mathrm{Tvg}\left(37,10,4^{\circ} \mathrm{C}\right)$ applied. The duration of the capsaicin-induced apnoea at $4{ }^{\circ} \mathrm{C}$ was decreased compared to its duration at higher temperatures.

\subsubsection{VAGOTOMY}

After vagotomy we were not able to evoke TIA by CNAP (Ptr $=-0.9 \mathrm{kPa})$ neither in the diaphragm nor in the ICM. Induction of TIA in response to CNAP was, therefore, related to afferent vagal activity. For the six animals studied after vagotomy $f$ was reduced to about $66 \% \pm 5.2 \%$ of $\mathrm{f}$ in control conditions.

\subsection{DISCUSSION}

One of the characteristics of an exacerbation of asthma is hyperinflation. Although airway resistance is decreased at increased lung volume ${ }^{4}$, the increased functional residual capacity is generally considered to be disadvantageous to inspiratory muscle function. $^{11}$. The mechanical disadvantages of hyperinflation for the parastemal intercostal muscles are much less than for the diaphragm ${ }^{8}$. In recent years TIA is considered as one of the causal mechanisms of hyperinflation in asthmatics ${ }^{9}$. TIA is also observed in man and animals after administration of histamine ${ }^{2.19}$.

We already showed that histamine-induced TIA in cats can be considered as the net result of excitation of inspiratory neurons by RARs and inhibition by SARs ${ }^{16}$. Recently, the mechanosensitive properties of RARs have been reappraised. RAR activity is increased by hyperinflation ${ }^{14}$ or when $\mathrm{CL}$,dyn is decreased ${ }^{2,24,25}$, as well as during pneumothorax ${ }^{18}$ and in response to pulmonary microembolism ${ }^{17}$.

CNAP is a mechanical stimulus known to activate RARs $s^{1,17,18,22}$. The present study confirms previous observations ${ }^{12,20}$, carried out in anaesthetized, spontaneously breathing cats and rabbits, that TIA can be elicited in the diaphragm and intercostal muscles by applying CNAP.

It has been shown that in eupnoeic dogs the triangularis sterni was active during expiration, causing a caudal displacement of the ribs? ${ }^{7}$. When breathing at rest activity 
in transversus abdominis muscles has been found in dogs ${ }^{10}$. There was no activity in external oblique abdominal muscles during CNAP in cats whereas during CPAP the abdominal muscles were active in expiration ${ }^{3}$. In cats we did not observe EMG activity in expiration from the electrodes inserted into the parasternals or the diaphragm, neither at control conditions (present study) nor even during CPAP (other experiments from our laboratory). Therefore, it seems very unlikely that during CNAP, which decreases FRC, the triangularis sterni or the transversus abdominis is active. To obtain EMGs from the diaphragm and ICM we inserted the needle electrodes directly into these muscles. By making the distance between the two electrodes of each pair as small as possible contamination from other sources has been prevented. E.g., even cardiac electric activity was not observed in our EMG recordings.

\subsubsection{RESPONSE OF TIA TO CNAP}

TIA in response to CNAP appeared to be significant both in the diaphragm and in the ICM (Figures 2.3 and 2.5). In some cats TIA in response to CNAP reached values of about $60-80 \%$ of peak inspiratory EMG activity during control conditions. If comparable values also appeared in man during mechanical stimulation of RARs lung mechanics would be much influenced. This may happen for instance during an exacerbation of asthma due to bronchoconstriction.

From Ptr $=-0.6$ down to $-1.2 \mathrm{kPa}$ TIA was larger for ICM than for the diaphragm (Figures 2.3 and 2.5). Although there were differences in the magnitude of the responses between animals, the sensitivity of ICM to CNAP was generally larger than that of the diaphragm. These results indicate that in cats in a supine position stimulation of RARs by CNAP affects the ICM more than the diaphragm. If in man ICM were atso more susceptible to stimulation by RARs than the diaphragm this could have consequences for breathing therapy in asthmatics.

\subsubsection{SELECTIVE BLOCK OF VAGAL LUNG AFFERENTS}

To distinguish between the reflex effects of the three types of pulmonary receptors various methods have been employed so far to block activity in the vagal afferents. Inhalation of the irritant gas sulphur dioxide $\left(\mathrm{SO}_{2}\right)$ is claimed to inhibit SARs selectively in rabbits ${ }^{6}$. Activation of RARs and simultaneous inhibition of SARs by $\mathrm{SO}_{2}$ would be an interesting method regarding the aim of our study. However, application of $\mathrm{SO}_{2}$ to inhibit SARs has not been very successful in cats ${ }^{13}$. Accordingly, we did not succeed in abolishing the Hering-Breuer inflation reflex with $\mathrm{SO}_{2}$ in our cats. We suggest, therefore, that the effect of $\mathrm{SO}_{2}$ on SARs is species dependent. It has been reported that application of the local anaesthetic procaine on the vagus nerves blocked the conduction in unmyelinated and in thin myelinated vagal fibres in rabbits ${ }^{2}$. A disadvantage of applying procaine is that differentiation between 
thin myelinated afferents from RARs and unmyelinated afferents from C-fibre endings is not possible. On the other hand, it has been. shown in single fibre studies that cooling the cervical vagus nerves can block conduction in the afferents of the three types of pulmonary receptors selectively ${ }^{14,21}$. In these studies RARs, SARs and C-fibre endings were identified by their characteristic patterns of discharge in response to lung distension and to injection of capsaicin, and by their fibre conduction velocities. These authors conclude that at vagus temperatures between $7{ }^{\circ} \mathrm{C}$ and $12{ }^{\circ} \mathrm{C}$ activity of SARs transmitted was only one third of that observed during control measurements at $37{ }^{\circ} \mathrm{C}$ whereas RAR activity did not fall below control levels until the vagus had been cooled down to $7{ }^{\circ} \mathrm{C}$ or lower. At a vagus temperature of $4{ }^{\circ} \mathrm{C}$ conduction in myelinated fibres was virtually blocked, whereas a large part of the activity of the unmyelinated C-fibres was still transmitted.

\subsubsection{LUNG RECEPTORS AND TIA}

After vagotomy no TIA can be induced any more, implying that intact vagi are necessary for TIA to come about. When both vagus nerves were cooled to $4{ }^{\circ} \mathrm{C}$, TIA was also abolished (Figure 2.5). It is known that at this temperature the conductance in myelinated fibres is blocked whereas conductance in unmyelinated fibres is only reduced. Intravenous injection of capsaicin, known as a chemical stimulating pulmonary $\mathrm{C}$-fibre, endings in cats ${ }^{1}$, did not evoke any TIA at all vagus temperatures applied suggesting that this type of receptor plays no role in evoking TIA.

At vagus temperatures between 8 and $12{ }^{\circ} \mathrm{C}$, temperatures at which we may assume that conduction of SAR activity is blocked, TIA did not change in response to CNA.P as compared to TIA at $\mathrm{Tvg}=37^{\circ} \mathrm{C}$ (Figure 2.5). If SARs were responsible for TIA it would be expected that during attenuation of the conductance in afferents from SARs TIA would decrease. At vagus temperatures between 8 and $12{ }^{\circ} \mathrm{C}$ TIA was slightly elevated in control breaths as compared to TIA at $\mathrm{Tvg}=37^{\circ} \mathrm{C}$. We speculate that this is due to a reduced conductance of SAR activity resulting in a diminished inhibition of TIA by SAR activity.

At each Tvg TIA was calculated with its own control value ( $\overline{\mathrm{EM}} \overline{\mathrm{G}} \mathrm{pk})$ obtained at the same temperature (see methods). We noticed that during vagal cooling, especially at $T_{v g}=14,12$ and $10{ }^{\circ} \mathrm{C}, \overline{\mathrm{EM}} \overline{\mathrm{G}}_{\mathrm{pk}} \mathrm{c}_{\mathrm{cme}}$ values were increased. Although relative TIA values did not differ much from values at $37^{\circ} \mathrm{C}$ (Figure 2.5) this implies that absolute TIA levels at these temperatures were still higher. Both effects can be explained by inhibition of SAR activity during vagal cooling.

\subsubsection{LUNG RECEPTORS AND RESPIRATORY TIMING}

Our data concerning changes in il and tE. confirmed indirectly the results from single fibre studies with regard to vagal cooling as a method to block selectively conduction in afferent fibres of lung receptors. It is commonly agreed that stimulation of SARs 
shortens II by activating the 'off switch' mechanism which terminates inspiratory activity ${ }^{5}$. Previous studies have shown that in the intact rabbit $t$ is controlled by SAR activity, and tE by a balance between the activities of SARs and RARs in which stimulation of RARs shortens $\mathbb{E}^{6}$.

At normal Pur we observed that ts already increased as compared to tr at $37^{\circ} \mathrm{C}$ if the vagi were cooled below $14^{\circ} \mathrm{C}$ (Figure 2.6, upper panel). On the contrary, tE did not increase significantly until Tvg was below $8{ }^{\circ} \mathrm{C}$. Comparable results were obtained during CNAP (Figure 2.6, lower panel). We showed that during vagal cooling from 37 down to $4{ }^{\circ} \mathrm{C}$ first tu increased (below $14{ }^{\circ} \mathrm{C}$ ) and then (below $8{ }^{\circ} \mathrm{C}$ ) tE (Figures 2.6 and 2.7). We conclude, therefore, that the gradual increase in tu for Tvg below $14{ }^{\circ} \mathrm{C}$ indicates a progressive block in the afferent fibres of SARs. The increase in tE in response to cooling below $8{ }^{\circ} \mathrm{C}$ should be attributed to impaired transmission of activity from RARs ${ }^{6}$.

\subsubsection{RESPONSES OF OTHER RESPIRATORY VARIABLES TO CNAP}

At all levels of CNAP we observed an increased $f$ as compared to control, due mainly to a decrease in tE (Table 2.1). The decrease in IE was significant for all levels of CNAP. Decrease of $\mathrm{u}$ as a result of CNAP was only significant at $-1.2 \mathrm{kPa}$. The decrease of $\mathrm{tE}$ in response to progressively larger, negative airway pressures is in agreement with stimulation of RARs by CNAP and shortening of $L E$ by activation of RARs.

Several authors have studied the relationship between $\mathrm{CL}$,dyn and the activity of lung receptors. It has been shown that spontaneous discharge of RARs in rabbits increased when $C_{L}$,dyn was reduced by briefly deflating the lungs and decreased when $C_{\text {,dyn }}$ was increased by briefly hyperinflating the lungs ${ }^{22}$. In dogs, rabbits and cats it has been shown that RARs discharged more vigorously during decreased $\mathrm{Cl}$,dyn by removing positive end expiratory pressure ${ }^{24,25}$. These authors concluded that RARs are sensitive to changes in CL.dyn: the stiffer the lungs the larger is the activity of RARs. Once again this suggests that changes in lung mechanics are very important in stimulating RARs. However, despite the correlation between RAR activity and CL,dyn no causal mechanism has been shown. It is still uncertain by which mechanism RARs, located in the conductive airways, are stimulated when the lung parenchyma becomes less compliant. In the present study we also observed a negative correlation between TIA due to a decreased Ptr- and CL,dyn (Figure 2.4). We conclude that $\mathrm{CL}_{\text {,dyn }}$ decreased in response to CNAP, and TIA increased simultaneously, as the result of mechanical stimulation of RARs.

The effect of mechanically decreased CL,dyn has also been compared to the response of RARs to histamine in cats $^{25}$. It was found that in both conditions the relation between RAR activity and $\mathrm{CL}$,dyn was similar. Further, the onset of the increase in RAR activity coincided with the increase in lung stiffness after histamine injection 
suggesting that the increase in RAR activity in response to histamine is also related to lung mechanical changes. It appears that stimulation of RARs is an important factor in histamine-induced TLA. Although it is not clear yet how RARs are stimulated by histamine, we feel that mechanical activation of RARs will be involved in histamineinduced TIA. In the present study it was shown that mechanical stimulation of RARs is a potent stimulus to induce TLA.

\subsubsection{CONCLUSIONS}

1) CNAP is a forceful stimulus to induce TIA in both the diaphragm and ICM in anaesthetized, spontaneously breathing cats. 2) In response to CNAP TIA reached values of at least 40 to $60 \%$ of peak EMG activity during control breaths, for the diaphragm and ICM, respectively. 3) TIA induced by CNAP is due to mechanical stimulation of RARs; the results strongly indicate that stimulation of SARs suppress TIA. 4) C-fibre endings are not involved in CNAP-induced TIA. 5) TIA in ICM was higher than TLA in the diaphragm. 6) TLA is correlated with reduction in $\mathrm{Cl}$,dyn. We speculate by extrapolating these results to asthmatic patients that part of the hyperinflation in bronchial asthma is caused by TIA in response to mechanical stimulation of RARs.

\subsection{REFERENCES}

1. Armstrong DJ and Luck JC (1974). A comparative study of irritant and type J receptors in the cat. Respir Physiol 21: 47-60.

2. Badier M, Jammes $\mathbf{Y}$, Romero-Colomer P and Lemerre C (1989). Tonic activity in inspiratory muscles and phrenic motoneurons by stimulation of vagal afferents. I Appl Physiol 66: 1613-1619.

3. Bishop B (1963). Abdominal muscle and diaphragm activities and cavity pressures in pressure breathing. J Appl Physiol 18: 37-42.

4. Bouhuys A. Pressure-flow relations. In: The physiology of breathing, edited by Bouhuys A. New York: Grune and Siratton, 1977, p. 173-201.

5. Clark FJ and von Euler C (1972). On the regulation of depth and rate of breathing. $J$ Physiol (Lond) 222: 267-295.

6. Davies A and Roumy M (1986). A role of pulmonary rapidly adapting receptors in control of breathing. Aust J Exp Biol Med Sci 64: 67-78.

7. De Troyer A and Ninane V (1986). Triangularis sterni: a primary muscle of breathing in the dog. J Appl Physiol 60: 14-21.

8. Decramer M. Effects of hyperinflation on respiratory muscle function. In: Chronic pulmonary hyperinflation, edited by Grassino A, Rampulla C, Ambrosino $\mathrm{N}$ and Fracchia C. London: Springer-Verlag, 1991, p. 83-89.

9. Demedts M (1990). Mechanisms and consequences of hyperinflation. Eur Respir J 3: 617-618. 
10. Gilmartin JJ, Ninane $\mathrm{V}$ and De Troyer A (1987). Abdominal muscle use during breathing in the anesthetized dog. J Appl Physiol 70: 159-171.

11. Grassino A and Begin P. The effect of lung hyperinflation on inspiratory muscle function. In: Chronic pulmonary hyperinflation, edited by Grassino A, Rampulla C, Ambrosino $\mathrm{N}$ and Fracchia C. London: Springer-Verlag, 1991, p. 91-99.

12. Grinten van der CPM, Vries de WR and Luijendijk SCM (1992). Vagally mediated modification of inspiratory activity by changes in airway pressure. Respir Physiol 90: 159-172.

13. Grunstein MM, Hazucha J, Sorli J and Milic-Enili J (1977). Effects of SO2 on control of breathing in anesthetized cats. I App! Physiol : Respirat Environ Exercise Physiol 43: 844-851.

14. Jomzon A, Pisarri TE, Roberts AM, Coleridge JCG and Coleridge HM (1988). Attenuation of pulmonary afferent input by vagal cooling in dogs. Respir Physiol $\mathbf{7 2}$ : 19-34.

15. Mead J and Whittenberger JL (1953). Physical properties of human lungs measured during spontaneous respiration. J Appl Physiol 5: 779-796.

16. Meessen NEL, Grinten van der CPM, Folgering HTM and Lujiendijk SCM (1990). Role of lung receptors in the generation of histamine-induced tonic inspiratory activity. Eur Respir J 3: 140s.(Abstract)

17. Mills JE, Sellick $\mathrm{H}$ and Widdicombe JG (1969). Activity of lung irritant receptors in pulmonary microembolism, anaphylaxis and drug-induced bronchoconstrictions. J Physiol (Lond) 203: 337-357.

18. Mills JE, Sellick $\mathrm{H}$ and Widdicombe JG (1969). Vagal deflation reflexes mediated by lung irritant receptors. J Physiol (Lond) 204: 137p.

19. Muller N, Bryan AC and Zamel N (1980). Tonic inspiratory muscle activity as a cause of hyperinflation in histamine-induced astuma. J Appl Physiol : Respirat Environ Exercise Physiol 49: 869-874.

20. Patberg WR (1983). Effect of graded vagal blockade and pulmonary volume on tonic inspiratory activity in rabbits. Pflügers Arch 398: 88-92.

21. Pisarri TE, Yu J, Coleridge HM and Coleridge JCG (1986). Background activity in pulmonary vagal C-fibers and its effects on breathing. Respir Physiol 64: 29-43.

22. Sellick $H$ and Widdicombe JG (1970). Vagal deflation and inflation reflexes mediated by lung irritant receptors. Q J Exp Physiol 55: 153-163.

23. Vidruk EH, Hahn HL. Nadel JA and Sampson SR (1977). Mechanisms by which histamine stimulates rapidly adapting receptors in dog lungs. J Appl Physiol : Respirat Environ Exercise Physiol 43: 397-402.

24. Yu J, Coleridge JCG and Coleridge HM (1987). Influence of lung stiffness on rapidly adapting receptors in rabbits and cats. Respir Physiol 68: 161-176.

25. Yu J and Roberts AM (1990). Indirect effects of histumine on pulmonary rapidly adapting receptors in cats. Respir Physiol 79: 101-110. 


\section{Histamine-induced end-tidal inspiratory activity and lung receptors in cats}




\subsection{ABSTRACT}

The main objective of the present study was to evaluate the role of rapidly adapting receptors (RARs), slowly adapting receptors (SARs) and C-fibre endings in generating end-tidal inspiratory activity (ETIA).

ETIA was induced by intravenous administration of histamine and continuous negative airway pressure (CNAP) in anaesthetized, spontaneously breathing cats. To differentiate between reflex activities from the three types of lung receptors both vagus nerves were cooled to 8 different ternperatures (Tvg) between 4 and $37^{\circ} \mathrm{C}$. It is known that CNAP stimulates RARs and inhibits SARs. Histamine was used to stimulate RARs, and this was combined with continuous positive airway pressure (CPAP) to further stimulate SARs.

ETIA was evoked in the diaphragm and in parasternal intercostal muscles by both stimuli-histamine and CNAP-in 8 out of 18 cats. After vagotomy neither histamine nor CNAP evoked ETIA any more. At Tvg $=37{ }^{\circ} \mathrm{C}$ CPAP suppressed histamineinduced ETIA whereas this suppression was diminished at Tvg between 14 and $8{ }^{\circ} \mathrm{C}$. ETIA sharply declined for Tvg between 8 and $4{ }^{\circ} \mathrm{C}$, and at $\mathrm{T}_{\mathrm{vg}}=4{ }^{\circ} \mathrm{C}$ ETIA had virtually disappeared. At Tvg $=37$ and $22{ }^{\circ} \mathrm{C}$ values of ETIA during CNAP were larger than those in response to histamine, whereas at Tvg $=10^{\circ} \mathrm{C}$ comparable ETIA values were obtained.

The data show that ETIA is a vagal reflex activity and that C-fibre endings are not involved in the induction of ETIA. It is concluded that histamine-induced ETIA originates from stimulation of RARs. Further, histamine-induced ETIA is inhibited by stimulation of SARs. Mechanical stimulation of RARs (CNAP) is a forceful stimulus to induce ETIA.

\subsection{INTRODUCTION}

Characteristics of acute asthma are bronchoconstriction and hyperinflation ${ }^{28}$. Hyperinflation is considered to be disadvantageous to inspiratory muscle function, more to the diaphragm than to parasternal intercostal muscles (ICM) ${ }^{8}$. Bronchoconstriction with an increased mechanical time constant and incomplete emptying of the lungs is one of the causes of hyperinflation ${ }^{5}$. Another factor is a persisting inspiratory muscle activity during expiration ${ }^{10,11,16}$. The electrical activity observed in the electromyogram (EMG) of inspiratory muscles at the end of expiration-just prior to the phasic increase in inspiratory activity-has been called tonic inspiratory activity ${ }^{11,16}$. As the origin of this so called tonic activity is not clear yet we prefer to use the term endtidal inspiratory activity (ETIA). In asymptomatic asthmatics it has been found that 
during histamine-induced hyperinflation the end-tidal pleural pressure was more negative than the predicted chest wall relaxation pressure at the corresponding endtidal lung volume ${ }^{10,11}$, indicating the presence of ETLA. In more direct measurements, by evaluating electromyograms (EMGs) of inspiratory muscles, ETIA has been observed in human subjects after administration of histamine ${ }^{16}$. These studies have shown a significant correlation between the increase in thoracic gas volume and the increase in ETIA. Recent studies have shown that with intact vagus nerves lowering of tracheal pressure $(\mathrm{Pu})$ could evoke ETIA in rabbits ${ }^{18}$ and cats ${ }^{7.15}$. Stimulation of thin vagal afferents by administration of histamine increased the magnitude of ETLA in rabbits.

Although it has been indicated by several studies that histamine can induce ETIA, the mechanism is still uncertain. It has been shown that histamine stimulates rapidly adapting receptors (RARs) both by a direct chemical effect and by an indirect mechanical effect resulting from bronchoconstriction ${ }^{2,13,25,29}$.

The main objective of the present study was to evaluate the role of RARs, slowly adapting receptors (SARs) and C-fibre endings, in histamine-induced ETIA. EMGs from the diaphragm and the ICM were recorded during control conditions and after intravenous administration of histamine, both with and without simultaneous application of continuous positive airway pressure (CPAP). Although histamine and CPAP are not specific stimuli for one particular type of lung receptors, it is generally agreed that RARs are stimulated by histamine whereas CPAP mainly activates $\mathrm{SARs}^{4}$. In order to further differentiate between the reflex activities of the lung receptors the experiments were performed at different temperatures of the cervical vagus nerves ( $\mathrm{T} v \mathrm{v})$. To investigate the origin of ETIA, ETIA was also evoked by continuous negative airway pressure (CNAP) and its magnitude was compared to that of histamine-induced ETIA at various vagal temperatures. During CNAP RARs are stimulated mechanically and SAR activity is inhibited. Effects on ETIA of both stimuli, histamine and CNAP, were also studied after vagotomy.

Preliminary data have been reported in abstract form ${ }^{14}$.

\subsection{METHODS}

\subsubsection{ANIMALS AND ANAESTHESIA}

Experiments were performed on 18 adult cats of either sex, body weight $4.8 \pm 0.20$ $\mathrm{kg}$ (mean \pm SE). They were anaesthetized with ketamine-hydrochloride $(10 \mathrm{mg} / \mathrm{kg}$ body weight, i.m.) and by intravenous injection of a chloralose-urethane mixture $(12.5 \mathrm{mg} / \mathrm{kg}$ and $62.5 \mathrm{mg} / \mathrm{kg}$, respectively). Supplemental doses of this anaesthetic mixture, $5 \%$ of the initial dose, were given if needed to maintain surgical anaesthesia. 
The cats were placed in the supine position on an operating table and breathed spontaneously.

\subsubsection{MEASUREMENTS}

Catheters were inserted into the left femoral artery and vein for monitoring blood pressure (Pol) and for intravenous administration of fluids. Pbl was measured with a differential pressure transducer (Statham). The trachea was exposed in the neck and a cannula (7 mm O.D., $40 \mathrm{~mm}$ long) was inserted just below the cricoid cartilage. The tracheal cannula was connected to a flow-pressure transducer (Fleisch type 0) of a pneumotachograph (Gould) for measuring airflow (ن்). The other end of the Fleisch head was connected to a main tube by means of a T-piece. Tracheal pressure (Ptr) was measured with a differential pressure transducer (Statham). Pr, relative to ambient pressure, was obtained from a side arm of the T-piece.

The breathing circuit has been described in detail previously ${ }^{15}$. Briefly, a constant bias flow of about $18 \mathrm{l} \cdot \mathrm{min}^{-1}$ was maintained in the main tube, which was sufficient to prevent rebreathing of expired air. By tuming a 3-way tap, the direct connection of this tube to room air was occluded and the bias flow was then directed to an adjustable flow resistance. At the same time the connection to a water manometer was accomplished. With the help of this manometer and the adjustable flow resistance a certain value of Prr was preset. During an experimental run a preset positive Prr could then be established almost instantaneously by rapidly turning the tap. By reversing the bias flow a preset negative Ptr could be applied. A large bottle filled with air $(50 \mathrm{l})$ and a water manometer with wide tubes $(9 \mathrm{~cm} \mathrm{I.D.)}$ were used to minimize pressure fluctuations in the main tube due to breathing by the cat.

Conductance of vagal afferent activity can be inhibited and finally blocked by cooling both cervical vagus nerves. The vagi were exposed in the mid neck, freed from the carotid sheaths, and placed in the gold coated grooves of two cooling devices. The grooves were $13 \mathrm{~mm}$ long, $2 \mathrm{~mm}$ deep and $1 \mathrm{~mm}$ wide. A Peltier element (cooling) and a transistor (heating) were used to achieve the required temperature. The temperature of the vagi ( $\mathrm{Tvg}$ ) could be adjusted between 37 and $0{ }^{\circ} \mathrm{C}\left( \pm 0.1^{\circ} \mathrm{C}\right)$. Both nerves were immersed in oxygenated paraffin oil.

At the end of the experimental protocol bilateral section of the cervical vagi was performed to eliminate all input from vagal lung receptors to central respiratory centres. Temperature of both proximal ends of the cut vagi were then maintained at 0 ${ }^{\circ} \mathrm{C}$ to prevent spontaneous excitations.

Hooked needle electrodes were used to obtain EMGs from inspiratory muscles. After a small abdominal incision had been made just below the ribcage, a pair of electrodes was inserted into the costal part of the diaphragm. A second pair of electrodes was inserted parasternally into the intercostal muscles approximately $1 \mathrm{~cm}$ lateral to the sternum in the third or fourth intercostal space. The electrical activities of the 
diaphragm and of the ICM were amplified, filtered $(150 \mathrm{~Hz}-3000 \mathrm{~Hz})$, rectified and fed into a leaky integrator with a time constant of $50 \mathrm{~ms}$ (Neurolog, Digitimer). The partial pressure of carbon dioxide in end-tidal gas $\left(\mathrm{PetCO}_{2}\right)$ was measured by a capnograph (Nellcor $\mathrm{N}-1000$ ). Body temperature was taken from the rectum and maintained between $36-38{ }^{\circ} \mathrm{C}$ by heating the operating table.

Signals representing integrated EMG activity of the diaphragm (EMGDI) and of ICM (EMGicM), Vे, Prr, $\mathrm{PetCO}_{2}, \mathrm{~Pb}$, rectal temperature and Tvg of both vagi were monitored continuously and were sampled $(50 \mathrm{~Hz})$ with a computer (Compaq 386) and stored on hard disk for off-line analysis.

\subsubsection{EXPERIMENTAL PROTOCOL}

Two different experimental protocols were used to study histamine-induced ETIA and CNAP-induced ETIA. a) Histamine-di-phosphate $(300 \mu \mathrm{g})$ was administered intravenously after 10 control breaths had been recorded. After ETIA in response to histamine was apparent for at least 8 breaths Pur was increased to $0.9 \mathrm{kPa}$ (CPAP) during an inspiration. CPAP was maintained at the adjusted level for at least 5 breaths after which normal Pur was restored during an expiration. In this way, we recorded subsequently 1) breaths during control conditions, 2) breaths during the occurrence of histamine-induced ETIA, 3) breaths during application of CPAP, and 4) breaths at normal Ptr. Between two consecutive experiments a recovery was allowed until blood pressure had retumed to the level prior to the administration of histamine. ETIA disappeared much earlier. b) After 10 control breaths had been recorded at normal $\mathrm{Ptr}$, airway pressure was decreased to $-0.9 \mathrm{kPa}$ during an expiration, maintained the adjusted level for at least 10 breaths and restored again to control conditions during an inspiration.

The two different protocols were carried out at the following values of Tvg: 37,22 , $14,12,10,8,6$ and $4{ }^{\circ} \mathrm{C}$. In practice, protocol b was carried out first and then protocol a. After completion of these experiments, the cervical vagi were transected whereupon the two types of experiments were repeated.

In 5 animals we studied the effects of stimulation of the C-fibre endings on ETIA. Capsaicin $(50 \mu \mathrm{g} / \mathrm{kg})$ - a chemical known to activate $\mathrm{C}$-fibre endings in cats ${ }^{2,4}$-was administered by intravenous injection at three values of $\mathrm{Tvg}\left(37,10\right.$ and $\left.4{ }^{\circ} \mathrm{C}\right)$.

\subsubsection{DATA ANALYSIS}

From the recordings we determined end-tidal EMG activity and peak inspiratory EMG activity for both the diaphragm and ICM. In order to eliminate the effects of instrumental, inter-animal and intra-animal scatter we quantified ETIA of each breath as the ratio of EMG activity at the end of expiration and mean peak inspiratory EMG activity $\left(\overline{E M}_{\overline{\mathrm{G}}} \overline{\mathrm{pk}}_{\mathrm{cmu}}\right)$ obtained from at least 5 control breaths from the beginning of the same recording, in formula: 


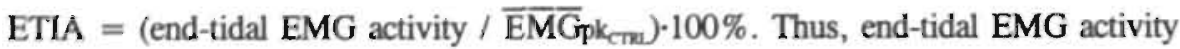
was expressed relative to the mean peak inspiratory EMG activity of control breaths. For both the diaphragm and ICM, three mean values for ETIA were calculated from. the results of at least 5 breaths during control breaths, during histamine-induced ETIA, and during CPAF, respectively (protocol a). Similarly, mean ETIA values were calculated for control breaths and CNAP (protocol b). Furthermore, the duration of expiration (EE) was calculated for all different types of experimental conditions; control, histamine, histamine + CPAP and CNAP.

End-tidal inspiratory activity may in part be due to incomplete decay of inspiratory activity during expiration. To evaluate this contribution the measured inspiratory activity during the expiratory phase of the breathing cycle was fitted with the function $\mathrm{Ae}^{-t / r}+\mathrm{B}$, where $t$ is time. $\mathrm{A}$ and $\mathrm{B}$ are amplitudes and $\tau$ is the time constant of the decay of inspiratory activity. The results for A, B and $\tau$ thus followed from the fitting procedure. From a mathematical point of view the end-tidal value of the exponential decay of inspiratory activity at time $\mathrm{t}=\mathbb{E}$ is fully determined by $\mathrm{Ae}^{-\mathrm{E} E / r}$. Similar to ETIA the contribution of the incomplete decay of inspiratory activity during expiration is presented as a percentage of $\overline{\mathrm{EM}} \overline{\mathrm{G}} \mathrm{pk}_{\mathrm{CTRL}}$. The fitting procedure was applied to the early part of expiration in which the decay of inspiratory activity is most pronounced and, therefore, also best defined. This procedure was further applied to all breaths used for the determination of ETIA.

All data presented are means \pm standard error (SE). Differences were evaluated for statistical significance using the Wilcoxon test for paired observations. A p-value $<0.05$ was considered to be significant.

\subsection{RESULTS}

In 8 out of 18 animals ETIA was evoked in response to i.v. administration of $300 \mu \mathrm{g}$ of histamine at normal or at decreased Tvg. In these 8 animals ETIA could also be induced by CNAP. In 9 out of the 18 animals no ETLA was evoked by CNAP $(\geq-0.9 \mathrm{kPa}$ ). In the present study the results of 7 responders to both stimuli, histamine and CNAP, will be evaluated (in one responder no CPAP was applied). Mean body weight ( \pm SE) of the responders $(5.1 \pm 0.3 \mathrm{~kg} ; \mathrm{n}=8)$ was not significantly different from that of the non-responders $(4.7 \pm 0.2 \mathrm{~kg} ; \mathrm{n}=10)$.

Original recordings of integrated EMG activity obtained from inspiratory muscles before and after i.v. administration of histarnine and during subsequent application of CPAP are shown in Figure 3.1. This figure shows that the increases in the end-tidal levels of integrated EMGDI and EMGICM activities (trace 1 and 2, respectively) start 
about $14 \mathrm{~s}$ after the administration of histamine. Immediately after the application of CPAP-indicated by the sharp increase of Pu (trace 3)-the end-tidal levels of both EMG activities return to their base line levels. This figure further demonstrates that after CPAP is released the end-tidal levels of EMG activities are increased again. Thus, ETIA was evoked by histamine and the histamine-induced ETIA was suppressed by CPAP. The decrease of $\mathrm{Pb}$ in response to the administration of histamine is shown in trace 5 .

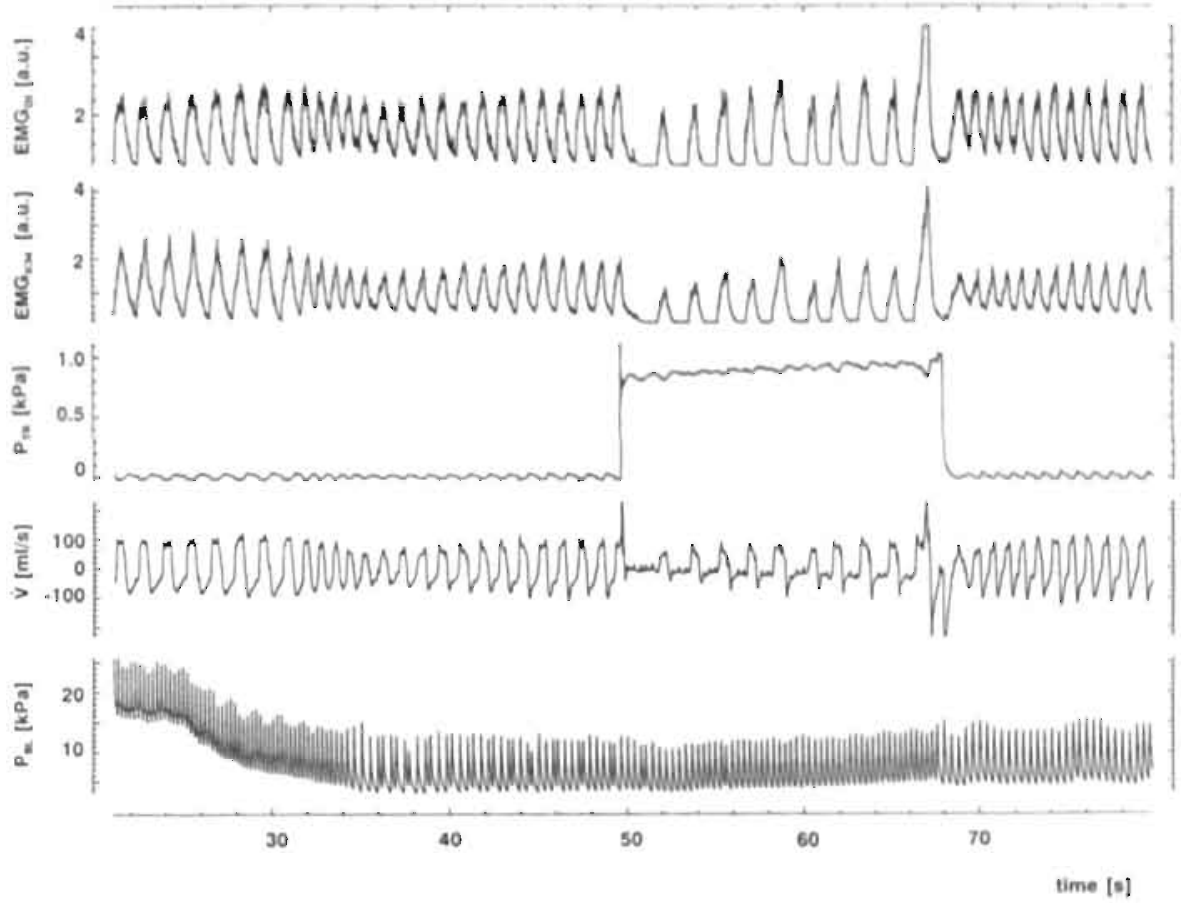

Figure 3.1 Recordings of integrated EMG activity of diaphragm EMGDI, integrated EMG activity of intercostal muscles (EMGICM), tracheal pressure (Ptr), airflow (V) and arterial blood pressure $(\mathrm{Pbl}$ after administration of histamine and during simultaneous application of CPAP for one representative animal. Histamine was administered at time $=14 \mathrm{~s}$ (not shown). Recording of Ptr shows when CPAP was applied. Note onset of tonic inspiratory activity (ETIA) about $18 \mathrm{~s}$ after histamine was administered, and its suppression when CPAP was applied (trace 1 and 2). Temperature of cervical vagi was $37^{\circ} \mathrm{C}$.

In response to intravenous injection of $300 \mu \mathrm{g}$ of histamine mean arterial blood pressure $(\overline{\mathrm{P}} \mathrm{bl})$ decreased significantly $(\mathrm{p}<0.05)$ compared to control in each animal and at all values of $\mathrm{Tvg}$. The average: decrease in $\overline{\mathrm{P}}$ bl for all individual experiments 
together was $8.5 \pm 0.36 \mathrm{kPa}(\mathrm{n}=56)$.

\subsubsection{EFFECTS OF VAGAL COOLING ON ETIA}

The mean results of histamine-induced ETIA in the diaphragm and ICM obtained from the responders at different Tvg (ranging from 37 to $4{ }^{\circ} \mathrm{C}$ ) are shown in Figure 3.2. (left panels). As compared to the values at $\mathrm{Tvg}_{\mathrm{vg}}=37^{\circ} \mathrm{C}$ histamine-induced ETIA reaches much higher levels for Tvg between 14 and $6{ }^{\circ} \mathrm{C}$ and for Tvg between 14 and $8{ }^{\circ} \mathrm{C}$ for the diaphragm and ICM, respectively. At Tvg $=37$ and $22{ }^{\circ} \mathrm{C}$ histamineinduced ETIA in the diaphragm is significantly inhibited by CPAP (Figure 3.2). In ICM the difference between the mean values (histamine versus histamine+CPAP) just failed to reach significance $(p=0.07)$ at $\mathrm{Tvg}=37{ }^{\circ} \mathrm{C}$, but similar to the diaphragm this difference is significant at $\mathrm{Tvg}=22{ }^{\circ} \mathrm{C}$. In the diaphragm CPAP did not suppress histamine-induced ETIA any more at Tvg between 14 and $6{ }^{\circ} \mathrm{C}$. In 4 out of 7 cats histamine-induced ETIA in the diaphragm even increased in response to CPAP at Tvg $=12{ }^{\circ} \mathrm{C}$. At Tvg between 12 and $8{ }^{\circ} \mathrm{C}$ ETIA values in ICM were significantly lower during CPAP than after histamine alone, but remained higher than control levels, which is in contrast to the findings at $\mathrm{Tvg}=37$ and $22{ }^{\circ} \mathrm{C}$ where ETIA after CPAP was smaller than ETIA at control conditions. Thus, as compared to the suppressing influence of CPAP on histamine-induced ETIA at Tvg $=37$ and $22{ }^{\circ} \mathrm{C}$ this influence is relatively smaller at $\mathrm{Tvg} \leq 144^{\circ} \mathrm{C}$. Between $\mathrm{T}_{\mathrm{vg}}=8$ and $4{ }^{\circ} \mathrm{C}$ ETIA declines sharply, and for $\mathrm{Tvg}=4{ }^{\circ} \mathrm{C}$ no change in ETIA is found in response to administration of histamine (Figure 3.2). At Tvg $=4{ }^{\circ} \mathrm{C}$ conduction in the afferents of both SARs and RARs is known to be largely blocked ${ }^{9,19}$.

\subsubsection{NEGATIVE AIRWAY PRESSURE}

In all animals in which ETIA could be evoked by histamine, ETIA was also induced by CNAP ( $P$ tr $=-0.9 \mathrm{kPa}$ ). ETIA values in response to CNAP were larger for the ICM than for the diaphragm (Figure 3.3, left panels). At $\mathrm{T}_{\mathrm{vg}}=4{ }^{\circ} \mathrm{C}$ no significant increase in ETIA was found in ICM. However, in the djaphragm a small significant increase in ETIA remained. At Tvg $=37^{\circ} \mathrm{C}$ the magnitude of CNAP-induced ETLA is much larger than that of histamine-induced ETIA both for the diaphragm and the ICM (Figures 3.2 and 3.3), whereas at temperatures between 14 and $8{ }^{\circ} \mathrm{C}$ ETIA values are comparable. Figure 3.3 further shows that ETIA values in response to CNAP are about the same for Tvg between 37 and $8{ }^{\circ} \mathrm{C}$. Between Tvg $=8$ and $4{ }^{\circ} \mathrm{C}$, however, ETLA declines sharply (Figure 3.3). This behaviour is similar to that seen for ETIA after histamine (Figure 3.2).

\subsubsection{CAPSAICIN}

C-fibre stimulation by intravenous injection of capsaicin was performed in 5 cats, of which two were responders to both stimuli: histamine and CNAP. The administration 
of this drug caused the well-known respiratory effects, a short period of apnoea followed by rapid breathing (Figure 3.4). In each cat capsaicin was injected at three different values for $\operatorname{Trg}\left(37,10\right.$ and $\left.4{ }^{\circ} \mathrm{C}\right)$, but in no single experiment was ETIA evoked.
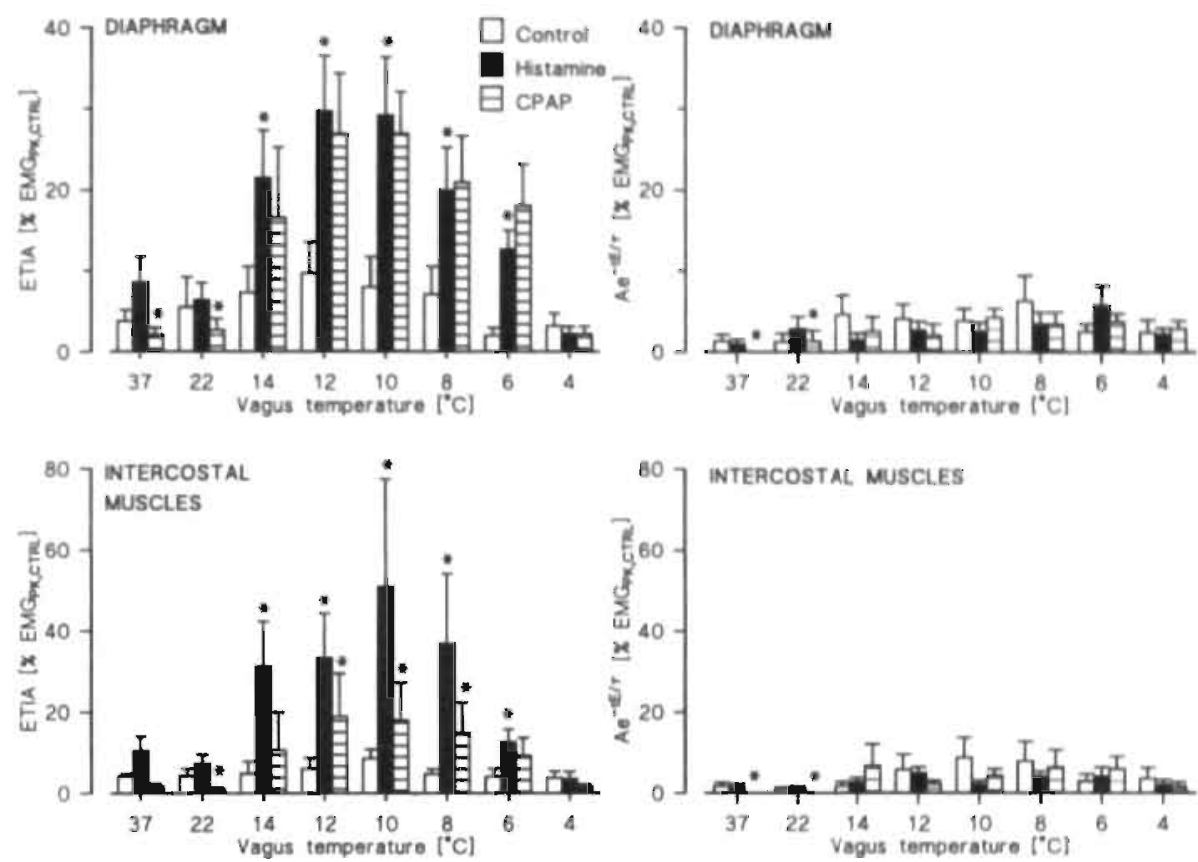

Figure 3.2. Left panels: Means $\pm S E$ of end-tidal inspiratory activity (ETLA) during control, after administration of histamine, and during subsequent $C P A P(0.9 \mathrm{kPa})$ at different vagal

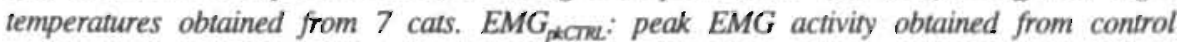
breaths. Asterisks indicate statistically significant differences in ETHA between histamine and control values, and between CPAP and histamine values for that temperature $\left(^{*} p<0.05\right.$; Wilcoxon test for paired observations). Right panels: Means $\pm S E$ of estimated end-tidal values (A, amplitude; $r$, time constant) of decaying inspiratory EMG activity during expiration.

\subsubsection{VAGOTOMY}

After both cervical vagus nerves had been cut end-tidal EMG levels corresponded in all experiments to the electrical zero level. Hence, in neither condition-during control, after administration of histamine or during; CNAP'-was ETIA found after vagotomy'. 


\subsubsection{ETIA AND EXPONENTIAL DECAY OF INSPIRATORY ACTIVITY DURING EXPIRATION}

The contribution of the incomplete decay of inspiratory activity during expiration to ETIA was estimated from $\mathrm{Ae}^{-\mathrm{E} / \mathrm{t}}$. The amplitude $\mathrm{A}$ and the time constant $\tau$ were obtained by fitting the measured inspiratory activity during expiration with the function $\mathrm{Ae}^{-t / r}+\mathrm{B}$ (see Methods). The results for $\mathrm{Ae}^{-\mathrm{E} / \mathrm{r}}$ are shown in the right panels of Figure 3.2 (control, histamine, histamine+CPAP) and Figure 3.3 (control,

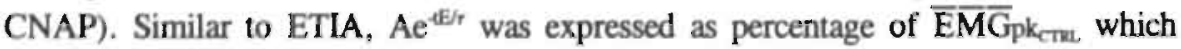
facilitates the comparison with ETIA. In general, $\mathrm{Ae}^{-\mathrm{E} / \mathrm{t}}$ is much smaller than ETLA for both the diaphragm and ICM when ETIA is enhanced by histamine, histamine+CPAP or CNAP (Figures 3.2 and 3.3). This, however, is not true for control conditions, where at several values of $\mathrm{Tvg} \mathrm{Ae}^{-\mathbb{E} / r}$ was more than halve the value of ETIA for either the diaphragm or ICM or both. This especially occurs at lower vagal temperatures.
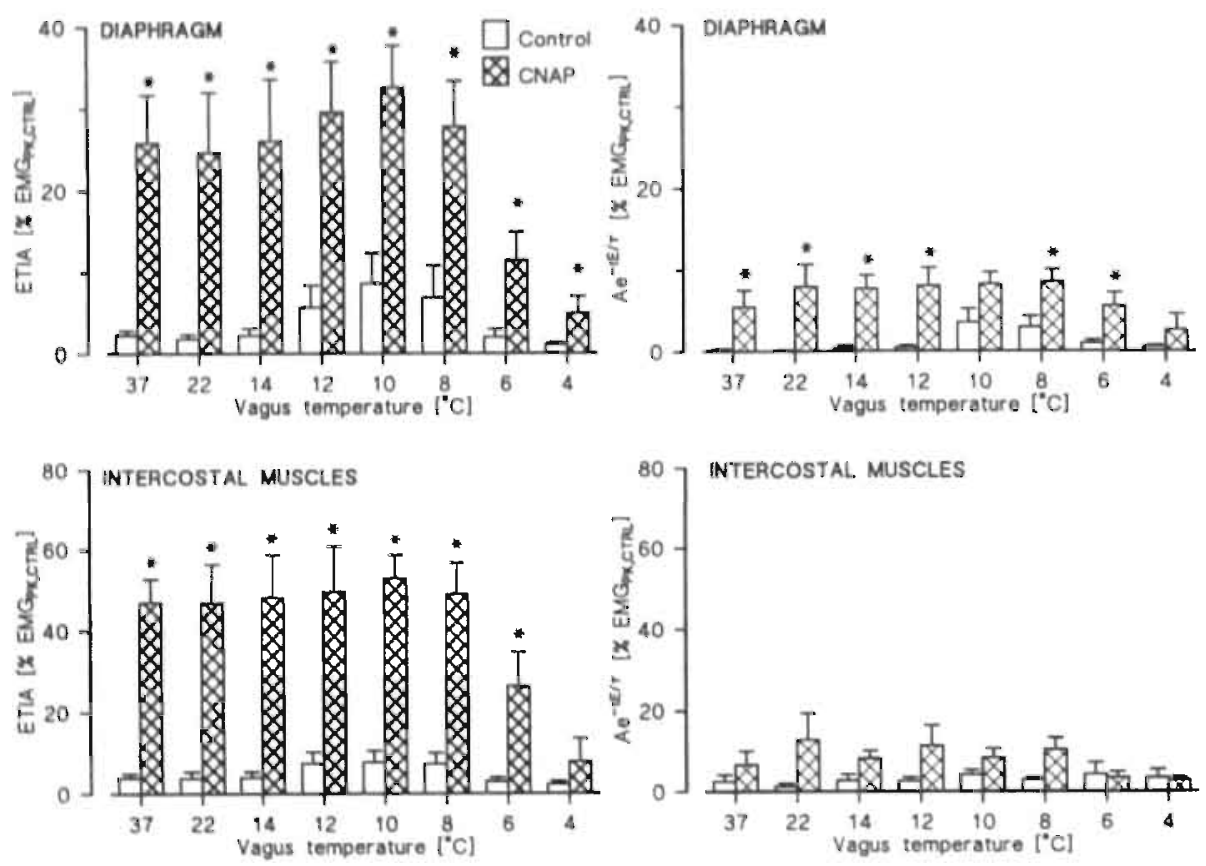

Figure 3.3 Left panels: Means \pm SE of ETHA during control and during CNAP' (-0.9 Kpa) at different vagal temperatures obtained from 7 cats. Asterisks indicate statistically significant differences between ETZA during CNAP and corresponding control values for each temperature $\rho^{*} p<0.05$; Wilcaxon test for paired observations). Note that ETZA values for diaphragm are smaller than those for intercostal muscles. Right panels: Means $\pm S E$ of estimated end-tidal values of decaying inspiratory EMG activity during expiration. (A. amplitude; $\tau$, time constant) 
After administration of histamine and for $\mathrm{Tvg}=14-8^{\circ} \mathrm{C}$ the average values for $\mathrm{Ae} \mathrm{eth}^{-\mathrm{i}}$ for both the diaphragm and ICM were about $12 \%$ of the corresponding values for ETIA. Similarly, at CNAP and for $\mathrm{Trg}=37-8{ }^{\circ} \mathrm{C}$ this percentage was about $23 \%$. Thus, in conditions in which ETIA is small, e.g. for Tvg $=4{ }^{\circ} \mathrm{C}$, most of ETIA is due to the incomplete decay of inspiratory activity at the end of expiration, on the contrary in conditions in which ETIA is much elevated, ETIA is mainly due to the remaining determinants of ETIA which will be discussed in the next section.

The duration of expiration, $\mathrm{E}$, and the time constant, $\tau$, for the decay of inspiratory activity during expiration are important determinants of $\mathrm{Ae}^{-\mathrm{t} / \mathrm{t}}$. The results for $\mathrm{tE}$ and $\tau$ are shown in Tables 3.1 and 3.2. These data show that in general $\mathrm{tE}$ and $\tau$ vary with Tvg and with changing experimental conditions.

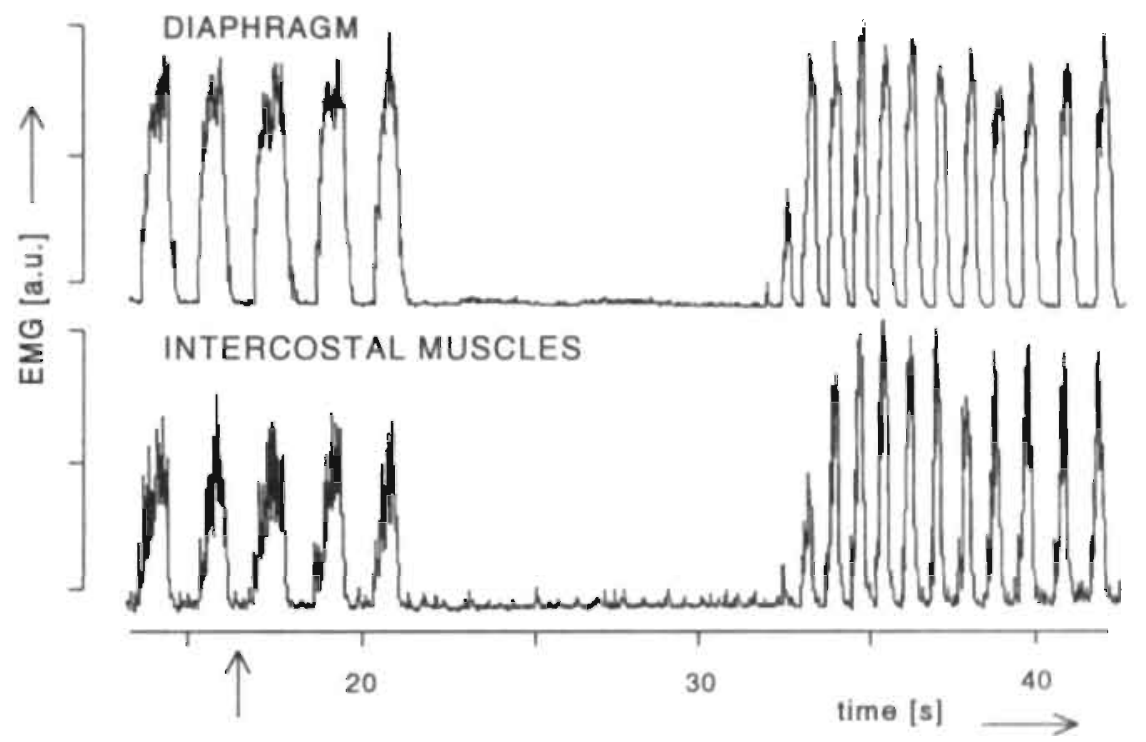

Figure 3.4 Recordings of integrated EMG activity of diaphragm and intercostal muscles (ICM) before and after intravenous administration of capsaicin (indicated by arrow) for one representative animal. Note apnoea and subsequent increase in breathing frequency in response to capsaicin and absence of end-tidal inspiratory activity.

\subsection{DISCUSSION}

ETIA was induced in response to CNAP' or intravenous injection of histamine both in the feline diaphragm and ICM. At Tvg between 8 and $4{ }^{\circ} \mathrm{C}$ the effects of both stimuli 
on ETIA decreased to low levels with decreasing temperature. After vagotomy histamine and CNAP could not evoke ETIA any more. At Tvg $=37{ }^{\circ} \mathrm{C}$ histamineinduced ETIA was suppressed by CPAP whereas at Tvg between 14 and $8{ }^{\circ} \mathrm{C}$ this suppression was diminished. These effects were most pronounced for the diaphragm. Both histamine-induced ETIA and CNAP-induced ETIA were larger in ICM than in the diaphragm (Figures 3.2 and 3.3).

Table 3.1 Duration of expiration (IE) and time constant $(\tau)$ obtained from the decay of the inspiratory EMG activity during expiration for three conditions; control, histamine and histamine + continuous positive ainway pressure (CPAP).

\begin{tabular}{|c|c|c|c|c|c|c|c|c|}
\hline Vagus temp. $\left({ }^{\circ} \mathrm{C}\right)$ & 37 & 22 & 14 & 12 & 10 & 8 & 6 & 4 \\
\hline $\begin{array}{l}\text { tE-ctrl (s) } \\
\pm \mathrm{SE}\end{array}$ & $\begin{array}{l}0.92 \\
0.11\end{array}$ & $\begin{array}{l}0.94 \\
0.11\end{array}$ & $\begin{array}{l}0.92 \\
0.11\end{array}$ & $\begin{array}{l}0.97 \\
0.12\end{array}$ & $\begin{array}{l}1.08 \\
0.14\end{array}$ & $\begin{array}{l}1.13 \\
0.13\end{array}$ & $\begin{array}{l}1.27 \\
0.13\end{array}$ & $\begin{array}{l}1.33 \\
0.10\end{array}$ \\
\hline $\begin{array}{l}\text { tE-hist } \\
\pm S E\end{array}$ & $\begin{array}{l}0.71^{\circ} \\
0.11^{\circ}\end{array}$ & $\begin{array}{l}0.72^{\circ} \\
0.09\end{array}$ & $\begin{array}{l}0.66^{\circ} \\
0.09\end{array}$ & $\begin{array}{l}0.72^{\circ} \\
0.08\end{array}$ & $\begin{array}{l}0.88^{\circ} \\
0.11\end{array}$ & $\begin{array}{l}0.93 \\
0.11\end{array}$ & $\begin{array}{l}1.03^{\circ} \\
0.09\end{array}$ & $\begin{array}{l}1.23 \\
0.14\end{array}$ \\
\hline $\begin{array}{l}\text { E-CPAP } \\
\pm \text { SE }\end{array}$ & $\begin{array}{l}1.37^{\circ} \\
0.16\end{array}$ & $\begin{array}{l}1.37^{\circ} \\
0.14\end{array}$ & $\begin{array}{l}1.00^{\circ} \\
0.11\end{array}$ & $\begin{array}{l}0.90^{\circ} \\
0.08\end{array}$ & $\begin{array}{l}1.04 \\
0.08\end{array}$ & $\begin{array}{l}1.08 \\
0.10\end{array}$ & $\begin{array}{l}1.03 \\
0.12\end{array}$ & $\begin{array}{l}1.14 \\
0.10\end{array}$ \\
\hline $\begin{array}{l}\text { DIAPHRAGM } \\
\tau \text {-ctrl (s) } \\
\pm S E\end{array}$ & $\begin{array}{l}0.18 \\
0.03\end{array}$ & $\begin{array}{l}0.17 \\
0.04\end{array}$ & $\begin{array}{l}0.27 \\
0.06\end{array}$ & $\begin{array}{l}0.31 \\
0.07\end{array}$ & $\begin{array}{l}0.32 \\
0.06\end{array}$ & $\begin{array}{l}0.40 \\
0.19\end{array}$ & $\begin{array}{l}0.34 \\
0.06\end{array}$ & $\begin{array}{l}0.28 \\
0.05\end{array}$ \\
\hline $\begin{array}{l}7 \text {-hist } \\
\pm \mathrm{SE}\end{array}$ & $\begin{array}{l}0.14^{\circ} \\
0.02\end{array}$ & $\begin{array}{l}0.18 \\
0.04\end{array}$ & $\begin{array}{l}0.21 \\
0.06\end{array}$ & $\begin{array}{l}0.17^{\circ} \\
0.03\end{array}$ & $\begin{array}{l}0.24 \\
0.02\end{array}$ & $\begin{array}{l}0.29 \\
0.05\end{array}$ & $\begin{array}{l}0.33 \\
0.05\end{array}$ & $\begin{array}{l}0.28 \\
0.04\end{array}$ \\
\hline $\begin{array}{l}\tau \text {-CPAP } \\
\pm \mathrm{SE}\end{array}$ & $\begin{array}{l}0.12 \\
0.02\end{array}$ & $\begin{array}{l}0.17 \\
0.07\end{array}$ & $\begin{array}{l}0.21 \\
0.06\end{array}$ & $\begin{array}{l}0.22 \\
0.04\end{array}$ & $\begin{array}{l}0.32 \\
0.04\end{array}$ & $\begin{array}{l}0.28 \\
0.02\end{array}$ & $\begin{array}{l}0.28 \\
0.03\end{array}$ & $\begin{array}{l}0.26 \\
0.02\end{array}$ \\
\hline \multicolumn{9}{|c|}{ INTERCOSTAL MUSCLES } \\
\hline $\begin{array}{l}r-\mathrm{ctrl} \text { (s) } \\
\pm \mathrm{SE}\end{array}$ & $\begin{array}{l}0.25 \\
0.05\end{array}$ & $\begin{array}{l}0.20 \\
0.04\end{array}$ & $\begin{array}{l}0.24 \\
0.04\end{array}$ & $\begin{array}{l}0.32 \\
0.06\end{array}$ & $\begin{array}{l}0.48 \\
0.10\end{array}$ & $\begin{array}{l}0.44 \\
0.06\end{array}$ & $\begin{array}{l}0.36 \\
0.08\end{array}$ & $\begin{array}{l}0.35 \\
0.09\end{array}$ \\
\hline $\begin{array}{l}\tau \text {-hist } \\
\pm \mathrm{SE}\end{array}$ & $\begin{array}{l}0.15 \\
0.02\end{array}$ & $\begin{array}{l}0.16 \\
0.02\end{array}$ & $\begin{array}{l}0.19 \\
0.02\end{array}$ & $\begin{array}{l}0.25 \\
0.02\end{array}$ & $\begin{array}{l}0.27 \\
0.03\end{array}$ & $\begin{array}{l}0.30 \\
0.04\end{array}$ & $\begin{array}{l}0.33 \\
0.03\end{array}$ & $\begin{array}{l}0.32 \\
0.03\end{array}$ \\
\hline $\begin{array}{l}\tau \text {-CPAP } \\
\pm \text { SE }\end{array}$ & $\begin{array}{l}0.13 \\
0.02\end{array}$ & $\begin{array}{l}0.13 \\
0.02\end{array}$ & $\begin{array}{l}0.23 \\
0.04\end{array}$ & $\begin{array}{l}0.37 \\
0.16\end{array}$ & $\begin{array}{l}0.32 \\
0.06\end{array}$ & $\begin{array}{l}0.33 \\
0.05\end{array}$ & $\begin{array}{l}0.28 \\
0.03\end{array}$ & $\begin{array}{l}0.23 \\
0.03\end{array}$ \\
\hline
\end{tabular}

Data represent means $\pm S E$ for 7 animals. Values after administration of histamine were compared with control, values during CPAP were compared with values after histamine. Wilcoxon matched-pairs signed-ranks test; $p<0.05$ was considered significant. ; $p<0.05$.

After vagotomy no ETIA was observed in response to CNAP which demonstrates that ETIA is not evoked by extra vagal mechanisms. A considerable fraction of our experimental animals did not respond to histarnine and CNAP. This shows that there is a wide natural variability in cats in terms of showing ETIA in response to the applied stimuli. In human subjects a similar variability is found for the response of the 
airway resistance during histamine challenge tests.

ETIA has also been studied in other species. In rabbits ETIA has been evoked in response to a decreased $\mathrm{Put}^{18}$ and after administration of histamine, both in the diaphragm and in $\mathrm{ICM}^{3}$. In man ETIA has been observed after administration of histamine ${ }^{16}$.

Table 3.2 Duration of expiration (IE) and time constant ( $\tau$ ) obtained from decay of the inspiratory EMG activity during expiration for two conditions, control and continuous negative ainway pressure (CNAP).

\begin{tabular}{|c|c|c|c|c|c|c|c|c|}
\hline Vagus temp. $\left({ }^{\circ} \mathrm{C}\right)$ & 37 & 22 & 14 & 12 & 10 & 8 & 6 & 4 \\
\hline tE-ctrl (s) & 0.99 & 0.99 & 0.97 & 0.93 & 0.87 & 0.98 & 1.19 & 1.29 \\
\hline$\pm \mathrm{SE}$ & 0.13 & 0.12 & 0.13 & 0.15 & 0.14 & 0.15 & 0.11 & 0.11 \\
\hline TE-CNAP & $0.64^{*}$ & $0.52^{\circ}$ & $0.49^{\circ}$ & $0.47^{*}$ & $0.48^{\circ}$ & $0.53^{*}$ & 0.85 & 1.20 \\
\hline$\pm \mathrm{SE}$ & 0.20 & 0.13 & 0.12 & 0.13 & 0.11 & 0.14 & 0.17 & 0.17 \\
\hline \multicolumn{9}{|l|}{ DIAPHRAGM } \\
\hline$T-\operatorname{ctrl}(\mathrm{s})$ & 0.12 & 0.12 & 0.13 & 0.15 & 0.28 & 0.27 & 0.27 & 0.23 \\
\hline$\pm \mathrm{SE}$ & 0.01 & 0.01 & 0.02 & 0.02 & 0.09 & 0.06 & 0.03 & 0.03 \\
\hline TCNAP & 0.20 & $0.24^{\circ}$ & 0.24 & 0.29 & 0.44 & 0.32 & 0.37 & 0.25 \\
\hline$\pm \mathrm{SE}$ & 0.04 & 0.04 & 0.03 & 0.09 & 0.18 & 0.10 & 0.09 & 0.05 \\
\hline \multicolumn{9}{|c|}{ INTERCOSTAL MUSCLES } \\
\hline$T$-ctrl (s) & 0.22 & 0.21 & 0.25 & 0.27 & 0.28 & 0.39 & 0.41 & 0.37 \\
\hline$\pm \mathrm{SE}$ & 0.06 & 0.05 & 0.06 & 0.08 & 0.06 & 0.12 & 0.10 & 0.10 \\
\hline$\tau$-CNAP & 0.24 & 0.35 & 0.27 & 0.39 & $0.34^{\circ}$ & $0.37^{\circ}$ & 0.29 & 0.32 \\
\hline$\pm \mathrm{SE}$ & 0.05 & 0.07 & 0.03 & 0.11 & 0.07 & 0.10 & 0.03 & 0.05 \\
\hline
\end{tabular}

Data represent means $\pm S E$ for 7 animals. Values during continuous negative airway pressure (CNAP) were compared with control. Wilcoxon matched-pairs signed-ranks test; $p<0.05$ was considered significant. " $p<0.05$.

\subsubsection{ETIA AND EXPONENTIAL DECAY OF INSPIRATORY ACTIVITY DURING EXPIRATTON}

It is known from the literature ${ }^{4,21,22}$ that the activities of SARs and/or RARs are affected when changing the experimental conditions from control to CNAP or CPAP and after administration of histamine. In turn, the activities of these receptors affect the behaviour of the inspiratory off-switch and on-switch mechanisms and, therefore, also $\mathrm{tE}, \mathrm{EM}, \mathrm{GPK}$ and $\tau$. This was also reflected by the changes in $\mathrm{tE}$ and $\tau$ that were observed in individual cats when changing from one experimental condition to another (Tables 3.1 and 3.2). Increases in EMGPK or EE/ $\tau$ or both will result in a larger contribution of the incomplete decay of inspiratory activity to ETIA. The changes in these parameters induced by the applied stimuli imply that the contribution of the incomplete decay of inspiratory activity to ETIA during stimulation cannot be 
determined independently from e.g. control breaths. For this reason, we had to determine this contribution and ETIA from the same EMGs, as described in Methods. Figures 3.2 and 3.3 show that the contribution of the incomplete decay of inspiratory activity to ETIA is modest in conditions in which ETIA is much elevated. It can be further inferred from Figures 3.2 and 3.3 that the behaviour of ETIA as a function of Tvg is not much affected by the contribution of the incomplete decay of inspiratory activity to ETIA. In other words, the initial rise in ETLA for histamine (and also for histamine+CPAP) at Tvg $=14^{\circ} \mathrm{C}$ and its decline for Tvg below $10^{\circ} \mathrm{C}$ can be safely attributed to changes in the remaining determinants of ETIA, and this also applies to the decline in ETIA for Tvg below $8^{\circ} \mathrm{C}$ for CNAP (Figure 3.3). A further detail of Figure 3.3 is, that if the individual values for ETIA at Tvg $=4{ }^{\circ} \mathrm{C}$ are corrected for the corresponding values of $\mathrm{Ae}^{-\mathrm{E} / r}$ the mean value of corrected ETIA is still significantly different from control but the difference is very small (about $2 \%$ of $\left.\overline{\mathrm{EM}} \overline{\mathrm{G}}_{\mathrm{pk}} \mathrm{ct \textrm {L }}\right)$.

\subsubsection{C-FIBRE ENDINGS AND ETIA}

Badier et al. ${ }^{3}$ used procaine to block selectively the electric conduction of thin vagal fibres and concluded that stimulation of thin sensory fibres elicits ETLA. However, differentiation between $\mathrm{C}$-fibre endings and RARs (both have thin vagal afferents) was not possible. In the present study we used vagal cooling to block selectively the conduction of the afferents from lung receptors. It has been shown that at temperatures below $5{ }^{\circ} \mathrm{C}$ the conduction in myelinated fibres (from. SARs and RARs) is almost completely blocked whereas a large fraction of the activity of unmyelinated Cfibres is still transmitted,19. At Tvg $=4{ }^{\circ} \mathrm{C}$ hardly any histamine-induced ETIA was found indicating that $\mathrm{C}$-fibre endings are not involved in inducing ETIA (Figure 3.2). We observed similar effects of vagal cooling on CNAP-induced ETIA (Figure 3.3). Our conclusion that C-fibre endings are not involved in ETIA is further supported by our observation that chemical stimulation of $\mathrm{C}$-fibres by capsaicin does not induce ETIA (Figure 3.4). It is not likely, therefore, that stimulation of $C$-fibre endings by histamine ${ }^{4}$ has attributed to the genesis of ETIA in our experiments. After vagotomy the different stimuli did not evoke ETIA any more and, thus, the occurrence of ETIA depends on vagal reflex mechanisms. Since C-fibre endings appear to play no role. ETLA may be attributed to reflex effects of either RARs or SARs or both.

\subsubsection{SARS, RARS AND ETIA}

It is generally accepted that stimulation of RARs excites inspiratory activity whereas this activity can be inhibited by stimulation of SARs ${ }^{4}$, RAR activity increases and SAR activity decreases when Pu is lowered ${ }^{1,21,22}$. Thus CNAP-induced ETIA (Figure 3.3) may result from excitation of inspiratory motoneurons by RARs or lack of. 
inhibition of these neurons by SARs or both. RARs and, in particular, SARs are stimulated by increased FRC as induced by CPAP4. As a consequence, the nearly complete suppression of histamine-induced ETIA at Tvg $=37{ }^{\circ} \mathrm{C}$ (Figure 3.2) in response to CPAP must be attributed to inhibition of inspiratory motoneuron activity by SARs. Lack of inhibition of inspiratory motoneurons by SARs, however, cannot be the only mechanism underlying ETIA because elimination of all afferent input from SARs by vagotomy does not result in ETIA. Hence, the primary cause for ETIA to occur in our experiments was the excitation of inspiratory motoneurons by RARs where the amplitude of ETIA was modulated by SAR activity through inhibition of inspiratory activity. The indicated role for RARs was further supported by the fact that high levels of ETIA could be induced by administration of histamine, a drug which is known to stimulate RARs.

The model resulting from the above discussion is depicted in Figure 3.5. Further evidence for this model was obtained from the effects of vagal cooling. In dogs and cats there is an overlap in conduction velocities of RARs and SARs though the mean. value for RARs appears to be lower ${ }^{20}$. In single fibre studies it has been found that at vagal temperatures below $14{ }^{\circ} \mathrm{C}$ conduction in afferents of SARs and RARs is progressively reduced ${ }^{9,1926}$. However, diminished conduction in afferents of SARs, occurs at slightly higher temperatures $\left(12-10^{\circ} \mathrm{C}\right)$ than in the afferents of RARs $(9$ $\left.7^{\circ} \mathrm{C}\right)^{19}$. In the present study several temperatures in the range of 37 down to $4{ }^{\circ} \mathrm{C}$ were applied. This explains the general behaviour of histamine-induced ETIA with decreasing Tvg which first increases at. $\mathrm{T} v g=14{ }^{\circ} \mathrm{C}$ (reduced central input of SAR activity) and then decreases again at temperatures below $10^{\circ} \mathrm{C}$ (reduced central input of RAR activity). For $\mathrm{Tvg}_{\mathrm{vg}}<14^{\circ} \mathrm{C}$, the percentage decrease in ETIA due to CPAP is substantially smaller than at $\mathrm{Tvg}_{\mathrm{vg}}=37^{\circ} \mathrm{C}$. This can be attributed to the reduced central input from SARs for $\mathrm{Tvg}<14^{\circ} \mathrm{C}$. At vagal temperatures where the conduction of SAR activity is (largely) blocked while that of most RARs is still transmitted, CPAP may augment ETIA through additional stimulation of RARs. This explains the augmentation of histamine-induced ETIA by CPAP which was seen in the diaphragm at: $\mathrm{Tvg}=8-6{ }^{\circ} \mathrm{C}$ in some of our experimental animals (Figure 3.2).

At $\mathrm{Tvg}=37^{\circ} \mathrm{C}$ the magnitude of ETIA in response to CNAP $(-0.9 \mathrm{kPa})$ was larger than that in response to histamine both for the diaphragm and ICM. When SAR activity was diminished by vagal cooling ETIA values after histamine and during CNAP were of the same magnitude. This suggests that the magnitude of RAR activation is comparable for both types of stimuli. SAR activity is already reduced at $P t r=-0.9 \mathrm{kPa}^{1}$ and, therefore, at this $\mathrm{Ptr}$ the decrease in central input of SAR activity due to vagal cooling will be considerably less than the corresponding decrease at $\mathrm{Ptr}=0 \mathrm{kPa}$ (control). In other words, at $\mathrm{Ptr}=-0.9 \mathrm{kPa}$ vagal cooling can hardly reduce afferent activity of SARs any further, resulting in much more constant levels of ETIA for Trg down to about $8{ }^{\circ} \mathrm{C}$ (Figure 3.3) as compared to those found after 
histamine (Figure 3.2). The right parts of the left panels of Figures 3.2 and 3.3 are comparable; i.e. at low temperatures ( $\operatorname{Trg}$ from $8{ }^{\circ} \mathrm{C}$ down to $4{ }^{\circ} \mathrm{C}$ ) ETIA values decline to low levels. In this range the activity in the afferents of RARs is diminished. The finding that at $\mathrm{Tvg}=4{ }^{\circ} \mathrm{C}$ there is still a small but significant increase in ETIA in response to CNAP in the diaphragm should be ascribed to the presence of some afferent activity from RARs. While ETIA decreases by vagal cooling FRC will decrease simultaneously. During CNAP this additional decrease in FRC will result in enhanced mechanical stimulation of RARs. Such an enhanced stimulation of RARs may explain why ETIA at $\mathrm{Tvg}=4^{\circ} \mathrm{C}$ is still significantly different from control values in the diaphragm during CNAP, while this is not the case when induced by histamine (Figures 3.2 and 3.3). In other words, the diminishing effect of vagal cooling (below 8 ${ }^{\circ} \mathrm{C}$ ) on the afferent activity of RARs during CNAP may, at least in part, be compensated for by the enhanced stimulation of RARs due to the concomitant decrease in FRC and end-tidal transpulmonary pressure ${ }^{6}$.

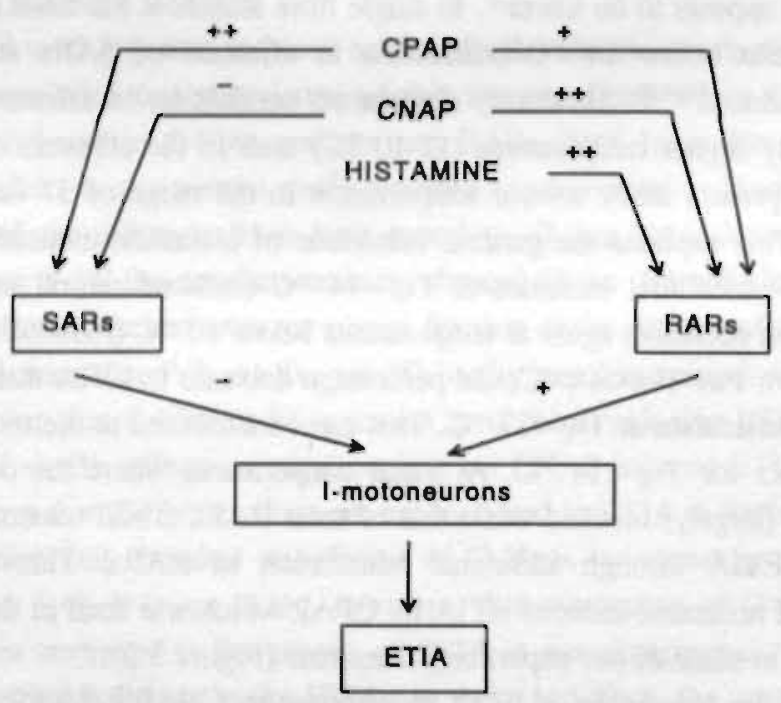

Figure 3.5 Schematic presentation of effects of CPAP, CNAP and histamine on SAR and RAR activity, and of impact of SAR and RAR activity on inspiratory motoneuron activity and ETHA. Plus and minus signs refer to stimulation and inhibition, respectively.

\subsubsection{ORIGIN OF HISTAMINE-INDUCED ETIA}

It has been shown in animals that the activity of RARs increases with decreasing $\mathrm{Pu}^{2,22}$, by hyperinflation ${ }^{2}$ and by administration (intravascular or by inhalation) of histamine $2,23,25,27,29$. Histamine is believed to stimulate RARs both indirectly by a 
mechanical effect and by a direct chemical effect ${ }^{24,25}$. Histamine-induced ETIA in cats may, therefore, have a dual origin arising from stimulation of RARs, by a direct, chemical effect and indirectly by a mechanical effect.

A difficulty in investigating reflex functions mediated by RARs is that all the naturally occurring chemicals known to stimulate RARs, such as histamine, are themselves powerful bronchoconstrictors, acting directly on airway smooth muscle and thus stimulating RARs also indirectly.

Although the stimuli (histamine and CNAP) are different in our experiments, the effects in terms of ETIA appear to be about the same at a vagus temperature of $10^{\circ} \mathrm{C}$ for both the diaphragm and ICM (Figures 3.2 and 3.3). This indicates a comparable stimulation of RARs, since at this temperature most of the afferent activity from SARs will be abolished. CNAP is a purely mechanical stimulus exciting RARs. Although the present study was not designed to differentiate between chemical and mechanical stimulation of RARs by histamine the above results for ETIA at Tvg $=10$ ${ }^{\circ} \mathrm{C}$ suggest that in histamine-induced ETIA mechanical stimulation of RARs might be the more important stimulus.

Muller et al. ${ }^{17}$ have shown that ETIA develops in asthmatics when their bronchodilator medication is withheld for 12 hours. These results can be explained by an increased stimulation of RARs due to rebound bronchoconstriction. We think that in asthma the balance between the levels of activity of RARs and SARs may be disturbed resulting in ETIA (Figure 3.5). This is supported by the observation that CPAP reduced the load on inspiratory muscles in asthmatics after inhalation of histamine ${ }^{12}$. It is not clear yet whether the sensitivity of the receptors or the number of receptors or the central processing of afferent impulses or a combination of these factors is involved in this balance.

\subsubsection{CONCLUSIONS}

1) In spontaneously breathing cats ETIA can be induced both in the diaphragm and ICM by intravenous administration of histamine and by application of CNAP. 2) For these conditions, the incomplete decay of inspiratory activity during expiration constitutes only a modest part of ETIA. 3) ETIA is mediated by a vagal reflex. 4) Cfibre endings are not involved in ETIA. 5) Stimulation of RARs excites ETIA, whereas ETIA is inhibited by stimulation of SARs. 


\subsection{REFERENCES}

1. Adrian ED (1933). Afferent impulses in the vagus and their effect on respiration. J Physiol (Lond) 79: 332-358.

2. Armstrong DJ and Luck JC (1974). A comparative study of irritant and type J receptors in the cat. Respir Physiol 21: 47-60.

3. Badier M, Jammes Y, Romero-Colomer P and Lemerre C (1989). Tonic activity in inspiratory muscles and phrenic motoneurons by stimulation of vagal afferents. $\mathrm{J}$ Appl Physiol 66: 1613-1619.

4. Coleridge HM and Coleridge JCG. Reflexes evoked from tracheobronchial tree and lungs. In: Handbook of Physiology, The Respiratory System, Control of Breathing, Vol. II, edited by Cherniack NS and Widdicombe JG. Bethesda, MD: American Physiological Society, 1986, p. 395-429.

5. Demedts M (1990). Mechanisms and consequences of hyperinflation. Eur Respir J 3: 617-618.

6. Grinten van der CPM. Vagal mechanisms in respiratory control. PhD thesis, State University Limburg, The Netherlands, Maastricht:Datawyse, 1991.

7. Grinten van der CPM, Vries de WR and Luijendijk SCM (1992). Vagally mediated modification of inspiratory activity by changes in airway pressure. Respir Physiol 90: 159-172.

8. Jiang TX, Deschepper $K$, Demedts $M$ and Decramer $M$ (1989). Effects of acute hyperinflation on the mechanical effectiveness of the parasternal intercostals. Am Rev Respir Dis 139: 522-528.

9. Jonzon A, Pisarri TE, Roberts AM, Coleridge JCG and Coleridge HM (1988). Attenuation of pulmonary afferent input by vagal cooling in dogs. Respir Physiol 72: 19-34.

10. Martin JG, Habib M and Engel LA (1980). Inspiratory muscle activity during induced hyperinflation. Respir Physiol 39: 303-313.

11. Martin JG, Powell E, Shore SA, Emrich J and Engel LA (1980). The role of respiratory muscles in the hyperinflation of bronchial asthma. Am Rev Respir Dis 121: 441-447.

12. Martin JG, Shore SA and Engel LA (1982). Effect of continuous positive airway pressure on respiratory mechanics and pattern of breathing in induced asthma. Am Rev Respir Dis 126: 812-817.

13. Matsumoto $S$ (1989). Effects of ammonia and histamine on lung irritant receptors in the rabbit. Respir Physiol 77: 301-308.

14. Meessen NEL, Grinten van der CPM, Folgering HTM and Luijendijk SCM (1990). Role of lung receptors in the generation of histamine-induced tonic inspiratory activity. Eur Respir J 3: 140s. (Abstract)

15. Meessen NEL, Grinten van der CPM, Folgering HTM and Luijendijk SCM (1993). Tonic activity in inspiratory muscles during continuous negative airway pressure. Respir Physiol 92: 151-166.

16. Muller N, Bryan AC and Zamel N (1980). Tonic inspiratory muscle activity as a cause of hyperinflation in histamine-induced asthma. J Appl Physiol : Respirat Environ Exercise Physiol 49: 869-874.

17. Muller N, Bryan AC and Zamel N (1981). Tonic inspiratory muscle activity as a cause of hyperinflation in asthma. J Appl Physiol : Respirat Environ Exercise Physiol 50: 279-282. 
18. Patberg WR (1983). Effect of graded vagal blockade and pulmonary volume on tonic inspiratory activity in rabbits. Pflügers Arch 398: 88-92.

19. Pisarri TE, Yu J, Coleridge HM and Coleridge JCG (1986). Background activity in pulmonary vagal C-fibers and its effects on breathing. Respir Physiol 64: 29-43.

20. Sant'Ambrogio G (1982). Information arising from the tracheobronchial tree of mammals. Physiol Rev 62: 531-569.

21. Sellick H and Widdicombe JG (1969). The activity of lung irritant receptors during pneumothorax, hyperpnoea and pulmonary vascular congestion. J Physiol (Lond) 203: 359-381.

22. Sellick $\mathrm{H}$ and Widdicombe JG (1970). Vagal deflation and inflation reflexes mediated by lung irritant receptors. Q J Exp Physiol 55: 153-163.

23. Sellick H and Widdicombe JG (1971). Stimulation of lung irritant receptors by cigarette smoke, carbon dust, and histamine aerosol. J Appl Physiol : Respirat Environ Exercise Physiol 31: 15-19.

24. Snapper JR, Drazen JM, Loring SH, Braash PS and Ingram RH,Jr. (1979). Vagal effects on histamine, carbachol, and prostaglandin F2a responsiveness in the dog. J Appl Physiol $\therefore$ Respirat Environ Exercise Physiol 47: 13-16.

25. Vidruk EH, Hahn HL, Nadel JA and Sampson SR (1977). Mechanisms by which histamine stimulates rapidly adapting receptors in dog lungs. J Appl Physiol : Respirat Environ Exercise Physiol 43: 397-402.

26. Widdicombe JG (1954). Respiratory reflexes from the trachea and bronchi of the cat. $J$ Physiol (Lond) 123: 55-70.

27. Winning $\mathrm{AJ}$ and Widdicombe JG (1976). The effect of lung reflexes on the pattern of breathing in cats. Respir Physiol 27: 253-266.

28. Woolcock AJ, Rebuck AS, Cade JF and Read J (1971). Lung volume changes in asthma measured concurrently by two methods. Am. Rev Respir Dis 104: 703-709.

29. Yu J and Roberts AM (1990). Indirect effects of histamine on pulmonary rapidly adapting receptors in cats. Respir Physiol 79: 101-110. 

Continuous negative airway pressure increases tonic activity in diaphragm and intercostal muscles in humans 


\subsection{ABSTRACT}

The main objective of the present study was to quantify the increase in tonic inspiratory activity ( $\triangle T$ TIA) in response to continuous negative airway pressure (CNAP) in man. TIA, represents the activity in inspiratory muscles at the end of expiration. In 20 subjects, electromyograms (EMGs) were recorded from the diaphragm and parasternal intercostal muscles (ICM) with surface electrodes during control and at three different levels of CNAP $(-0.3,-0.6$ and $-0.9 \mathrm{kPa})$. From these recordings we determined $\triangle T I A$ and the amplitudes of phasic EMG activities (EMGphas) during CNAP and control. To evaluate the effects of CNAP on functional residual capacity (FRC), respiratory frequency, tidal volume and minute ventilation, the subjects were connected to a closed breathing circuit. When the pressure at the airway opening was $-0.9 \mathrm{kPa}$, mean values of $\triangle$ TIA were 53 and $49 \%$ of EMGphas ctrL $_{\text {. }}$ for the diaphragm and ICM, respectively. In addition, EMGphas at airway opening pressure of $-0.9 \mathrm{kPa}$ had increased to 195 and $162 \%$ of control EMGphas for the diaphragm and ICM, respectively. The concomitant decrease in FRC was on average $18.7 \%$ of predicted FRC. Minute ventilation had increased significantly $(p<0.05)$ at all levels of CNAP compared with control. We conclude that CNAP is a forceful stimulus to increase TIA in humans in both the diaphragm and the ICM.

\subsection{INTRODUCTION}

The electrical activity observed in the electromyogram (EMG) of inspiratory muscles at the end of expiration is called tonic inspiratory activity (TIA) $)^{18,23}$. Bronchoconstriction and TIA are generally accepted as causes of hyperinflation in bronchial asthma ${ }^{10}$. In a recent study in cats we have shown that TIA is due to a vagal reflex evoked by stimulation of rapidly adapting receptors (RARs) ${ }^{20}$. Several conditions have been shown to increase the discharge of RARs. Among them are inhalation of irritant gases $^{2}$, administration of histamine ${ }^{11,21}$, and deflation of the lung ${ }^{2,26}$. These properties of RARs thus explain why TIA can be evoked by histamine both in animals ${ }^{3,19}$ and in humans ${ }^{18.23}$.

It has been shown in animals that TIA can also be induced by continuous negative airway pressure (CNAP) $)^{4.13 .24}$. In the literature, however, there is no information. concerning the magnitude of TIA in response to CNAP in humans. The aim of the present study was, therefore, to quantify the increase in TIA in the diaphragm and in parasternal intercostal muscles (ICM) in response to CNAP in human subjects. To evaluate whether responses to CNAP depend on the sensitivity of the airways, the 
results of subjects with bronchial hyperresponsiveness were compared with those of normal subjects.

\subsection{METHODS}

\subsubsection{SUBJECTS}

Twenty subjects, 9 men and 11 women, ranging in age from 14 to $72 \mathrm{yr}$, participafed in the study. To obtain a diversity in bronchial responsiveness, experiments were performed in healthy subjects and in patients with mild stable asthma. Subjects with forced expiratory volume in $1 \mathrm{~s}\left(\mathrm{FEV}_{1}\right)<1$ litre or $<50 \%$ of predicted FEV 1 were excluded from the study. A histamine challenge test showed that seven subjects were hyperresponsive (provocative concentration of histamine causing $\geq 20 \%$ fall in FEV 1 $<8.0 \mathrm{mg} / \mathrm{ml}$ ). Characteristics of the subjects are presented in Table 4.1. Informed consent was obtained from all subjects, and all but two were naive with respect to the aim of the study. The study was approved by the hospital Medical Ethics Committee.

Table 4.1 Characteristics of the subjects

\begin{tabular}{llll}
\hline & total & BHR & BHR \\
\hline$n$ & 20 & 7 & 13 \\
age [yr] & $33.4(3.0)$ & $35.3(8.0)$ & $32.3(2.0)$ \\
sex [M/F] & $9 \mathrm{M} / 11 \mathrm{~F}$ & $3 \mathrm{M} / 4 \mathrm{~F}$ & $6 \mathrm{M} / 7 \mathrm{~F}$ \\
height $[\mathrm{cm}]$ & $174.3(1.7)$ & $169.1(2.2)$ & $177.1(1.9)$ \\
weight $[\mathrm{kg}]$ & $70.2(2.7)$ & $65.0(3.0)$ & $72.9(3.6)$ \\
FRC pred [I] & $3.1(0.8)$ & $3.0(0.1)$ & $3.2(0.1)$ \\
FEV $1[1 / \mathrm{min}]$ & $3.5(0.2)$ & $2.8(0.2)^{* *}$ & $3.9(0.21)$ \\
FEV 1 [\%pred] & $95.93(3.6)$ & $85.3(7.2)$ & $101.6(2.8)$ \\
PC20 [mg/ml] & - & $0.63(0.22)$ & $>8$ \\
\hline
\end{tabular}

Values are means $\pm S E ; n$, no. of subjects. BHR ${ }^{+}$, subjects with bronchial hyperresponsiveness; $B H R$, normal subjects; $F R C_{\text {prat }}$, predicted functional residual capacity: FEVI, forced expiratory volume in 1s; PC20, provocative concentration of histamine causing a fall of $\geq 20 \%$ in FEV1 relative to control values; \%pred, as percentage of predicted value; 'Significani' difference between 2 groups by Wilcoxon-Mann-Whitney test, $p<0.01$.

\subsubsection{EXPERIMENTAL SET-UP AND MEASUREMENTS}

Subjects were connected to a closed breathing circuit (Figure 4.1) by a mouthpiece. This circuit included a wedge spirometer that was connected to the mouthpiece by a. wide tube (diam $50 \mathrm{~mm}$, length $100 \mathrm{~cm}$ ). From the electrical output of this spirometer we determined respiratory frequency (f), tidal volume (VT), minute ventilation (VE; 
$=f \cdot V T)$, and the changes in functional residual capacity $(\triangle F R C)$. Oxygen was supplied to maintain oxygen concentration in the circuit constant (21\%). Gas was sampled continuously from the circuit for the measurement of the oxygen concentration (Taylor Servomex) and subsequently fed back into the systern (Figure 4.1). A pump maintained a continuous bias flow in the circuit of $\geq 80 \mathrm{l} / \mathrm{min}$, which. prevented rebreathing of $\mathrm{CO}_{2}$. Exhaled $\mathrm{CO}_{2}$ was absorbed by soda lime. The main tube containing the mouthpiece was cooled and maintained at $\sim 18{ }^{\circ} \mathrm{C}$.

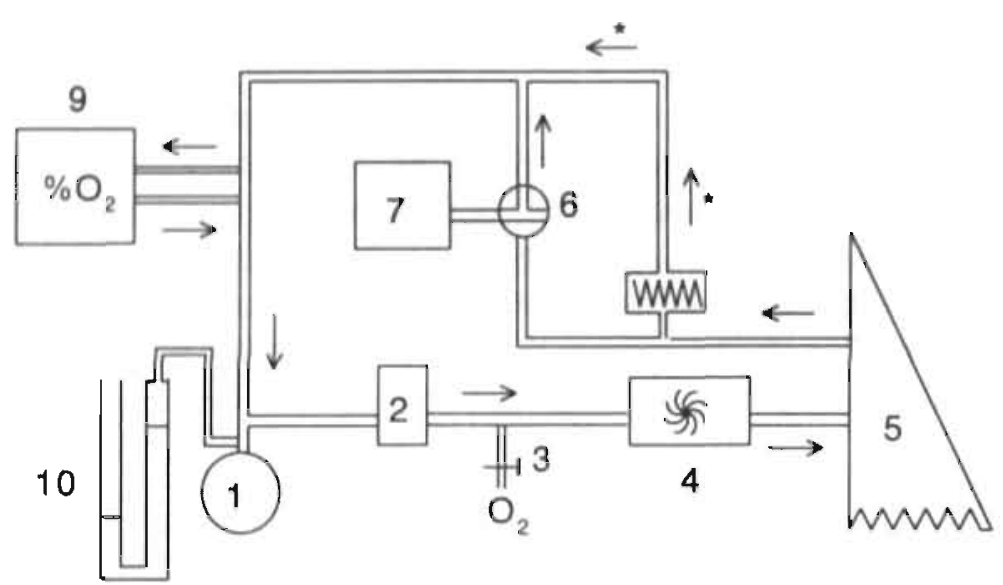

Figure 4.1 Diagram of closed breathing circuit. Preset negative pressure can be established in part containing mouth piece by tuming tap (6) to indicated position. Aifflow, shown by arrows marked with asterisks, is sucked through the resistance (8). Part of circuit containing spirometer remains at normal pressure during all experimental conditions. Dead space between the circuit and subject is $49 \mathrm{ml}$.

1, subject connected to circuit by mouthpiece; 2, container with soda lime; 3, port for supplying $\mathrm{O}_{2}: 4$, pump for bias flow (80 L/min); 5, wedge spirometer; 6, 3-way tap; 7, bottle (25 litres); 8 , adjustable resistance; $9, \mathrm{O}_{2}$ analyzer; 10 , water manometer.

The breathing circuit was adapted for the application of CNAP. Under control conditions, airflow in the circuit passed through a large three-way tap (diam $30 \mathrm{~mm}$ ). By tuming this tap, as indicated in Figure 4.1, the airflow was forced through an adjustable resistance. This resulted in a negative pressure, relative to ambient pressure, in the part of the circuit containing the mouthpiece. During the entire experiment, the wedge spirometer remained under normopressure conditions. Before the subject was connected to the circuit, the adjustable resistance was set according to the negative pressure required, which was measured near the mouthpiece by a water manometer. 
Three different pressures at the airway opening (Pao) were applied $(-0.3,-0.6$ and $-0.9 \mathrm{kPa}$ relative to ambient pressure). During CNAP a bottle ( 25 litres) filled with air was connected to the circuit and was used to minimize pressure fluctuations due to the subject's breathing.

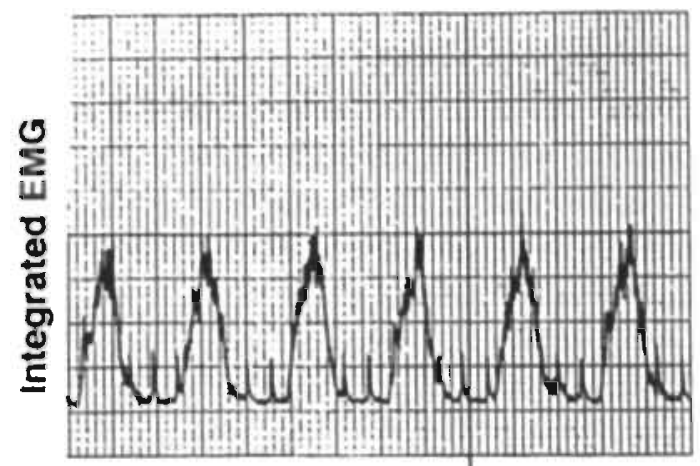

Figure 4.2

Recording of EMG of parasternal intercostal muscles during quiet breathing. Shown are integrated $E M G$, normal fittered EMG, and concomitant changes in volume. Inspiration, up; expiration, down. Integrated' EMG shows phasic activity during inspiration, which returns to baseline during expiration.

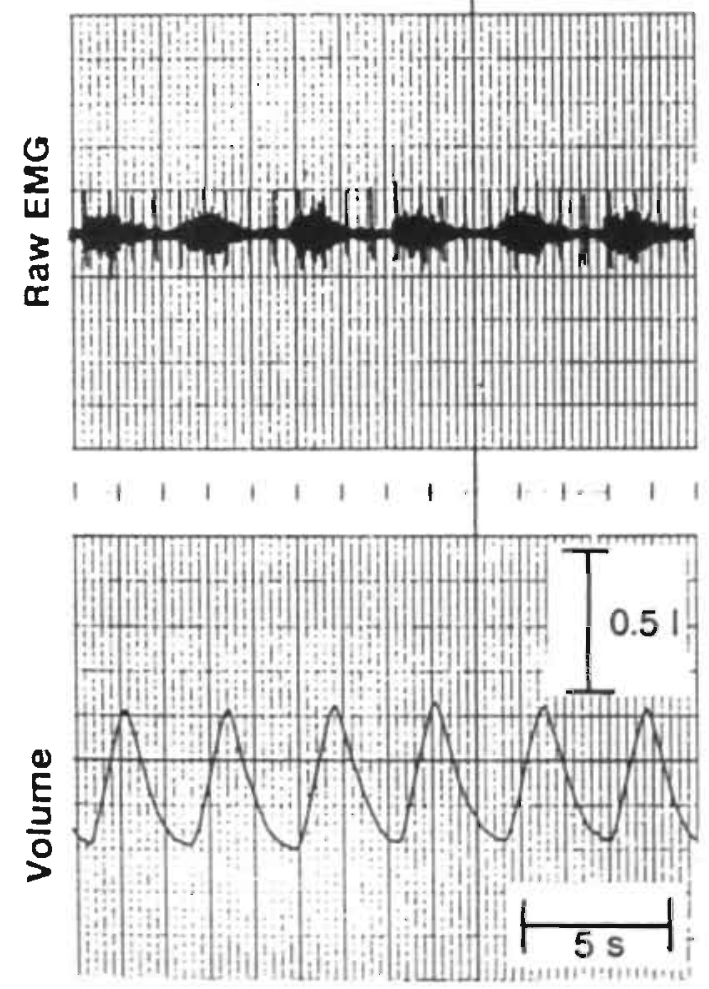


All subjects, while breathing spontaneously, were tested in the sitting position with their hands resting on their legs. To minimize the subject's attention to breathing, subjects were asked to concentrate on a poster placed in front of them.

The electrical activities of the diaphragm and ICM were obtained from two pairs of electrodes. Each pair consisted of two silver discs (diam $=7 \mathrm{~mm}$ ) which were secured to the skin at a mutual distance of $2 \mathrm{~cm}$ by means of double adhesive tape rings. Low impedance electrode conduction was improved by adding Electro-Gel (Conmed, U.S.A.) between the electrodes and the skin. For registration of the EMG of the ICM, the one pair of electrodes was placed parastemally in the left second intercostal space. To obtain the EMG of the diaphragm, the other pair of electrodes was placed between the mid-clavicular and mid-axillary line in the seventh or eighth right intercostal space. The electrical activities were amplified, filtered $(200-1,200 \mathrm{~Hz})$, rectified and fed into a leaky integrator with a. time constant of $50 \mathrm{~ms}$ (Neurolog, Digitimer). Figure 4.2 shows the EMG of ICM before and after integration. In the present work, the effects of CNAP were studied from integrated EMGs. The integrated EMGs of the diaphragm and ICM, the volume changes, and the oxygen concentration of the gas in the circuit were recorded (Kipp chart recorder, Holland) for off-line analysis.

CONTROL CNAP

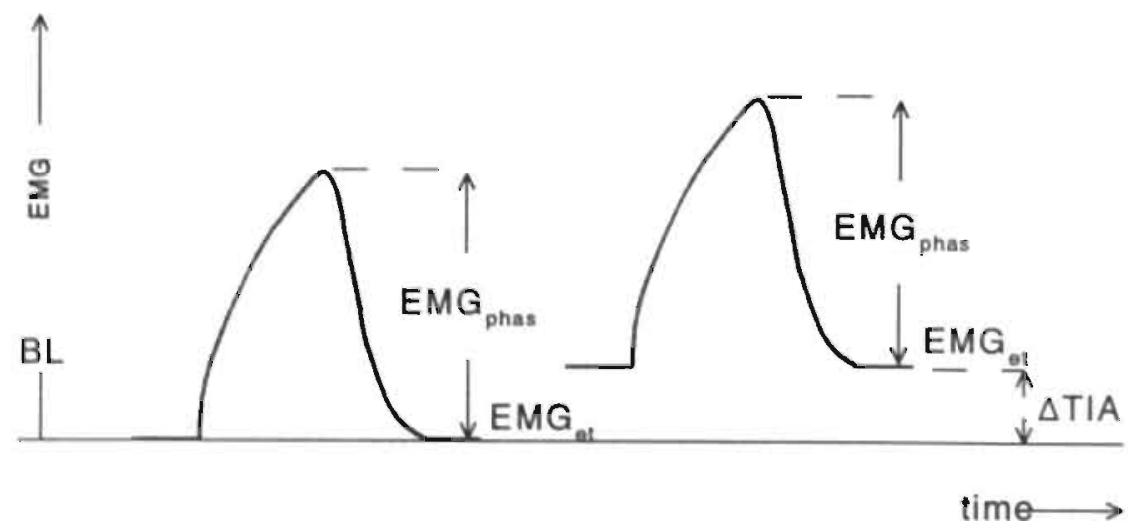

Figure 4.3 Schematic diagram of integrated EMGs from inspiratory muscles during control and continuous negative ainway pressure (CNAP). In present study, changes in tonic inspira. tory activity ( $\triangle T Z A)$ were defined as differences between end-tidal EMG (EMGa) during CNAP and control [baseline (BL)]. In our experiments, BL was close to electrical zero level. Phasic EMG (EMGphas) was defined as difference between peak activity and EMGat. 


\subsubsection{EXPERIMENTAL PROTOCOL}

After the different signals were recorded during control conditions for $\sim 30 \mathrm{~s}$, Pao was decreased in a step-like fashion to $-0.3,-0.6$ or $-0.9 \mathrm{kPa}$. Between two consecutive trials a recovery period of $\geq 3 \mathrm{~min}$ was allowed. Each registration was preceded by a deep inspiration to obtain the same starting-point for all tests with regard to the mechanical properties and volume history of the lungs. No bronchodilators were used for $\geq 8 \mathrm{~h}$ before the experiment.

\subsubsection{DATA ANALYSIS}

In our experiments end-tidal EMG activities (EMGet) during control were in general small, but not always stable in time. Therefore, mean EMGet during control just before the onset of CNAP was defined as baseline (Figure 4.3). EMGet and peak EMG activity were calculated relative to this baseline. Phasic EMG activity (EMGphas) was defined as the difference between peak EMG and EMGet activities. $\triangle T I A$ in response to CNAP was defined as the difference between EMGet during CNAP and control (baseline) (Figure 4.3), $\triangle \mathrm{TIA}$ and EMGphas were determined for 5 consecutive breaths during CNAP, starting with the 3rd breath after the onset of CNAP. Mean $\triangle$ TIA and mean EMGphas for these breaths were expressed as percentage of mean EMGphas during control (EMGphas ${ }_{n-10}$ ), which was determined from 5 control breaths of the same recording. This analysis was carried out separately for the two EMGs of the diaphragm and ICM, respectively. For the two selected groups of breaths (control and CNAP) several other parameters were calculated from the volume signal of the spirometer: f, VT, VE, $\triangle$ FRC. All values reported are means \pm SE.

Unless otherwise indicated, differences were evaluated for statistical significance by using the two-tailed Wilcoxon test for paired observations; $\mathrm{p}<0.05$ was considered to be significant.

\subsection{RFSULTS}

Figure 4.4 shows recordings of integrated EMG activity obtained from ICM before and during application of CNAP. After at least 5 control breaths had been recorded, Pao was decreased in a steplike fashion. Figure 4.4 demonstrates that EMGet increases instantaneously after the onset of CNAP. Similar results were obtained from the diaphragm. Figure 4.4 further shows that FRC decreases after application of CNAP. 


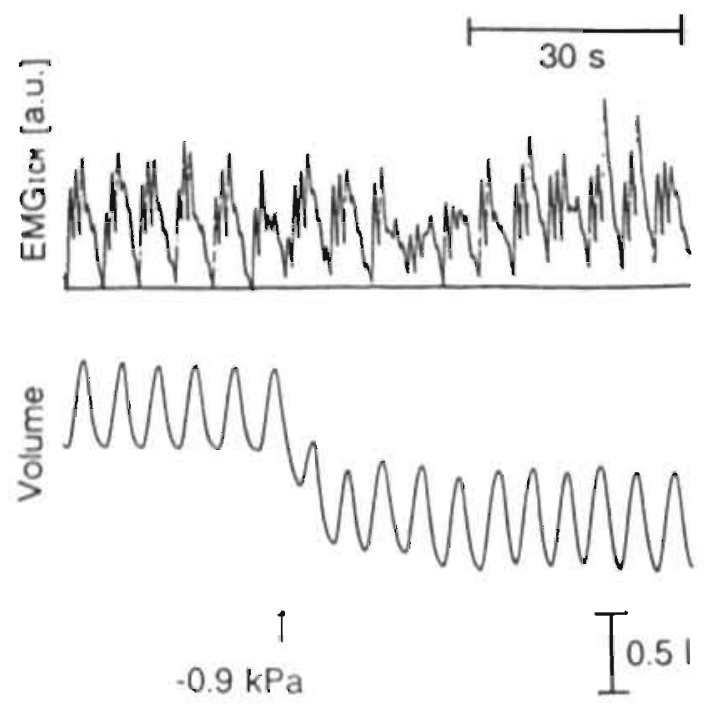

Figure 4.4 Reconding during changes in pressure at airway opening. TLA in integrated EMG of ICM (EMGICM) increased in response to CNAP $(-0.9 \mathrm{kPa})$. Functional residual capacity (FRC) decreased simultaneously. In spirogram (2nd trace), inspiration is upward. a.u., arbitrary units.

\subsubsection{EFFECTS OF DIFFERENT LEVELS OF CNAP ON $\triangle T L A$ AND ON $\triangle F R C$}

One of the 20 subjects showed no augmentation of EMGet in response to CNAP at all. In the remaining 19 subjects EMGet increased in response to CNAP. Average values of $\triangle T I A$ for the 20 subjects as a function of Pao are shown in Figure 4.5 , left panel. TIA was significantly $(p<0.001)$ increased relative to control $\left(\mathbb{P a o}_{a}=0\right)$ for all levels of CNAP. $\triangle T$ TLA at Pao of $-0.9 \mathrm{kPa}$ was significantly larger than at $\mathrm{Pao}$ of -0.6 $\mathrm{kPa}$. At Pao of $-0.9 \mathrm{kPa}$, average $\triangle \mathrm{TLA}$ was $53 \%$ and $49 \%$ of EMGphas for the diaphragm and $\mathrm{ICM}$, respectively.

During CNAP, FRC was significantly lower $(p<0.001)$ than at control. This occurred within the first 2 or 3 breaths after the drop in $\mathrm{Pao}$. At $\mathrm{Pao}$ of $-0.6 \mathrm{kPa}$ the decrease in FRC was significantly $(\mathrm{p}<0.001)$ greater than at $\mathrm{Pao}$ of $-0.3 \mathrm{kPa}$, and at Pao of $-0.9 \mathrm{kPa}$ it was significantly $(\mathrm{p}<0.001)$ greater than at $\mathrm{Pao}$ of $-0.6 \mathrm{kPa}$. At $\mathrm{Pao}$ of $-0.9 \mathrm{kPa}$, the decrease in FRC was on average $18.7 \pm 1.2 \%$ of FRC predicted (Figure 4.5, right panel). 
The relationships between the mean values of $\triangle T L A$ and the mean values of $\triangle F R C$ at control and at the three different levels of CNAP are presented in Figure 4.6 for both the diaphragm and ICM. The mean slopes obtained from linear regression applied to the two sets of four data points were $-2.80 \pm 0.50$ and $-2.77 \pm 0.53$ for the diaphragm and ICM, respectively, and both these slopes were significantly different from zero $(p<0.001)$.
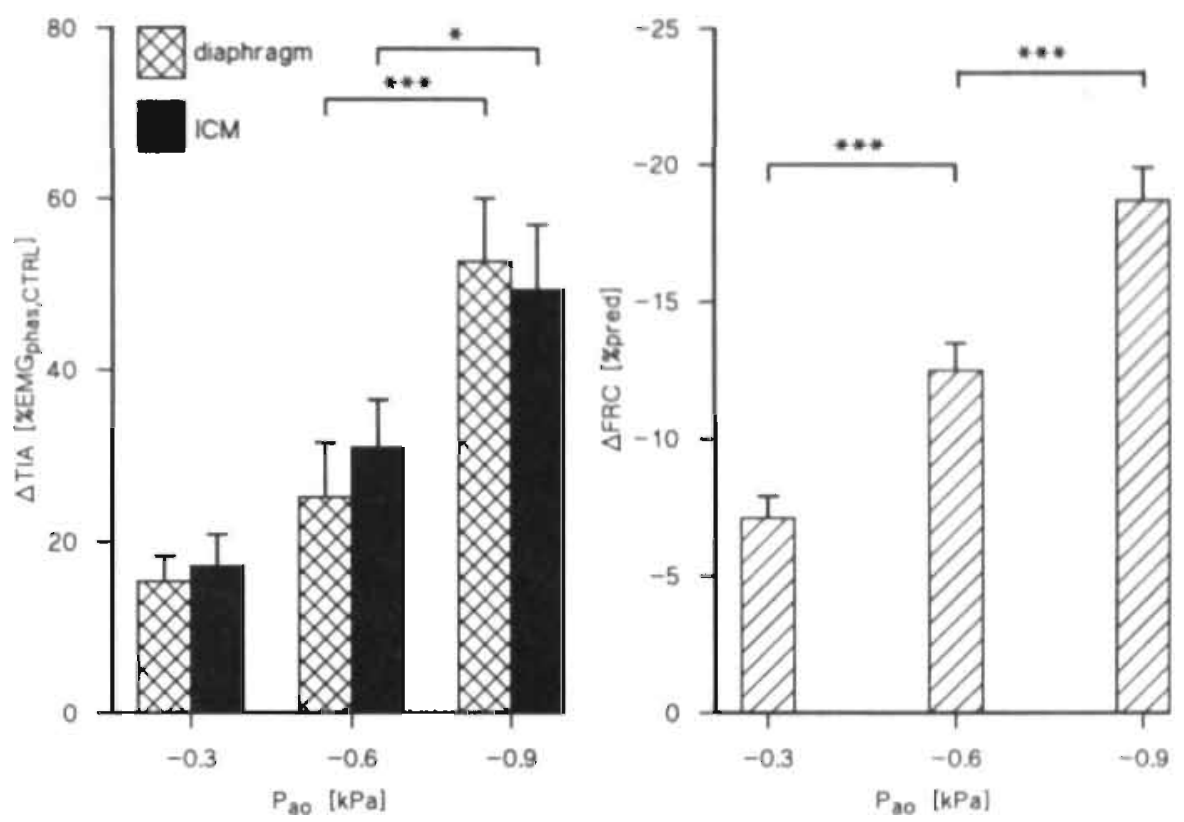

Figure 4.5 Left panel: effects of different levels of CNAP on TLA in diaphragm and JCM. $\triangle T$ II is expressed as percentage of phasic EMGphas activity of control breaths (EMGphas ${ }_{c o s}$ ). Data represent means $\pm S E$ obtained from 20 subjects. Right panel: average change in FRC ( $\triangle F R C)$, expressed as percentage of FRC predicted (\%pred), in response to different levels of CNAP. Pao, pressure at airway opening during CNAP. *, $p<0.05 ;{ }^{* * *}, p<0.001$.

No significant differences were found between subjects with bronchial hyperresponsiveness and normal subjects for $\triangle F R C$, for $\triangle T I A$ in the diaphragm in response to $\mathrm{Pao}$ of $-0.3,-0.6$ and $-0.9 \mathrm{kPa}$, and for $\triangle T I A$ in ICM in response to $\mathrm{Pao}$ of -0.3 and $-0.6 \mathrm{kPa}$. $\triangle \mathrm{TIA}$ in ICM in response to $\mathrm{Pao}$ of $-0.9 \mathrm{kPa}$, however, was significantly different between the two groups ( $p<0.05$; Mann-Whitney-U test). Mean $\triangle T I A$ values of ICM (at $\mathrm{Pao}$ of $-0.9 \mathrm{kPa}$ ) were $62.6 \pm 8.9$ and $25.0 \pm 7.7 \%$ of EMGphas $\mathrm{em}$. for normal subjects and subjects with bronchial hyperresponsiveness, respectively. 


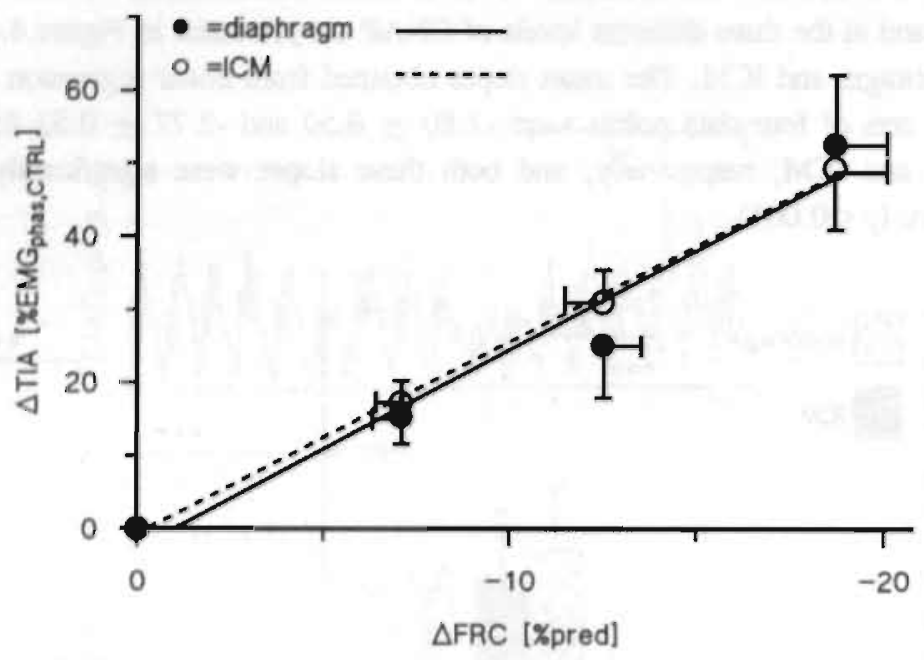

Figure 4.6 Relationship between increase in $\triangle T L A$ in diaphragm and ICM and concomitant decrease in FRC, expressed as percentage of FRC predicted, during control and 3 different levels of CNAP $(-0.3,-0.6,-0.9 \mathrm{kPa})$. Data points (means $\pm S E$ ) were obtained from 20 subjects. Regression lines through data points are shown; $r=-0.98 \quad(p<0.05)$ and -0.99 $(p<0.01)$ for diaphragm and ICM, respectively.

Table 4.2 Effects of different levels of CNAP on breathing patterm.

\begin{tabular}{lllllll}
\hline & \multicolumn{2}{c}{$f$ U/min] } & \multicolumn{2}{c}{ VT Iml] } & \multicolumn{2}{c}{$\dot{V E[t / m i n]}$} \\
[kPa] & Control & CNAP & Control & CNAP & Control & CNAP \\
\hline-0.3 & $13.8(1.0)$ & $13.8(1.0)$ & $575(37)$ & $655(48)^{*}$ & $7.42(0.33)$ & $8.37(0.51)^{*}$ \\
-0.6 & $14.4(1.0)$ & $14.8(1.1)$ & $548(43)$ & $699(57)^{\circ}$ & $7.30(0.40)$ & $9.45(0.56)^{\cdots}$ \\
-0.9 & $15.1(1.0)$ & $15.3(1.1)$ & $504(33)$ & $785(78)^{*}$ & $7.26(0.38)$ & $11.12(0.98)^{\cdots}$ \\
\hline
\end{tabular}

Values are means $\pm S E ; n=20$ subjects. CNAP, continuous negative ainway pressure; $f$, respiratory frequency; $V$, tidal-volume; $\dot{V}$, minute ventilation. Significant differences between CNAP and control from same recording by Wilcoxon test for paired observations: **: $p<0.001 ; * *, p<0.01 ; *, p<0.05$.

\subsubsection{EFFECTS OF DIFFERENT LEVELS OF CNAP ON OTHER RESPIRATORY VARIABLES}

In hyperresponsive subjects the responses of $\mathrm{f}, \mathrm{VT}$, and $\dot{\mathrm{VE}}$ to CNAP were not significantly different from those in normal subjects. In Table 4.2 the effects of CNAP on $f, V T$ and $\dot{V}_{E}$ are presented. During CNAP $f$ was not significantly different from control. VT had increased significantly at all levels of CNAP as compared to control. The significant increase in $\dot{V E}$ in response to CNAP was, therefore, mainly 
due to the increase in VT. The differences between CNAP and control in VE and VT were significantly larger at $\mathrm{Pao}$ of $-0.9 \mathrm{kPa}$ than at $\mathrm{Pao}$ of $-0.6 \mathrm{kPa}(\mathrm{p}<0.01$ and $\mathrm{p}<0.01$, respectively), and at $\mathrm{Pao}$ of $-0.6 \mathrm{kPa}$ the difference was significantly larger than at $\mathrm{Pao}$ of $-0.3 \mathrm{kPa}(\mathrm{p}<0.01$ and $\mathrm{p}<0.05$, respectively). EMGphas, expressed as percentage of EMGphas $\mathrm{Em}_{\mathrm{m}}(=100 \%)$, had increased significantly for all CNAP levels $(-0.3,-0.6,-0.9 \mathrm{kPa})$ both for the diaphragm and ICM. At Pao of $-0.9 \mathrm{kPa}$ EMGphas was on average $195 \%$ and $162 \%$ of EMGphas for the diaphragm and ICM, respectively (Figure 4.7, left panel). Plots of mean values of VT vs. mean values of EMGphas (\%EMGphas (n) $_{\text {) }}$ for the three levels of CNAP are shown in Figure 4.7, right panel. In 15 and 17 of the 20 subjects, the slopes obtained from linear regression applied to the two sets of three data points were positive for the diaphragm and ICM, respectively.
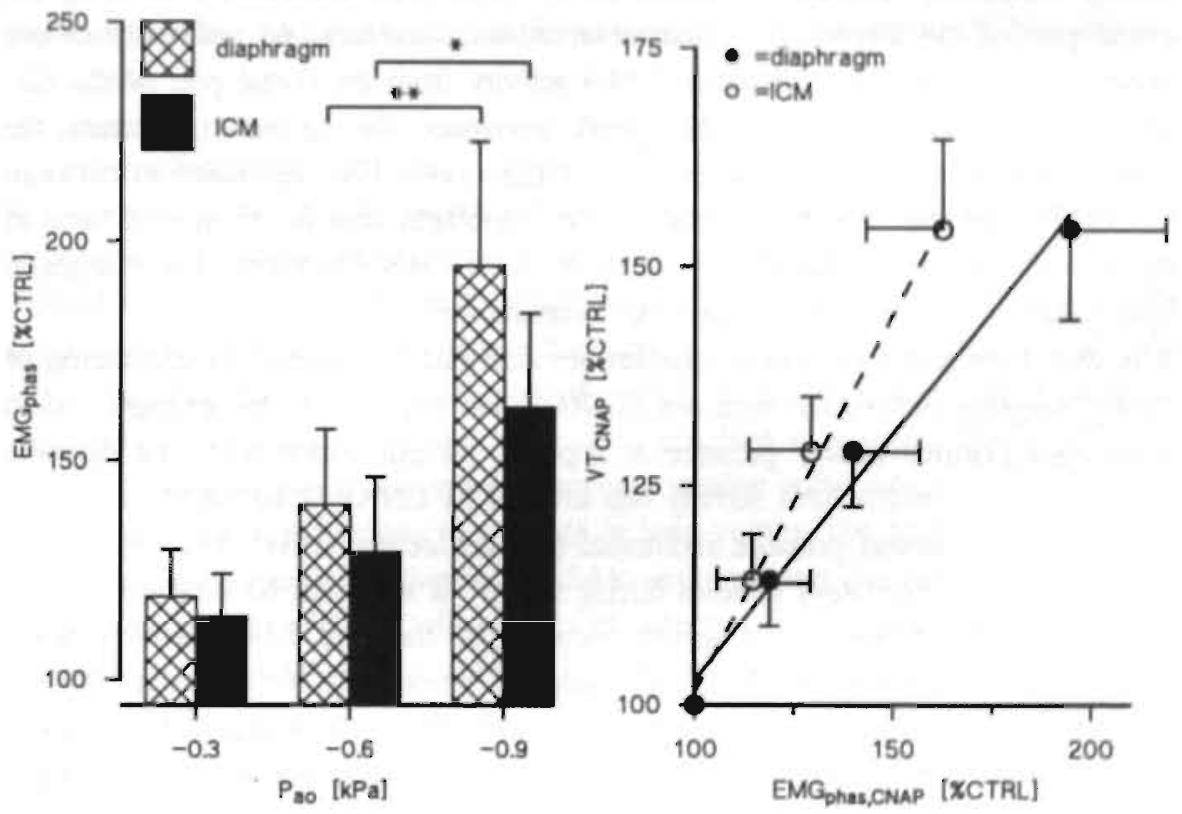

Figure 4.7 Left panel: effects of 3 different levels of CNAP $(-0.3,-0.6,-0.9 \mathrm{kPa})$ on EMGphas activity of diaphragm and ICM. Phasic activity is expressed as percentage of phasic activity of control breaths. Data are means $\pm S E$ obtained from 20 subjects. $* *, p<0.01 ; *, p<0.05$. Right panel: relationship between tidal volume $(V T)$ and EMGphas activity as percentages of control, during control and 3 different levels of CNAP. Data points (means $\pm S E$ ) were obtained from 20 subjects. Regression lines through data points are shown; $r=0.99(p<0.01)$ and $0.99(p<0.01)$ for diaphragm and ICM, respectively. 


\subsection{DISCUSSION}

\subsubsection{APPLICATION OF SURFACE ELECTRODES}

Application of surface electrodes to study the electrical activity of the diaphragm is sometimes criticized 1) for possible contamination by the activity of ICM and abdominal muscles and 2) for possible effects of variations in lung volume and posture. It has been reported that the electrical activity of the diaphragm, detected by surface electrodes, is comparable to the activity detected by oesophageal electrodes indicating that there might be only a minimal contanination from the activity of other chest muscles. ${ }^{14,25,29}$. Gandevia and McKenzie $^{12}$ have found changes in the EMG signals from the diaphragm when lung volume or posture was changed. These results mainly concerned recordings obtained from oesophageal electrodes measuring the crural part of the diaphragm. These observations, therefore, do not apply to our experiments in which we measured EMG activity from the costal part of the diaphragm by surface electrodes in the seventh interspace. During our experiments, the subjects were sitting in the same position. Furthermore, FRC decreased in response to CNAP; therefore, the close contact of the diaphragm with the chest wall (area of apposition) was maintained during CNAP. It is not likely, therefore, that changes in lung volume or posture have affected our measurements.

It is well known that expiratory muscles are activated in response to stimulation of slowly adapting pulmonary receptors (SARs) ${ }^{1}$, and this occurs, for example, when continuous positive airway pressure is applied ${ }^{5}$. In our experiments the opposite condition existed where SAR activity was lowered by CNAP. It has been shown that during negative airway pressure abdominal muscles are not active 4 . For this reason, EMG activity of expiratory muscles during CNAP, if any, will be smaller than that during control. Hence, the observed increase in end-tidal EMG activity when changing from control to CNAP can only be ascribed to enhanced activity of inspiratory muscles. Furthermore, it may be worthwhile to note that end-tidal EMG activity during control was very small. This further indicates that it is very unlikely that expiratory muscles have affected the determination of TIA in our experiments. CNAP is a typical condition which stimulates inspiratory muscles, comparable to the Breuer-Hering deflation reflex?

\subsubsection{EFFECTS OF CNAP ON TIA}

The present study with human subjects largely confirmed our earlier results obtained in cats ${ }^{20}$. Significantly increased values of $\triangle T L A$ were found both in the diaphragm and ICM in response to different levels of CNAP. In some subjects $\triangle T I A$ reached

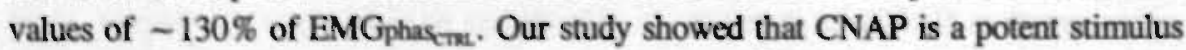
to increase TIA. In contrast to our observations in cats $^{20}$ in which TIA increased more 
in ICM than in the diaphragm, in man there was no significant difference in $\triangle T L A$ between the diaphragm and ICM. Apart from species differences, the body position in which the experiments were performed (the cats in supine position and our human subjects in sitting position) may be involved in this discrepancy.

Except for $\triangle T$ TIA in ICM at Pao of $-0.9 \mathrm{kPa}$, no differences were found between subjects with bronchial hyperresponsiveness and normal subjects. This indicates that the magnitude of CNAP-induced TIA is not determined by the responsiveness of the airways to non-specific stimuli (e.g. histamine).

It has been shown that upper airway resistance increases during CNAP with a concomitant increase in airway collapsibility ${ }^{28}$ and decreases during continuous positive airway pressure? ${ }^{27}$. Furthermore, it is known that airway resistance is increased for lung volumes below $\mathrm{FRC}^{6}$. An increased airway resistance might limit the CNAP-induced decrease in FRC, which in turn, may limit the CNAP-induced increase in TIA. It cannot be excluded that changes in airway resistance have affected EMGphas.

\subsubsection{LUNG RECEPTORS AND TIA}

Of special interest in this respect are our earlier observations in cats, in which we found that after vagal cooling to $6{ }^{\circ} \mathrm{C}$ or after vagotomy no TIA could be evoked by CNAP any more. The latter result indicates that TIA is a vagal reflex activity, and the former result indicates that $\mathrm{C}$-fibre endings are not involved in this reflex ${ }^{20}$. We also have found in cats that dis-inhibition of central inspiratory activity by a decreased activity of SARs is not a causal mechanism involved in evoking TIA ${ }^{20}$. SARs are mechanoreceptors which respond to changes in tension in the airway walls. RARs are mechanoreceptors susceptible to changes in lung volume due to inflations or deflations. Deflation reduces the input from SARs and increases that from RARs ${ }^{1}$. During CNAP the activity of SARs will be reduced, whereas that of RARs will be increased. The effects of CNAP on TIA shown in the present study are in accordance with the effects of CNAP on TIA in rabbits and cats ${ }^{2024}$. The things mentioned may, therefore, indicate that mechanical stimulation of RARs plays an important role in the genesis of TIA also in humans.

\subsubsection{HYPERINFLATION AND TIA}

It is generally accepted that hyperinflation is disadvantageous to inspiratory muscles because of a shift in their length-tension curve ${ }^{17}$. TIA is one of the causes of hyperinflation during exacerbations of asthma ${ }^{10}$. Recently it has been suggested that hyperinflation contributes importantly to acute breathlessness in asthma ${ }^{16}$. The present study indicates that mechanical stimulation of RARs may be important in increasing TIA. Another effect of stimulation of RARs is a reflexly increased activity in the efferent vagal nerve, leading to bronchial constriction ${ }^{30}$. This is one of the basic 
pathophysiologic mechanisms of bronchial asthma. This bronchoconstriction again may stimulate RARs. This suggests a positive feedback mechanism. Hyperinflation might interfere with this feedback in the following way. RAR-stimulation by chemical "physical or immunological stimuli leads to increased TIA. This in tum causes an increase in FRC with a concomitant increase in airway diameters, which subsequently reduces stimulation of RARs. In this perspective, TIA seems to be a useful reflex for counteracting the bronchoconstrictive effects of stimulation of RARs.

\subsubsection{EFFECTS OF CNAP ON BREATHING PATTERN}

Airway sensitivity to histamine appeared not to be a predicting parameter for the responses of the respiratory variables (VT, $f$ and $\dot{V} E$ ) or TIA to CNAP. Except for $\triangle T I A$ in ICM at Pao of $-0.9 \mathrm{kPa}$, no differences were found between subjects with bronchial hyperresponsiveness and normal subjects.

In cats we have shown that $V_{E}$ increased in response to CNAP, due to an increase in $\mathrm{f}^{20}$. This was attributed to stimulation of RARs. The present study demonstrates that in man $\dot{V}$ E also increases in response to CNAP. Expiratory duration (IE) appears to be highly dependent on end-expiratory volume: IE decreases when end-expiratory volume is decreased ${ }^{\text {is }}$. It has been shown that when rabbit lungs are deflated with a maintained negative airway pressure there is a large increase in $\mathrm{f}$ due to the decrease in $\mathrm{E}^{8}$. With SARs blocked, maintained lung deflation still produced decreases in $\mathrm{tE}^{9}$. Our observations in cats during vagal cooling also indicated that the decrease in $\mathrm{tE}$ was due to stimulation of $\mathrm{RARs}^{20}$.

In the present study simultaneous increases in both $\mathrm{VT}$ and $\mathrm{VE}$, were found in response to CNAP without significant adaptation of $f$. In contrast with the animal studies, $\dot{V} E$ in man thus increased because of an increase in VT, whereas $f$ did not change significantly, probably because of increases in inspiratory duration (t). If the level of end-expiratory lung volume, is decreased, less stimulation of SARs will occur during inspiration and, accordingly, the off-switch of inspiration may be delayed. This may involve an increase in $\mathrm{t}$, which will enhance EMGphas activity. The enhanced EMGphas activity will result in an increase in VT. f, however, did not change. Thus, tI may be increased whereas tE was decreased due to stimulation of RARs by CNAP. The effects of CNAP on tu and tE still need to be studied.

\subsubsection{CONCLUSIONS}

1) CNAP is a forceful stimulus to increase TIA in humans; 2) Mean values of $\triangle T$ TA in response to CNAP (Pao of $-0.9 \mathrm{kPa}$ ) were $\sim 53$ and $49 \%$ of EMGphas activity during control for the diaphragm and ICM, respectively; 3) $\dot{V}_{E}$ was increased by CNAP due to the increase in VT, whereas $f$ remained constant. 


\subsection{REFERENCES}

1. Adrian ED (1933). Afferent impulses in the vagus and their effect on respiration. I Physiol (Lond) 79: 332-358.

2. Armstrong DJ and Luck JC (1974). A comparative study of irritant and type J receptors in the cat. Respir Physiol 21: 47-60.

3. Badier M, Jammes Y, Romero-Colomer P and Lemerre C (1989). Tonic activity in inspiratory muscles and phrenic motoneurons by stimulation of vagal afferents. J Appl Physiol 66: 1613-1619.

4. Bishop. B (1963). A.bdominal muscle and diaphragm activities and cavity pressures in pressure breathing. J Appl Physiol 18: 37-42.

5. Bishop B (1967). Diaphragm and abdominal muscle responses to elevated airway pressures in the cat. J Appl Physiol 22: 959-965.

6. Bouhuys A. Pressure-flow relations. In: The physiology of breathing, edited by Bouhuys A. New York: Grune and Stratton, 1977, p. 173-201.

7. Coleridge HM and Coleridge JCG. Reflexes evoked from tracheobronchial tree and tungs. In: Handbook of Physiology, The Respiratory System, Control of Breathing, Vol. II, edited by Cherniack NS and Widdicombe JG. Bethesda, MD: American Physiological Society " 1986 " p. 395-429.

8. Davies A, Dixon M, Callanan D, Huszczuk A, Widdicombe IG and Wise JCM (1978). Lung reflexes in rabbits during pulmonary stretch receptor block by sulphur dioxide. Respir Physiol 34: 83-101.

9. Davies $\mathbf{A}$ and Roumy $\mathrm{M}$ (1986). A role of pulmonary rapidly adapting receptors in control of breathing. Aust J Exp Biol Med Sci 64: 67-78.

10. Demedts $\mathbf{M}$ (1990). Mechañisms and consequences of hyperinflation. Eur Respir $\mathbf{J} 3$ : 617-618.

11. Dixon M, Jackson DM and Richards IM (1979). The effects of histamine, acetylcholine and 5-hydroxytryptamine on lung mechanics and irritant receptors in the dog. J Physiol (Lond) 287: 393-403.

12. Gandevia SC and McKenzie DK (1986). Human diaphragmatic EMG: changes with lung volume and posture during supramaximal phrenic stimulation. J Appl Fhysiol 60: 1420-1428.

13. Grinten van der CPM. Vries de WR and Luijendijk SCM (1992). Vagally mediated modification of inspiratory activity by changes in airway pressure. Respir Physiol 90 : 159-172.

14. Gross D, Grassino A, Ross WRD and Macklem PT (1979). Electromyogram pattern of diaphragmatic fatigue. J Appl Physiol : Respirat Environ Exercise Physiol 46: 1-7.

15. Cirunstein MM, Wyszogrodski I and. Milic-Emili $\mathbf{J}$ (1975). Regulation of frequency and depth of breathing during expiratory threshold loading in cats. J Appl Physiol 38: 869-874.

16. Lougheed MD, Lam M, Forkert L, Webb A and O'Donnell DE (1993). Breathlessness during acute bronchoconstriction in asthma: pathophysiologic mechanisms. Am Rev Respir Dis 148: 1452-1459.

17. Macklem PT (1984). Hyperinflation. Am Rev Respir Dis 129: 1-2.

18. Martin JG, Habib M and Engel LA (1980). Inspiratory muscle activity during induced hyperinflation. Respir Physiol 39: 303-313. 
19. Meessen NEL, Grinten van der CPM, Folgering HTMI and Luijendijk SCM (1990). Role of lung receptors in the generation of histamine-induced tonic inspiratory activity. Eur Respir J 3: 140s.(Abstract)

20. Meessen NEL, Grinten van der CPM, Folgering HTM and Luijendijk SCM (1993). Tonic activity in inspiratory muscles during continuous negative airway pressure. Respir Physiol 92: 151-166.

21. Mills JE, Sellick H and Widdicombe JG (1969). Activity of lung irritant receptors in pulmonary microembolism, anaphylaxis and drug-induced bronchoconstrictions. J Physiol (Lond) 203: 337-357.

22. Mills JE, Sellick $H$ and Widdicombe JG (1969). Vagai deflation reflexes mediated by lung irritant receptors. I Physiol (Lond) 204: 137p.

23. Muller N, Bryan AC and Zamel N (1980). Tonic inspiratory muscle activity as a cause of hyperinflation in histarnine-induced asthma. J Appl Physiol : Respirat Environ Exercise Physiol 49: 869-874.

24. Patberg WR (1983). Effect of graded vagal blockade and pulmonary volume on tonic inspiratory activity in rabbits. Pflügers Arch 398: 88-92.

25. Scano G, Duranti R, Spinelli A, Gorini M, Lo Conte C andi Gigliottie F (1987). Control of breathing in normal subjects and in patients with chronic airflow obstruction. Bull Eur Physiopathol Respir 23: 209-216.

26. Sellick $\mathbf{H}$ and Widdicombe JG (1970). Vagal deflation and inflation reflexes mediated by lung irritant receptors. Q J Exp Physiol 55: 153-163.

27. Series F, Cormier $\mathrm{Y}$, Couture J and Desineules $\mathbf{M}$ (1990). Changes in upper airway resistance with lung inflation and positive airway pressure. J Appl Physiol 68: 1075-1079.

28. Series F and Marc I (1993). Effects of continuous negative airway pressure-related lung deflation on upper airway collapsibility. J Appl Physiol 75: 1222-1225.

29. Sieck GC, Mazar A and Belman MJ (1985). Changes in diaphragnnatic EMG spectra during hyperpneic loads. Respir Physiol 61: 137-152.

30. Widdicombe JG. Nervous receptors in the respiratory tract and lungs. In: Lung Biology in Health and Disease, Regulation of breathing, Vol. 17, pant 1 , edited by Hornbein T. New York: Dekker, 1981, p. 429-472. 


\section{Histamine-induced bronchoconstriction and end-tidal inspiratory activity in man}

Submitted for publication as: Histamine-induced bronchoconstriction and end-tidal inspiratory activity in man. N.E.L. Meessen, C.P.M. van der Grinten, S.C.M. Luijendijk, H.Th.M. Folgering. 


\subsection{ABSTRACT}

End-tidal inspiratory activity (ETIA) in diaphragm and parasternal intercostal muscles can be evoked in man and in animals by administration of histamine. Exacerbations of asthma and administration of histamine are often accompanied with hyperinflation. The aims of the study were to determine 1) the magnitude of ETIA in response to histamine in man, 2) the relative contributions of chemical and mechanical stimulation of airway receptors to ETIA, and 3) the importance of ETIA to hyperinflation.

The effects of inhalation of histarnine on the electrical activities of the diaphragm and parasternal intercostal muscles (ICM) measured with surface electrodes were studied in 21 subjects. The experiments were repeated after inhalation of $600 \mu \mathrm{g}$ of salbutamol to prevent histamine-induced bronchoconstriction and concomitant mechanical stimulation of airway receptors. Subjects were connected to a closed breathing circuit to measure the changes in functional residual capacity (FRC) for the different experiments.

Mean values of histamine-induced ETIA were 60.6 and $46.9 \%$ of peak inspiratory activities during control conditions for the diaphragm and ICM, respectively. After salbutamol histamine-induced ETIA was reduced to about one fourth of pre-salbutamol values. FRC increased by $427 \mathrm{ml}$ as a result of inhalation of histamine. After salbutamol this increase was only $53 \mathrm{ml}$. The data for ETLA and FRC were interpreted to indicate that the contributions of airflow limitation and ETIA to histamineinduced hyperinflation are comparable.

Histamine is a forceful stimulus to induce ETIA. Both chemical and mechanical stimulation of airway receptors contribute to evoke ETLA, where the contribution of mechanical stimulation is the more important one. ETIA contributes substantially to histamine-induced hyperinflation.

\subsection{INTRODUCTION}

EMG activity of inspiratory muscles at the end of expiration has been observed in response to administration of histamine both in animals $\mathrm{s}^{3,20}$ and $\operatorname{man}^{16,23}$. We have shown in cats that this so called end-tidal inspiratory activity (ETIA) is a vagal reflex activity which is due to stimulation of rapidly adapting pulmonary receptors (RARs) ${ }^{19,20}$. RARs can be stimulated by histamine in cats ${ }^{2}, \operatorname{dogs}^{32}$ and rabbits ${ }^{22}$. It is not known whether RARs are stimulated by histamine via direct chemical effects or via indirect mechanical effects due to bronchoconstriction or by a combination of both $^{11,12,18,22,29,3}$,

Exacerbations of asthma and administration of histamine are often accompanied with 
hyperinflation ${ }^{173334}$. Although both bronchoconstriction and ETLA are accepted as causes of hyperinflation in bronchial asthma ${ }^{10}$, it has not been demonstrated yet which is more important. Hence, the aims of the present study were to determine 1) the magnitude of ETIA in response to histamine in man, 2) the relative contributions of chemical and mechanical stimulation of airway receptors to ETIA, and 3) the importance of ETIA to hyperinflation. To this end, experiments were performed on human subjects, who were challenged with histamine both before and after administration of the $\mathrm{B}_{2}$-agonist salbutamol. Salbutamol provides protection against bronchoconstriction caused by different stimuli such as histamine ${ }^{8.25}$, therefore, in the latter experiment histamine-induced bronchoconstriction was largely prevented.

Table 5.1 Characteristics of the subjects.

\begin{tabular}{ll}
\hline subjects (n) & 21 \\
mean age (yr) & $32.5(2.5)$ \\
sex (M/F) & $9 / 12$ \\
height (cm) & $174.9(1.5)$ \\
weight (kg) & $71.7(2.6)$ \\
FEV, (I) & $3.6(0.19)$ \\
FEV, (\% pred) & $94.7(3.2)$ \\
FEV,/FVC (\%) & $78.9(1.9)$ \\
FRCprod (I) & $3.1(0.08)$ \\
Rrs (hPa. & $3.5(0.36)$ \\
\hline
\end{tabular}

Data are means $\pm S E$. FEV , forced expiratory volume in $1 s ; \%$ pred, a percentage of predicted value; $F V C$, forced expiratony vital capacity; $R s_{6}$, aimway resistance determined at 6 $\mathrm{Hz}$ by forced oscillation technique (FOT).

\subsection{METHODS}

\subsubsection{SUBECTS}

Twenty-one subjects, 9 men and 12 women, in age in age from $14.62 \mathrm{yr}$, participated in this study. To obtain a diversity in bronchial responsiveness, experiments were performed in healthy subjects and in patients with mild stable asthma. Characteristics of the subjects are presented in table 5.1. Informed consent was obtained from all subjects, who were naive with respect to the aims of the study. The study was approved by the hospital Medical Ethics Committee.

\subsubsection{EXPERIMENTAL SET-UP}

Subjects were connected to a closed breathing circuit (Figure. 5.1) through a mouthpiece. Oxygen was supplied to maintain oxygen concentration in the circuit constant $(21 \%)$. Gas was sampled continuously from the circuit for the measurement of the oxygen concentration (Taylor Servomex) and subsequently fed back into the system 
(Figure 5.1). A pump maintained a constant bias flow in the circuit of at least 120 $1 /$ min which prevented rebreathing of $\mathrm{CO}_{2}$. Exhaled $\mathrm{CO}_{2}$ was absorbed by sodal lime. An aerosol of saline or histamine could be delivered by a jet-nebulizer (DeVilbiss 646) which was connected to the circuit near the mouthpiece (Figure 5.1). The calibrated output of the nebulizer was $0.13 \mathrm{ml} / \mathrm{min}$.

The electrical activities of the diaphragm and ICM were obtained from 2 pairs of electrodes. Each pair consisted of 2 silver discs $(\phi=7 \mathrm{~mm})$ which were glued to the skin, $2 \mathrm{~cm}$ apart. The electromyogram (EMG) of ICM was obtained from electrodes placed parasternally in the left second intercostal space. EMG of the diaphragm was obtained from another pair of electrodes placed between the mid-clavicular and midaxillary line in the seventh or eighth right intercostal space. The raw EMG activities were amplified, filtered $(200-1200 \mathrm{~Hz})$, rectified and fed into a leaky integrator with a time constant of $50 \mathrm{~ms}$ (Neurolog, Digitimer). The integrated activities of the diaphragm and ICM, the volume signal of the wedge spirometer and oxygen concentration of the gas in the breathing circuit were recorded with a multi-channel $\mathrm{X}-\mathrm{t}$ recorder (Kipp, The Netherlands). The responses of the diaphragm, ICM and FRC to inhalation of histamine were studiex from these recordings. EMG activities were also monitored by an audio monitor.

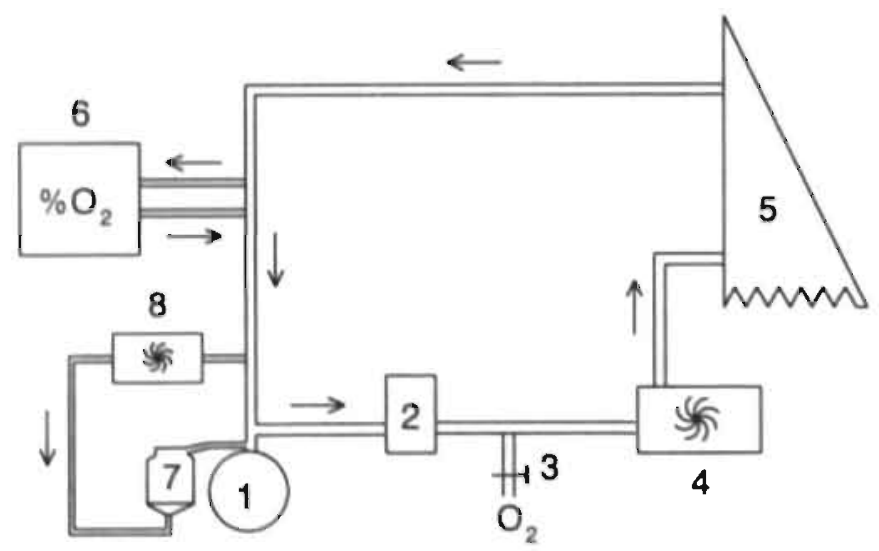

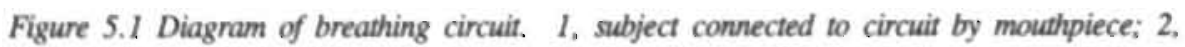
soda lime; 3, port for supplying $\mathrm{O}_{2} ; 4$, pump for bias flow; 5, wedge spirometer; 6, $\mathrm{O}_{2}$ analyzer; 7, nebulizer; 8, pump generating flow for aerosol. The equipment dead space of circuit was $49 \mathrm{ml}$. 
All subjects were tested in the sitting position. After the subjects were seated in a relaxed posture they were asked to remain seated that way till the end of the recording. Thus, in good cooperation with our subjects we were able to minimize the impact of postural muscles on recorded EMG activities. To divert their attention to breathing, they were asked to concentrate on a poster placed in front of them.

\subsubsection{EXPERIMENTAL PROTOCOL}

The provocative concentration of histamine $\left(\mathrm{PC}_{20}\right)$ at which forced expiratory volume in $1 \mathrm{~s}\left(\mathrm{FEV}_{1}\right)$ dropped by $20 \%$ to $80 \%$ of pre-challenge $\mathrm{FEV}_{1}$ (=control $\mathrm{FEV}_{1}$ ) was determined on day 1 . with a concise histamine challenge test according to Hargreave et al. ${ }^{14}$. On day 2 the effects of inhalation of one single concentration of histamine on EMGs of the diaphragm and ICM and on FRC were studied. This concentration was the one at which on day $1 \mathrm{FEV}_{1}$, had fallen below $80 \%$ of control or, in case of a non hyperresponsive subject, the highest concentration used on day $1(\geq 8 \mathrm{mg} / \mathrm{ml})$. After the subject had been connected to the breathing circuit the recording was started. The recording included at least 5 stable control breaths and further covered the period of 2 min of inhalation of histamine and $1.5 \mathrm{~min}$ thereafter. Subsequently $600 \mu \mathrm{g}$ of salbutamol (Ventolin ${ }^{*}$ ) was administered by a standard metered dose inhaler. Fifieen min later the single dose histamine test was repeated. In order to evaluate effects of histamine and salbutamol on airway mechanics, respiratory resistance $\left(R_{r s}\right)$ and FEV, were determined during four conditions: before histamine (control), after inhalation of histamine (histamine), $15 \mathrm{~min}$ after inhalation of salbutamol (control $\mathrm{sab}_{\mathrm{ab}}$ ) and after subsequent inhalation of histamine (histamine ${ }_{\text {mab }}$ ).

\subsubsection{PULMONARY FUNCTION MEASUREMENTS}

Changes in FRC ( $\triangle F R C)$ in response to histamine were calculated from the spirogram. Forced vital capacity (FVC) and FEV, were obtained by standard spirometry (Fukuda Sangyo). All values were related to the reference values of the European Community for Coal and Steel ${ }^{26}$.

Rrs was determined by means of the forced oscillation technique (FOT) described in detail elsewhere ${ }^{15}$. It has been reported that $\operatorname{Rrs}$ measured at low frequencies correlates well with airway resistance (Raw) ${ }^{7}$. In the present study the resistance at $6 \mathrm{~Hz}$ was used $\left(\operatorname{Rrs}_{6}\right)$.

\subsubsection{DATA. ANALYSIS}

Mean values of end-tidal EMG activity and of peak EMG activity were calculated from 5 consecutive breaths recorded about $60 \mathrm{~s}$ after the inhalation of histamine had been stopped. These mean values will be referred to as EMGetwas and EMGpkwar, respectively. In a similar way we determined $\mathrm{EMGpk}_{\mathrm{c} n \mathrm{~s}}$, from the recordings of 5 consecutive control breaths of the same experiment taken from the last part of the 
control period. ETIA is represented by $\mathrm{EMG}_{e \mathrm{e}}$. In order to minimize the effeets of instrumental, inter-subject and intra-subject scatter in the measured EMG activity ETIA was expressed as a percentage of EMGpk $\mathrm{E}_{\mathrm{Cr} \text {. }}$, and for the same reason $\mathrm{EMGpk}_{\text {nos }}$ was also expressed as a percentage of EMGpk $\mathrm{K}_{\mathrm{CTRL}}$.

$\triangle F R C$ was determined from the difference in FRC between the same groups of breaths, 5 control breaths and 5 breaths $60 \mathrm{~s}$ after the inhalation of histamine had been stopped. A mismatch between $\mathrm{O}_{2}$-supply and $\mathrm{O}_{2}$-uptake will cause the baseline of the spirometer signal to drift one way or the other, which would affect the results for $\triangle F R C$. The shift in the baseline of the spirometer signal $(\Delta \mathrm{V})$ is proportional to the deviation of the $\mathrm{O}_{2}$-concentration $\left(\Delta \mathrm{C}_{\mathrm{O} 2}\right)$ from $21 \%$. The relationship between $\Delta \mathrm{V}$ and $\Delta \mathrm{C}_{\mathrm{O}_{2}}$ was determined experimentally by adding a known amount of pure oxygen to the system and by reading, the corresponding change in $\mathrm{C}_{\mathrm{O}_{2}}$. With the help of this relationship we have corrected the raw data for $\triangle \mathrm{FRC}$ for the aforementioned $\mathrm{C}_{\mathrm{O}_{2}}$ related shift of the spirometer signal. The inaccuracy of the correction was $\pm 6 \mathrm{ml}$. This error adds to the overall, random error in the determination of $\triangle F R C$.

All values reported are means \pm standard error (SEM). Unless otherwise indicated differences were evaluated for statistical significance using the Wilcoxon test for paired observations. $p<0.05$ was considered to be significant. Statistical analysis was performed using the statistical software package SPSS/PC+ (SPSS Inc., Chicago. Illinois).

\subsection{RESULTS}

\subsubsection{EFFECTS OF HISTAMINE ON EMG AND ON FRC}

Figure 5.2 shows for one subject recordings of integrated electrical activities of the diaphragm and ICM and of the corresponding changes in lung volume. The recordings show that before inhalation of salbutamol ETIA is evoked in the diaphragm and in ICM in response to histamine as end-tidal EMGs do not return to base-line levels (left panel). At the same time FRC is increased. After administration of salbutamol inhalation of histamine evokes hardly any ETIA and FRC does not change at all in this subject (right panel).

Before inhalation of salbutamol mean values (SEM) of histamine-induced ETIA, obtained from 21 subjects, were $60.6(8.5 \%)$ and $46.9(7.0 \%)$ of $\mathrm{EMG}_{\mathrm{pk}}$. for the diaphragm and ICM, respectively (Figure 5.3). The mean increase in FRC ( $\triangle F R C$ ). was $427(67) \mathrm{ml}$ or $13.7(2.1 \%)$ of FRC predicted (Table 5.2, Figure 5.4). In response to histamine, peak inspiratory EMG activity increased to $375(46) \%$ and 364 (49)\% of EMGpk cre for the diaphragm and ICM, respectively (Figure 5.5).

After inhalation of salbutamol histamine-induced ETIA was $16.6(4.1 \%)$ and 10.9 
$(2.7 \%)$ for the diaphragm and ICM, respectively (Figure 5.3). Histamine-induced ETIA was significantly lower after inhalation of salbutamol as compared to presalbutamol values $(\mathrm{p}<0.01$ and $\mathrm{p}<0.001$ for the diaphragm and $\mathrm{ICM}$, respectively). After salbutamol FRC was only slightly though significantly $(p<0.001)$ elevated in response to histamine. The mean increase in FRC was $53(16) \mathrm{ml}$ or $1.7(0.5 \%)$ of FRC predicted (Table 5.2, Figure 5.4). After salbutamol peak inspiratory EMG activity did not change significantly in response to histamine, $109(10 \%)$ and 110 $(11 \%)$ of $\mathrm{EMG}_{\mathrm{CT}}$ of the same recording for the diaphragm and ICM, respectively (Figure 5.5).
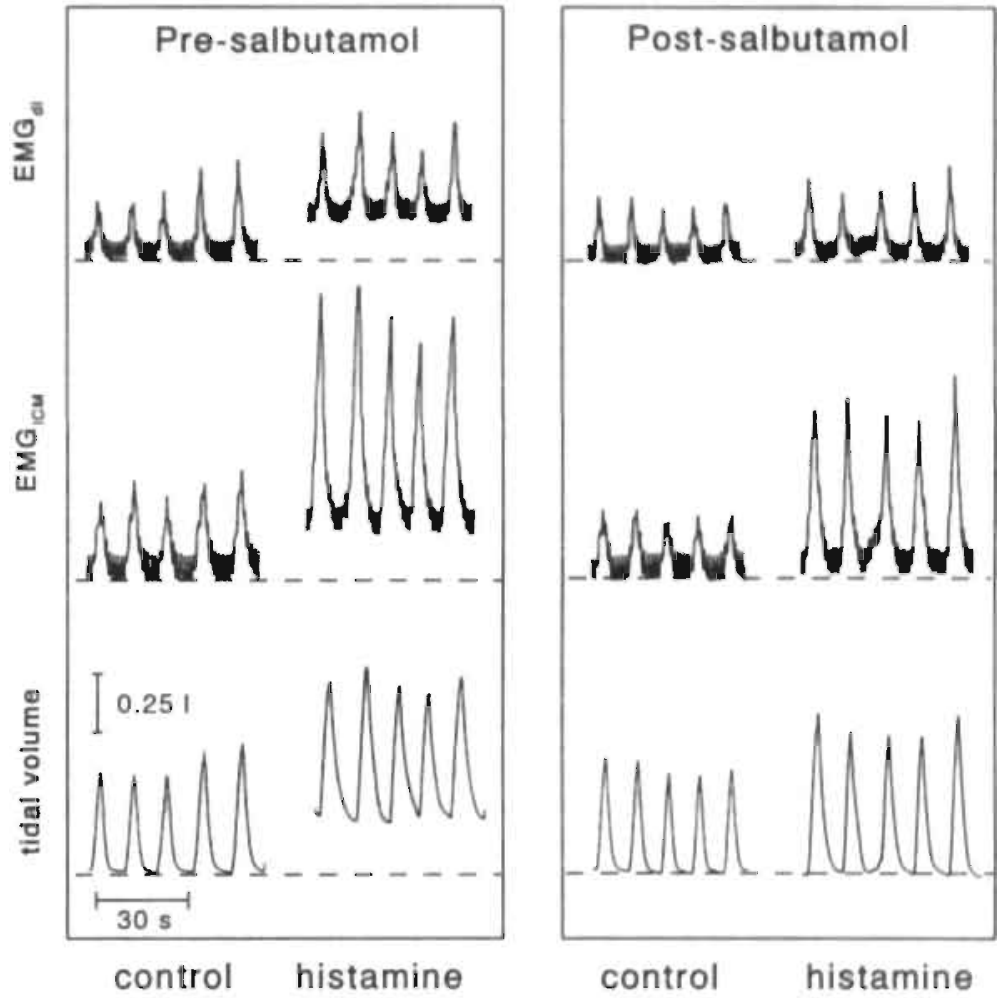

Figure 5.2 Representative recordings of integrated electromyograms of diaphragm (EMGdi) and of parastemal intercostal muscles (EMGICM) and of corresponding changes in spirometer volume (inspiration up "expiration down) in response to histamine. A histamine concentration was applied which produced a fall in FEV of more than 20\%. Left panel shows breaths during control and after inhalation of histamine. End-tidal inspiratory activity is induced in EMGDI and EMGICM in response to histamine and FRC is increased. After inhalation of $600 \mu \mathrm{g}$ salbutamol experiment was repeated' with same histamine concentration (right panel). End-tidal levels of both EMGs are hardly elevated in response to histamine, and in this example FRC does not change at all in response to histamine. 

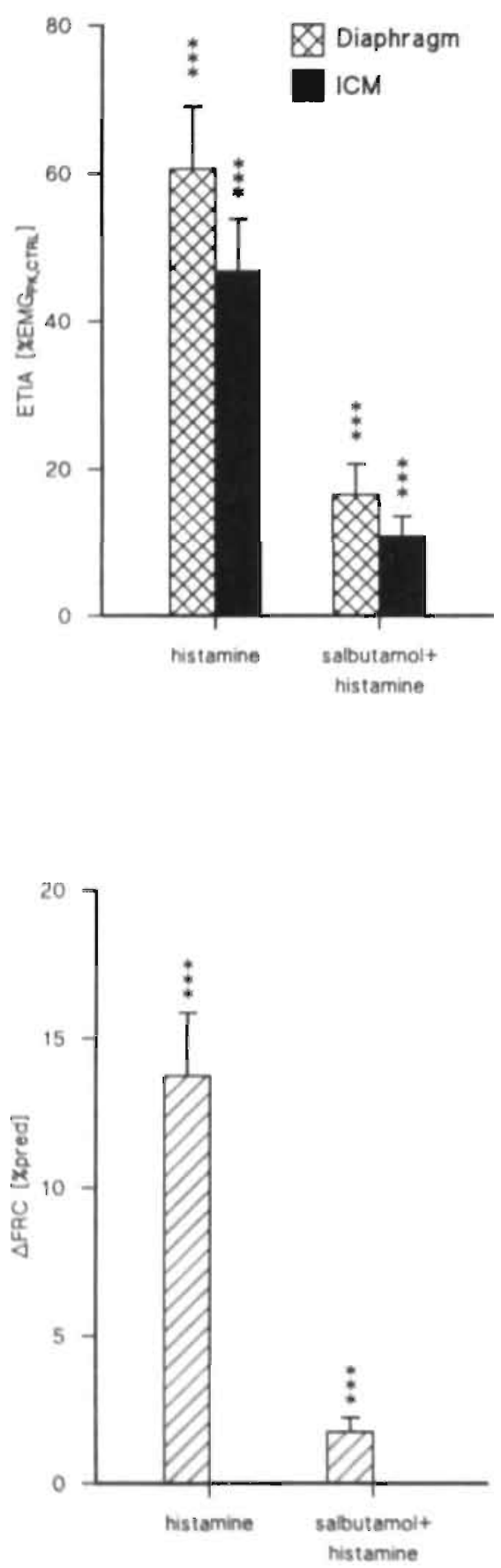

Figure 5.3 Effects of inhalation of histamine on end-tidal inspiratory activity (ETLA) in diaphragm and intercostal. muscles (ICM). ETTA is expressed as a percentage of mean peak EMG activity of corresponding control breaths. After inhalation of $600 \mu \mathrm{g}$ salbutamol histamineinduced ETMA had decreased significantly $(p<0.01$ and $p<0.001$ for diaphragm and ICM, respectively) as compared with values before salbutamol. Data represent mean values $\pm S E$ obtained from $2 I$ subjects. Asterisks indicate significant differences compared with control (***, p$<0.001$; Wilcoxon test for paired observations).

Figure 5.4 Effects of histamine on FRC before and after inhalation of $600 \mu \mathrm{g}$ salbutamol. Changes in FRC are presented as a percentage of $F R C$ predicted. Data represent means $\pm S E$ obtained from 21 subjects. Asterisks indicate significant differences compared with values before salbutamol (****, $p<0.001$; Wilcaxon test for paired observations). 


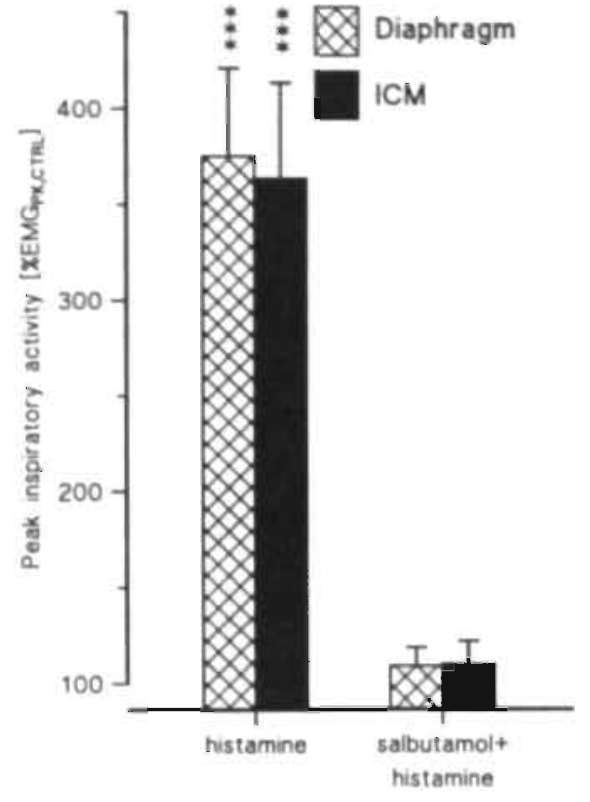

Figure 5.5 Effects of inhalation of histamine on peak inspiratory EMG activity in diaphragm and intercostal muscles (ICM). Peak EMG activity is expressed as a percentage of mean peak inspiratory EMG activity of correspon-ding control breaths. After inhalation of $600 \mu \mathrm{g}$ salbutamol effects of histamine on peak inspiratory EMG activities are abolished. Data represent means $\pm S E$ obtained from 21 subjects. Asterisks indicate significant differences compared with control (***, $p<0.001$; Wilcaxon test for paired observations).

\subsubsection{EFFECTS OF HISTAMINE AND SALBUTAMOL ON Rrs, AND FEV,}

Changes in airway diameter will influence $\mathrm{Rr}_{6}$ and $\mathrm{FEV}_{1}$. Effects of histamine on $\mathrm{Rrs}_{6}$ and $\mathrm{FEV}_{1}$ obtained from 21 subjects before and after inhalation of salbutamol are shown in Table 5.2 and Figure 5.6. $\mathrm{Rrs}_{6}$ increased significantly $(p<0.001)$ in response to histamine as compared to control. After salbutamol only a small increase in $\mathrm{Rrs}_{6}$ was found in response to histamine as compared to post salbutamol control values (Figure 5.6). FEV decreased significantly as compared to control $(\mathrm{p}<0.001)$ in response to histamine (Table 5.2, Figure 5.6). After salbutamol a small but still significant $(p<0.01)$ fraction of that response remained (Table 5.2, Figure 5.6).

For the sake of the further interpretation of the results a subgroup was defined including only those subjects whose $\mathrm{FEV}_{1}$ decreased by less than 2 percent in response to histamine after salbutamol. The mean values of ETIA, $\triangle F R C$ and FEV, for this subgroup are presented in Table 5.3.

\subsection{DISCUSSION}

Inhalation of histamine evoked ETIA in the diaphragm and ICM in all of our subjects. After administration of salbutamo! the magnitude of histamine-induced ETIA was considerably diminished. Similarly, FRC increased significantly in response to histamine, while this increase was minimal after salbutamol. FEV, 
decreased and $\mathrm{Rrs}_{6}$ increased in response to histamine. After salbutamol, inhalation of histamine only slightly affected these indices of bronchoconstriction.

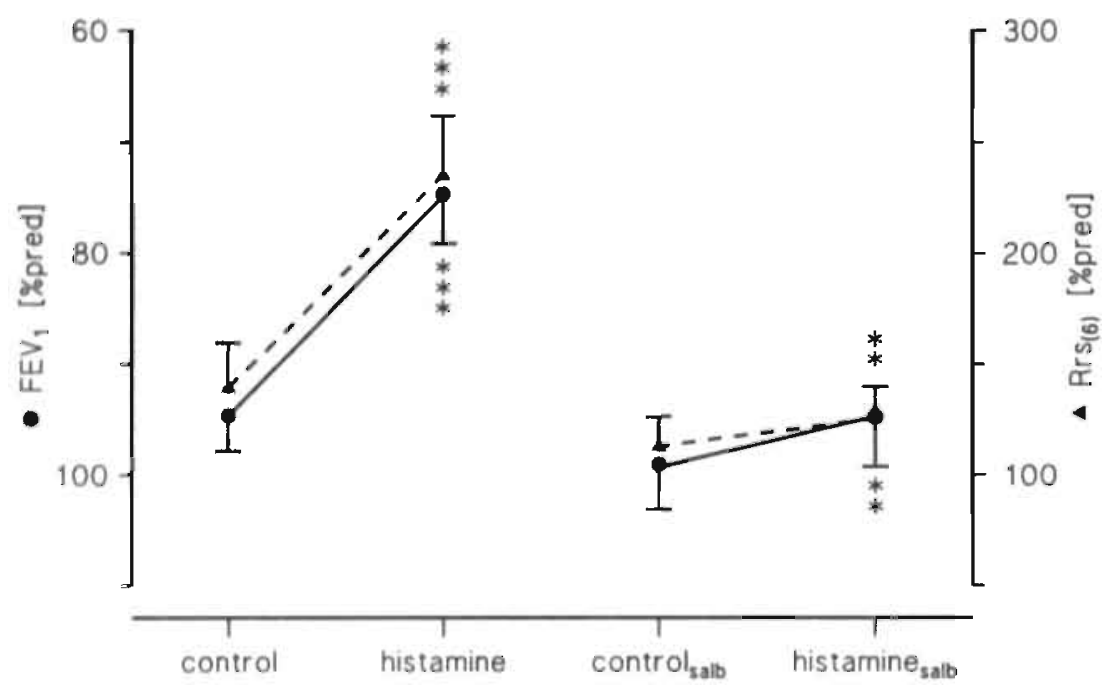

Figure 5.6 Responses of $F E V_{1}(\bullet)$ and $R r_{6}(\Delta)$, as a percentage of predicted (pred), in response to histamine, before and after inhalation of $600 \mu \mathrm{g}$ salbutamol. Before inhalation of salbutamol respiratory resistance at $6 \mathrm{~Hz}\left(\mathrm{Rrs}_{\phi}\right)$ increased and $\mathrm{FEV}$, decreased significantly in response to histamine (histamine versus control). After inhalation of salbutamol responses to histamine are much diminished (histamine, versus control ${ }_{\text {sad }}$. Data represent means $\pm S E$ obtained from 21 subjects. Asterisks indicate statistically significant differences $\left(^{* * *}, p<0.001\right.$; ${ }^{* *}, p<0.01$; Wilcoxon test for paired observations). Note inverse scale for FEV $V_{l *}$

\subsection{EMGS AND SURFACE ELECTRODES}

It has been reported that the electrical activity of the diaphragm, detected. by surface electrodes, is comparable with that detected by oesophageal electrodes ${ }^{13.28 .31}$, and the authors conclude that there is only a minimal contamination from the activity of other chest muscles. In man electrical expiratory activity was found in transversus abdominis muscle, but not in external oblique nor in the rectus abdominis muscles during expiration ${ }^{24}$. It is not likely, therefore, that the EMG of the diaphragm, detected by surface electrodes, is contaminated by electrical activity of abdominal muscles during expiration. Furthermore, the relationship between surface and oesophageal EMGs has not been found to be modified by changes in lung volume $e^{4.28}$. Contamination of inspiratory EMGs by expiratory activity is unlikely since our results for the EMGs of the diaphragm and ICM (Figures 5.3 and 5.5) were comparable and were qualitatively the same as found in our experiments in animals ${ }^{20}$, in which we 
used intramuscular electrodes. It appears valid, therefore, to use surface electrodes to record EMGs of the diaphragm and ICM during the experimental conditions as applied in this study.

\subsubsection{INDICES OF BRONCHOCONSTRICTION}

Several pulmonary function variables can quantify the patency of the airways. FEV, decreases with increasing bronchoconstriction. It has been shown that $\mathrm{Rrg}_{6}$ is increased in patients with chronic obstructive pulmonary disease (COPD) and with asthma ${ }^{7}$. The changes in $\mathrm{FEV}_{1}$ and $\mathrm{Rr}_{\mathrm{\gamma}}$ in response to histamine and after salbutamol were as expected (Table 5.2, Figure 5.6). After salbutamol these indices reached values which were not different from pre-salbutamol control values or even 'better'. FEV $_{1}$ decreased significantly in response to histamine even after inhalation of salbutamol (Table 5.2, Figure 5.6). Thus, histamine-induced bronchoconstriction was not fully prevented by salbutamol, although mean values of FEV 1 after histamine ( $94.8 \%$ of predicted) were comparable with pre-salbutamol control values $(94.7 \%$ of predicted). Further, changes in $\mathrm{FEV}_{1}$ and $\mathrm{Rrs}_{8}$ were very similar with respect to administration of histamine and salbutamol (Figure 5.6).

Table 5.2 Responses of $F R C, F E V$, and $R s_{6}$, before and after salbutamol.

\begin{tabular}{|c|c|c|c|c|}
\hline & \multicolumn{2}{|c|}{ before salbutamol } & \multicolumn{2}{|c|}{ after salbutamol } \\
\hline & control & histamine & control & histamine \\
\hline$\triangle \mathrm{FRC}(\mathrm{ml})$ & & $427(67)$ & & $53(16)$ \\
\hline FEV, (I) & $3.6(0.19)$ & $2.8(0.21)^{\cdots}$ & $3.7(0.21)$ & $3.5(0.23)^{\circ}$ \\
\hline $\mathrm{Rrs}_{6}\left(\mathrm{hPa} \cdot \mathrm{I}^{-1}\right.$.s) & $3.5(0.36)$ & $5.9(0.48)^{\cdots}$ & $2.8(0.22)$ & $3.3(0.23)^{*}$ \\
\hline
\end{tabular}

Data are means (SEM) obtained from 21 subjects. $\triangle F R C$, change in functional residual capacity in response to histamine; $F E V_{l}$, forced expiratory volume in $1 s ; R_{s_{6}}$ airway resistance determined at $6 \mathrm{~Hz}$. Asterisks indicate significance between control and histamine; ", $P<0.05$; **, $P<0.01$; ***, $P<0.001$.

\subsubsection{PEAK INSPIRATORY EMG ACTIVITY}

EMGpk was increased considerably in response to histamine (about 3.5 times control values). A delayed off-switch of inspiration because of elevated airway resistance as well as enhanced stimulation of inspiratory activity by airway receptors may account for this finding. This is supported by the observation that no increase in EMGpk activity was observed any more after bronchoconstriction had been prevented by salbutamol. Further, mean minute ventilation after administration of histamine $(8.7 \pm$ $0.5 \mathrm{1} / \mathrm{min})$ was not significantly different from control $(8.1 \pm 0.5 \mathrm{1} / \mathrm{min})$. Hence, changes in $\mathrm{EMGpk}$ activity cannot be attributed to changes in arterial $\mathrm{P}_{\mathrm{CO}}$. 


\subsubsection{END-TIDAL INSPIRATORY ACTTVITY}

It has been shown that histamine can induce ETIA in rabbits ${ }^{3}$, cats ${ }^{20}$ and $\operatorname{man}^{17,23}$. In a previous study in cats we have shown that stimulation of RARs elicits ETLA, whereas ETIA is inhibited by stimulation of slowly adapting receptors (SARs) ${ }^{19.20}$. Histamineinduced bronchoconstriction is caused both by stimulation of $\mathrm{H}_{1}$-receptors in bronchial smooth muscles and by stimulation of RARs via a vagal reflex ${ }^{5,6}$. In animals RAR activity has been found to be increased in response to inhalation of irritant gases $^{9}$ and by intravenous or intratracheal application of histamine ${ }^{11,22}$. It has been shown in dogs that when histamine is administered at intervals greater than $15 \mathrm{~min}$ the responses of RARs were reproducible ${ }^{27}$. In the further discussion we start from the assumption that the underlying mechanisms of ETIA in man are similar to those found in experimental animals summarized above.

The present study shows that inhalation of histamine is a powerful stimulus to induce ETIA both in the diaphragm and in ICM in man. After inhalation of salbutamol histamine-induced ETIA was considerably reduced indicating that bronchoconstriction was involved in causing ETIA, and by extrapolation of the abovementioned findings obtained in experimental animals this would mean that the enhanced ETLA after administration of histamine is mainly due to mechanical stimulation of RARs by bronchoconstriction. This will be discussed in more detail below. SARs are stimulated by increased lung volume, therefore, if stimulation of SARs also inhibits ETIA in man, histamine-induced hyperinflation may diminish the magnitude of histamineinduced ETIA through RARs.

After salbutamol + histamine, $\mathrm{FEV}_{1}$ and $\mathrm{Rrs}_{6}$ reached levels which didn't differ from their control values before salbutamol $(p=0.71$ and 0.69 , respectively). This suggests that the remaining ETIA after salbutannol+histamine is due to direct chemical stimulation of RARs. After salbutamol, however, a small but significant decrease in $\mathrm{FEV}_{1}$ and increase in $\mathrm{Rr}_{6}$ (as compared to control ${ }_{\text {wath }}$ ) were still observed in response to histamine (Figure 5.6). Thus, it cannot be ruled out that after salbutarnol some mechanical stimulation of RARs by histanine-induced bronchoconstriction was still present. In the section Results a subgroup was defined including 9 subjects. FEV, in these subjects decreased in response to histamine before salbutamol. After salbutamol, however, there was no significant decrease in FEV, in response to histamine as compared to control alb (Table 5.3). Values of ETLA after salbutamol thistamine should, therefore, be attributed to chemical stimulation of RARs in these subjects. Mean values of histamine-induced ETIA in these nine subjects were $41 \%$ and $36 \%$ of their pre-salbutamol values for the diaphragm and ICM, respectively. Thus, chemical stimulation of RARs contributed for somewhat more than one third to the magnitude of ETIA. Hence, with respect to this subgroup we may conclude that, mechanical stimulation of RARs by contraction of bronchial smooth muscles was the more important stimulus in histamine-induced ETIA before salbutamol. That ETIA can be 
induced by mechanical stimulation of RARs is in accordance with our previous findings that continuous negative airway pressure (CNAP) -which is a strong mechanical stimulus for RARs- induces ETLA in cats $^{19}$ and in man $^{21}$.

The contribution of chemical stimulation to the total stimulation of RARs may depend on the magnitude of the applied histamine concentration. in subjects with bronchial hyperresponsiveness a low dose of histamine causes a rather pronounced bronchoconstriction with corresponding mechanical stimulation of RARs, but because of the low histamine concentration chemical stimulation of RARs may be small. $\mathrm{PC}_{20}$ of 8 out of our 9 subjects discussed above was $\geq 8 \mathrm{mg} / \mathrm{ml}$ histamine. Consequently "the concentration of histamine which was administered to these subjects was rather high (mean $12.5(1.9) \mathrm{mg} / \mathrm{ml}$ ). In the remaining 12 subjects this concentration was lower (mean $9.68 \pm 2.03 \mathrm{mg} / \mathrm{ml}$ ). It is likely, therefore, that the conclusion derived from the subgroup of 9 non-responsive subjects will also apply to the responsive subjects, namely that mechanical stimulation of RARs is the more important stimulus in histamine-induced ETIA.

The properties of RARs suggest a positive feedback mechanism, as stimulation of RARs induces reflex-bronchoconstriction, which in turn stimulates RARs. However, the concomitant increases in ETIA and flow limitation result in an increase in FRC which is beneficial by increasing airway diameter.

Table 5.3 Responses of ETIA, FRC and FEV, to histamine.

\begin{tabular}{|c|c|c|c|}
\hline & histamine & & salbutamol + histamine \\
\hline subjects (n) & 9 & & \\
\hline $\operatorname{ETIA}_{a}(\%)$ & $77.6(14.4)$ & $*$ & $31.9(6.5)$ \\
\hline $\operatorname{ETIA}_{\text {IOM }}(\%)$ & 49.9 (11.9) & • & $17.7(4.9)$ \\
\hline$\triangle F R C$ ( $\%$ FRCpred) & $15.6(3.7)$ & $\cdots$ & $2.0(0.9)$ \\
\hline $\mathrm{FEV},(\% \mathrm{ctrl})$ & $80.5(4.2)$ & $\cdots$ & $100.1(0.6)$ \\
\hline
\end{tabular}

Data are means $\pm S E$ obtained from a group of nine subjects which showed no significant decrease in $F E V$, in response to histamine after inhalation of salbutamol. End-tidal inspiratory activity in diaphragm (ETIAAi) and intercostal muscles (ETZAICM) in response to histamine before and after salbutamol. Asterisks indicate significant differences (Wilcoxon test for paired observations; *, $p<0.05 ; * *, p<0.01$ ) between values before and after salbutamol. ETIA in diaphragm was significantly $(p<0.05)$ higher than in ICM for both conditions.

\subsubsection{ETIA AND HYPERINFLATION}

In asymptomatic asthmatics the end-expiratory pleural pressure has been shown to be more negative during histamine-induced hyperinflation than can be accounted for by the chest wall relaxation pressure, indicating the presence of ETIA ${ }^{17}$. Therefore, in addition to airflow limitation. ETIA may be one of the causes of hyperinflation. As 
mentioned before, after salbutamol thistamine $\mathrm{FEV}_{1}$ and $\mathrm{Rrs}_{6}$ reached levels which were comparable to their pre-salbutamol control values. It is likely, therefore, that the small histamine-induced increase in FRC afier salbutamol (Table 5.2, Figure 5.4) is solely due to ETIA which is also small in that condition (Figure 5.3). Siafakas et al. ${ }^{30}$ showed that there is a close, proportional relationship between phrenic activity and the driving pressure of the respiratory system (Prs) during inspiration. In static respiratory conditions $\mathrm{Prs}$ is linearly related to lung volume in the mid-range of lung volumes $^{1}$. In quiet breathing as occurred in our experiments static conditions are approximated at the turning points of inspiration and expiration. The findings of Siafakas et al. then suggest that in control conditions with quiet breathing restricted to the mid-range of lung volumes tidal volume (VT) is proportional to EMGpk, and further that ETIA alone may account for an increase in FRC equal to ETIA times $\mathrm{VT}_{\mathrm{CTRL}}$ or $\triangle \mathrm{FRC}=\mathrm{ETIA} \cdot \mathrm{VT}_{\mathrm{CTRL}}$. Note that ETIA is expressed as a percentage of $\mathrm{EMGpk}_{\text {crn. }}$. Computation of this product for the total group of 21 subjects, using the mean values of ETIA for the diaphragm and ICM, resulted in the following, estimated values for $\triangle F R C$ for ETLA alone: 328 (55) $\mathrm{ml}$ for the experiments before salbutamol and $90(24) \mathrm{ml}$ for the experiments after salbutamol. A comparison of these data with the measured data for $\triangle F R C$ (Table 5.2) suggests that at least in our experiments the contribution of ETIA to histamine-induced hyperinflation is larger than that of flow limitation before salbutamol, and that ETIA is the sole determinant of hyperinflation after salbutamol, which is consistent with the absence of flow limitation in that condition.

\subsection{REFERENCES}

1. Agostoni E and Hyatt RE. Static behavior of the respiratory system. In: Handbook of Physiology, The respiratory System, Mechanics of Breathing, Vol. III, edited by Macklem PT and Mead J. Bethesda: Am.Phys.Soc., 1986, p. 113-130.

2. Armstrong DJ and Luck JC (1974). A comparative study of irritant and type J receptors in the cat. Respir Physiol 21: 47-60.

3. Badier M, Jammes Y, Romero-Colomer P and Lemerre C (1989). Tonic activity in inspiratory muscles and phrenic motoneurons by stimulation of vagal afferents. J Appl Physiol 66: 1613-1619.

4. Banzett RB, Inbar GF, Brown R, Goldman M, Rossier A and Mead J (1981). Diaphragm electrical activity during negative lower torso pressure in quadriplegic men. J Appl Physiol : Respirat Environ Exercise Physiol 51: 654-659.

5. Barnes PJ. Neural control of airway smooth muscle. In: The lung: Scientific foundations, edited by Crystal' RG, West JB, Barnes PJ. Cherniack NS and Weibel ER. New York: Raven Press, 1991, p. 903-916. 
6. Barnes PJ. Pharmacology of airway smooth muscle. In: The lung: Scientific foundations, edited by Crystal RG, West JB, Barnes PJ, Cherniack NS and Weibel ER. New York: Raven Press, 1991, p. 977-985.

7. Clement J, Landser FJ and Van de Woestijne KP (1983). Total resistance and reactance in patients with respiratory complaints with and without obstruction. Chest 2: 215-220.

8. Cockcroft DW, Killian DN, Mellon JJA and Hargreave FE (1977). Protective effect of đrugs on histamine-induced asthma. Thorax 32: 429-437.

9. Davies A and Roumy M (1986). A role of pulmonary rapidly adapting receptors in control of breathing. Aust J Exp Biol Med Sci 64: 67-78.

10. Demedts M (1990). Mechanisms and consequences of hyperinflation. Eur Respir J 3: 617-618.

11. Dixon M, Jackson DM and Richards IM (1979). The effects of histamine, acetylcholine and S-hydroxytryptamine on lung mechanics and irritant receptors in the dog. J Physiol (Lond) 287: 393-403.

12. Dixon M, Jackson DM and Richards IM (1979). The effects of H1- and H2-receptor agonists and antagonists on total lung resistance, dynamic lung compliance and irritant -receptor discharge in the anaesthetized dog. $\mathrm{Br} \mathrm{J}$ Pharmacol 66: 203-209.

13. Gross D, Grassino A, Ross WRD and Macklem PT (1979). Electromyogram pattern of diaphragmatic fatigue. J Appl Physiol : Respirat Environ Exercise Physiol 46: 1-7.

14. Hargreave FE, Ryan G, Thomson NC, et al (1981). Bronchial responsiveness to histamine or methacholine in asthma: measurement and clinical significance. I Allergy Clin Immunol 68: 347-355.

15. Landser FJ, Nagels J, Demedts M, Billiet L and Van de Woestijne KP (1976). A new method to determine frequency characteristics of the respiratory system. J Appl Physiol 41: 101-106.

16. Martin JG, Habib $M$ and Engel LA (1980). Inspiratory muscle activity during induced hyperinflation. Respir Physiol 39: 303-313.

17. Martin JG, Powell E, Shore SA, Emrich J and Engel LA (1980). The role of respiratory muscles in the hyperinflation of bronchial asthma. Am Rev Respir Dis 121: 441-447.

18. Matsumoto $S$ (1989). Effects of ammonia and histamine on lung irritant receptors in the rabbit. Respir Physiol 77: 301-308.

19. Meessen NEL, Grinten van der CPM, Folgering HTM and Luijendijk SCM (1993). Tonic activity in inspiratory muscles during continuous negative airway pressure. Respir Physiol 92: 151-166.

20. Meessen NEL, Grinten van der CPM, Folgering HTM and Luijendijk SCM (1995). Histamine-induced end-tidai inspiratory activity and lung receptors in cats. Eur Respir $\mathbf{J}$ 8: 2094-2103.

21. Meessen NEL, Grinten van der CPM, Luijendijk SCM and Folgering HTM (1994). Continuous negative airway pressure increases tonic activity in the diaphragm and intercostal muscles in humans. J Appl Physiol 77: 1256-1262.

22. Mills JE, Sellick H and Widdicombe JG (1969). Activity of lung irritant receptors in pulmonary microembolism, anaphylaxis and drug-induced bronchoconstrictions. J Physiol (Lond) 203: 337-357.

23. Muller N, Bryan AC and Zamel N (1980). Tonic inspiratory muscle activity as a cause. of hyperinflation in histamine-induced asthma. J Appl Physiol : Respirat Environ. Exercise Physiol 49: 869-874. 
24. Ninane V, Rypens F, Yemault J-C and De Troyer A (1992). Abdominal muscle use during breathing in patients with chronic airflow obstruction. Am Rev Respir Dis 146: 16-21.

25. Phillips GD, Finnerty JP and Holgate ST (1990). Comparative effect of the inhaled beta2-agonist salbutamol (albuterol) on bronchoconstriction provoked by histamine, metacholine, and ađenosine 5'-monophosphate in asthrna. J Allergy Clin Immunol 85(4): 755-76.2.

26. Quanjer PhH,ed.n (1983). Standardized lung function testing. Report Working Party 'Standardization of Lung Function tests'. Bull Eur Physiopathol Respir 19(suppl.): 1-95.

27. Sampson SR and Vidruk EH (1979). The nature of the receptor mediating stimulant effects of histamine on rapidly' adapting vagal afferents in the lungs. J Physiol (Lond) 287: 509-518.

28. Scano G, Duranti R, Spinelli A, Gorini M, Lo Conte C and Gigliottie F (1987). Control of breathing in nomal subjects and in patients with chronic airflow obstruction. Bull Eur Physiopathol Respir 23: 209-216.

29. Shore SA, Bai TR, Wang CG and Martin JG (1985). Centrai and local cholinergic component of histamine-induced bronchoconstriction in dogs. J Appl Physiol 58: 443-451.

30. Siafakas NM, Chang HK, Bonora M, Gauthier AP, Milic-Emili J and Duron B (1981). Time course of phrenic activity and respiratory pressures during airway occlusion in cats. J Appl Physiol : Respirat Environ Exercise Physiol 51: 99-108.

31. Sieck GC, Mazar A and Belman MJ (1985). Changes in diaphragmatic ElMG spectra during hyperpneic loads. Respir Physiol 6il: 137-152.

32. Vidruk EH, Hahn HL, Nadel JA and Sampson SR (1977). Mechanisms by which histamine stimulates rapidly adapting receptors in dog lungs. J Appl Physiol : Respirat. Environ Exercise Fhysiol 43: 397-402.

33. Woolcock AJ (1988). Asthma- what are the important experiments? Am Rev Respir Dis 138: $730-744$.

34. Woolcock AJ, Rebuck. AS, Cade JF and Read J (1971). Lung volume changes in aschma measured concurrently by two methods. Am Rev Respir Dis 104: 703-709. 


\section{6}

\section{Breathing pattern during bronchial challenge in}

humans

Submitted for publication as: Breathing pattern during bronchial challenge in humans.

N.E.L. Meessen, C.P.M. van der Grinten, S.C.M. Luijendijk, H.Th.M. Folgering. 


\subsection{ABSTRACT}

Increases in minute ventilation (VE) have been observed during exacerbation of asthma and in response to administration of histamine. However, it is not clear yet how the breathing pattern is affected and whether the increase in VE is generally found. In the present study effects of inhalation of histamine on breathing frequency (f), tidal volume (VT), ( $\dot{V}$ ) and on functional residual capacity (FRC) were evaluated in 75 humans. Fifty subjects were hyperresponsive. The applied doses of histamine for the present study in these subjects (mean $5.0 \mathrm{mg} / \mathrm{ml}$ ) in each subject caused a decrease in forced expiratory volume in $1 \mathrm{~s}\left(\mathrm{FEV}_{\mathrm{i}}\right)$ that was larger than $20 \%$ of controll FEV $\mathrm{F}_{1}$. The doses of histamine applied in the 25 non-hyperresponsive subjects were substantially larger (mean $9.9 \mathrm{mg} / \mathrm{ml}$ ) while for these doses the decrease in FEV , was less than $20 \%$ of control $\mathrm{FEV}_{1}$. The changes in $\dot{V}_{E}$, $f$ and $V_{\mathbb{T}}$ were nonuniform; comparable numbers of subjects responded with increases $(n=42)$ and decreases $(n=33)$ in $\dot{V} E$, and for $f$ these numbers were $n=44$ and $n=31$, respectively, and similar for $V T n=36$ and $n=39$, respectively. We interpret these findings to indicate that different mechanisms, excitation of central inspiratory activity by stimulation of rapidly adapting receptors and bronchoconstriction, with opposite contributions are involved in the effects of histamine on $\dot{V}_{E}$, f and $V_{T}$. As a consequence, dependent on the net result of these opposite contributions to e.g. VंE, administration of histamine will cause an increase in $\mathrm{VE}$ in one subject and a decrease in $\dot{V}_{E}$ in the other subject.

\subsection{INTRODUCTION}

Bronchoconstriction and hyperventilation occur during exacerbations of asthma. Generally $\mathrm{PaCO}_{2}$ does not change or even decreases during exacerbations of asthma, indicating that ventilation must have increased ${ }^{13.30}$. It has been known for years that patients with asthma hyperventilate, when acutely ill ${ }^{9,11,28}$. It has also been found that minute ventilation ( $\left.\dot{V}_{E}\right)$ increases in response to progressive methacholine-induced and histamine-induced bronchoconstriction ${ }^{2,10,11,17,22}$. Other studies, however, have indicated that inhaled histamine or methacholine may result in a rapid, sometimes shallow, breathing pattern ${ }^{29}$ or that the breathing pattern is not changed in response to histamine and methacholine $e^{12,21}$. Thus, results on ventilatory responses to induced bronchoconstriction reported in the literature are not consistent. Stromberg and Gustafsson ${ }^{25}$ have found that during a histamine challenge four out of eight patients responded with an increase in $\dot{V}_{E}$, whereas $\dot{V}_{E}$ was unchanged or tended to decrease in the remaining patients. These authors suggested that the latter patients were 


\section{'ventilatory nonresponders'.}

Recently, it has been shown in a selected group of patients with asthma, that during histamine challenge tests changes in breathing pattern occur prior to changes in the forced expiratory volume in $1 \mathrm{~s}\left(\mathrm{FEV}_{1}\right)^{7}$. This finding suggests that airway obstruction does not play the only role in the change in the pattern of breathing, and further this finding suggests that vagal airway receptors may be involved by direct stimulation. It is well known that pulmonary receptors influence the breathing pattern ${ }^{16.20}$. The duration of inspiration (t) is mainly controlled by slowly adapting stretch receptors (SARs) through the off-switch mechanism, and, at least in part, the duration of expiration (tE) is determined by rapidly adapting stretch receptors (RARs) ${ }^{1,45}$. In a previous study in cats we found that breathing frequency (f) increased significantly $(p<0.01)$ in response to stimulation of RARs by intravenous administration of histamine. During mechanical stimulation of RARs by continuous negative airway pressure, an increase in $\mathrm{f}$ was also found ${ }^{14}$. RARs can be stimulated by histamine in two ways: mechanically by bronchoconstriction and chemically $0.23,26,27$.

Control of breathing during exacerbations of asthma may also be affected by the concomitant anxiety and increased catecholamines. The asthmatic patient may get into a vicious circle of irritation of airway receptors (i.e. stimulation of RARs), bronchoconstriction, hyperventilation, anxiety, hypocapnia, bronchoconstriction, increased stimulation of RARs, and so on.

It is not clear yet how the breathing pattern changes during exacerbations of asthma and induced bronchoconstriction. Aims of the present study, therefore, were: 1) to evaluate the effects of administration of histamine on the breathing pattern and on FRC in man and 2) to evaluate whether the degree of bronchial responsiveness plays a role in histamine-induced changes in ventilation.

\subsection{METHODS}

\subsubsection{SUBJECTS}

Seventy five subjects participated in this study. To obtain a diversity in bronchial responsiveness, experiments were performed in healthy subjects and in patients with mild stable asthma. Characteristics of the subjects are shown in Table 6.1. Bronchodilators were withheld for at least $8 \mathrm{~h}$ prior to the study. In a standardised histamine challenge test the histamine concentration was determined which caused a fall of $20 \%$ in $\mathrm{FEV}_{1}\left(\mathrm{PC}_{20}\right)^{3.19}$. Generally a histamine concentration of $8 \mathrm{mg} / \mathrm{ml}$ was, used as upper limit of the histamine challenge test. In our experiments some subjects received a histamine concentration up to $16 \mathrm{mg} / \mathrm{ml}$. Fifty subjects. showed bronchial hyperresponsiveness. $\left(\mathrm{PC}_{20} \leq 16 \mathrm{mg} / \mathrm{ml}\right)$. These subjects will be indicated by $\mathrm{BHR}^{+}$and 
the remaining subjects by BHR $^{-}$. Informed consent was obtained from all subjects. They were naive with respect to the scientific goals of the study. The study was approved by the hospital Medical Ethics Committee.

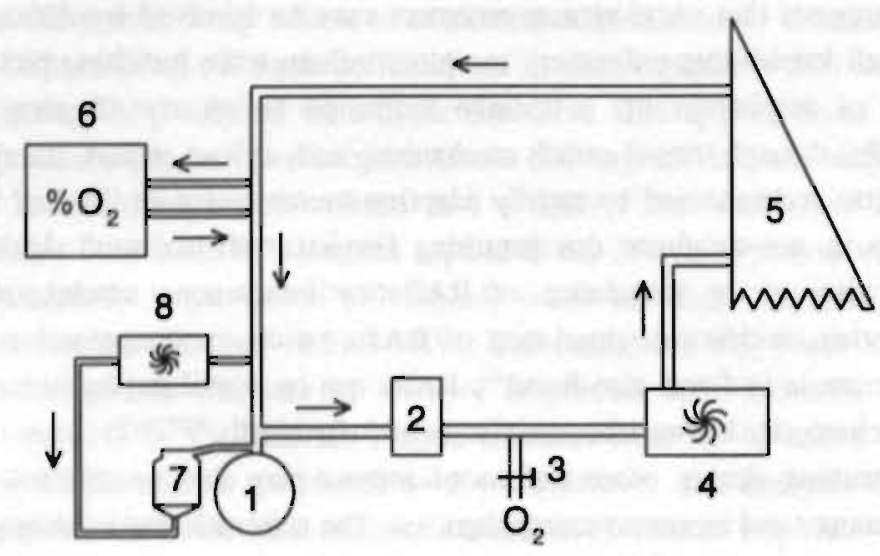

Figure 6.1 Diagram of breathing circuit. 1, subject connected to circuit by mouthpiece; 2, soda lime; 3, port for supplying $\mathrm{O}_{2}, 4$, blower for bias flow; 5, wedge spirometer; $6, \mathrm{O}_{2}$ analyzer; 7, nebulizer; 8, blower generating flow for aerosol. Dead space of the circuit was 49 $m l$.

\subsubsection{EXPERIMENTAL SET-UP}

In all subjects bronchial hyperresponsiveness was measured by a histamine challenge test $^{3}$. To shorten the duration of the test the starting concentration of histamine varied depending on the response to an aerosol of saline and medication requirements $s^{8,19,24}$. Aerosols were generated by a DeVilbiss 646 jet nebulizer. The calibrated output of the nebulizer was $0.13 \mathrm{ml} / \mathrm{min}$. The histamine concentration that was used depended on the individual result of the challenge protocol. In BHR ${ }^{+}$subjects, ventilatory parameters were studied at the $\mathrm{PC}_{20} \mathrm{FEV}_{1}$-dose. In $\mathrm{BHR}^{-}$subjects, the ventilatory parameters were studied at the highest histamine dose used in the challenge protocol ( 8 or $16 \mathrm{mg} / \mathrm{ml}$ ).

$\mathrm{FEV}_{1}$ and FVC were measured by a pneumotachograph (Fukuda Sangyo). Changes in FRC, $\mathrm{f}$, tidal volume (VT) and $\mathrm{VE}$ were calculated from the recordings obtained before and after inhalation of histamine. Two methods were applied to record these spirograms: 1) by a wedge spirometer which was part of a closed breathing circuit, 2) by respiratory inductive plethysmography (RIP) (Respitraces). Values were related to 
the reference values of the European Respiratory Society ${ }^{18}$.

Fifty-three subjects ( $35 \mathrm{BHR}^{+}$and $18 \mathrm{BHR}^{-}$) were connected to the closed breathing circuit by a mouthpiece. Gas was sampled continuously from the circuit for measurement of the oxygen concentration (Taylor Servomex) and subsequently fed back into the system (Figure 6.1). Oxygen was supplied to maintain oxygen concentration in the circuit constant $(21 \%)$. A blower maintained a constant bias flow in the circuit ( $120 \mathrm{l} / \mathrm{min}$ ). Exhaled $\mathrm{CO}_{2}$ was absorbed by soda lime. An aerosol of histamine could be delivered by a nebulizer which was connected to the circuit near the mouthpiece (Figure 6.1).

The remaining subjects (15 $\mathrm{BHR}^{+}$and $7 \mathrm{BHR}^{-}$) were connected to the RIP system and connected with a mouthpiece to a nebulizer. The RIP was used in the DC-mode. Volume calibration of the Respitrace was performed with a spirometer (Hospal, Littleton, Colorado, USA) just prior to the administration of the aerosol and immediately after the last measurements while the subject was still sitting in the same position. If the two calibration factors differed by more than $10 \%$ the measurement was excluded from the study. Thus, for each subject a conversion factor was calculated from the lung volume changes measured with the spirometer and the associated deflections obtained from the RIP.

The spirograms were recorded with a multi-channel $X-t$ recorder (Kipp, The Netherlands) for off-line analysis of the changes in $\dot{V}_{E}, \mathrm{VT}, \mathrm{f}$ and FRC.

All subjects were tested in the sitting position while breathing through the mouthpiece with the nose clipped. To minimize the subject's attention to breathing, they were asked to concentrate on a poster placed in front of them.

Table 6.1 Characteristics of subjects

\begin{tabular}{|c|c|c|c|c|}
\hline & & Total & $\mathrm{BHR}^{*}$ & $\mathrm{BHR}^{-}$ \\
\hline n & & 75 & 50 & 25 \\
\hline $\operatorname{sex}[M / F]$ & & $34 \mathrm{M} / 41 \mathrm{~F}$ & $23 \mathrm{M} / 27 \mathrm{~F}$ & $11 \mathrm{M} / 14 \mathrm{~F}$ \\
\hline age [y] & & $33.9(1.5)$ & $34.0(2.0)$ & $33.5(2.0)$ \\
\hline height [crn] & & $173.4(0.9)$ & $172.8(1.1)$ & $174.7(1.6)$ \\
\hline histamine [mg/ml] & & $6.6(0.60)$ & $5.0(0.73)$ & $9.9(0.70)^{\cdots}$ \\
\hline \multirow[t]{2}{*}{$\mathrm{FEV},[\%$ pred $]$} & control & $93.6(1.9)$ & $88.9(2.2)$ & $103.2(2.6)^{n+.}$ \\
\hline & histamine & $72.8(2.4)^{\prime \prime \prime}$ & $62.1(2.1)^{10 \prime}$ & $94.1(2.5)^{\prime \prime \prime} \cdots$ \\
\hline
\end{tabular}

Data are means $\pm S E$. \% pred, percentage of predicted value; $\#$ H, indicates significant $(p<0.001)$ differences between histamine and control values. Asterisks indicate significant $(p<0.001)$ differences between BHR ${ }^{+}$and $B H R^{-}$.

\subsubsection{EXPERIMENTAL PROTOCOL}

Recording was started after the subjects had been connected to the mouthpiece. The 
uninterrupted recording included control ventilation, the period of $2 \mathrm{~min}$ of inhalation of histamine and at least $1 \mathrm{~min}$ following inhalation of histamine. $\mathrm{FEV}_{1}$ and $\mathrm{FVC}$ were measured immediately before this recording and $1.5 \mathrm{~min}$ after inhalation of histamine had been stopped.

\subsubsection{DATA ANALYSIS}

Mean values \pm standard error (SE) of $\mathrm{f}, \mathrm{VT}, \dot{\mathrm{V}}$ and changes in FRC ( $\triangle F R C$ ) were calculated from 5 consecutive control breaths just prior to the inhalation of histamine, and from 5 consecutive breaths $1 \mathrm{~min}$ after inhalation of histamine.

Differences between the results before (control) and after inhalation of histamine and differences between the results of the two groups $\left(\mathrm{BHR}^{+}\right.$and $\left.\mathrm{BHR}^{-}\right)$were evaluated for statistical significance using the t-test for paired observations and the t-test for unpaired observations, respectively. $p<0.05$ was considered to be significant.

Table 6.2 Effects of aerosolized histamine on breathing patterm.

\begin{tabular}{|c|c|c|c|c|}
\hline & & Total & $\mathrm{BHR}^{*}$ & $\mathrm{BHR}^{-}$ \\
\hline$n$ & & 75 & 50 & 25 \\
\hline \multirow[t]{2}{*}{ VEE [I/min]: } & control & $8.0(0.3)$ & $8.2(0.4)$ & $7.5(0.5)$ \\
\hline & histamine & $8.7(0.4)^{\prime \prime}$ & $8.7(0.5)$ & $8.5(0.7)^{\prime}$ \\
\hline \multirow[t]{2}{*}{$f(/ \mathrm{min}):$} & control & $16.1(0.6)$ & $17.1(0.7)$ & $14.1(1.0)^{\circ}$ \\
\hline & histamine & $17.3(0.8)^{\prime \prime}$ & $18.4(0.9)^{\prime}$ & $15.2(1.3)^{\circ}$ \\
\hline \multirow[t]{2}{*}{ VT [ml]: } & control & $521(18)$ & $498(18)$ & $568(40)$ \\
\hline & histamine & $533(21)$ & $496(22)$ & $605(40)^{\circ}$ \\
\hline$\triangle F R C$ [\%FRCpred] & & $8.4(0.9)$ & $10.0(1.2)$ & $5.2(1.0)^{*}$ \\
\hline$\triangle F R C[m]]$ & & $265(28)$ & $317(37)$ & $160(32)^{*}$ \\
\hline
\end{tabular}

Data are means $\pm S E$ for all subjects (total), subjects with hyperresponsiveness. $\left(B H R^{+}\right)$, and normal subjects (BHR). $\Delta$ refers to changes relative to controt. Asterisks indicate significant differences between BHR' and BHR' and 'H' indicate significant differences between histamine and control values. ", H, $p<0.05$ and $* *$, \#\#, $p<0.01$.

\subsection{RESULTS}

In Table 6.1 characteristics of the subjects are shown. Sex, age and height were not significantly different between $\mathrm{BHR}^{+}$and $\mathrm{BHR}^{-}$. For $\mathrm{BHR}^{+}, \mathrm{BHR}^{-}$and the whole group together, $\mathrm{FEV}_{1}$ decreased significantly in response to the applied dose of 
histamine as compared with control values. Mean concentration of histamine administered to $\mathrm{BHR}^{+}(5.0 \mathrm{mg} / \mathrm{ml})$ was only half that administered to $\mathrm{BHR}^{-}(9.9$ $\mathrm{mg} / \mathrm{ml})$.

Ventilatory responses to inhalation of histamine determined with spirometer system and RIP were qualitatively and quantitatively the same, and, as a consequence, the data were pooled. Table 6.2 shows the results. VE increased significantly in the whole group and in $\mathrm{BHR}^{-}$as compared with control values before inhalation of histamine. However, the changes in $\dot{V}_{E}$ were not significant in $\mathrm{BHR}^{+}$. Breathing frequency increased significantly in the whole group and in $\mathrm{BHR}^{+}$, but not in $\mathrm{BHR}^{-}$. Control values of $\mathrm{f}$ were significantly different between $\mathrm{BHR}^{+}$and $\mathrm{BHR}^{-}$. This difference persisted after inhalation of histamine. Thus, although, on average, the control values of $f$ were higher in $\mathrm{BHR}^{+}$, a further significant increase in $\mathrm{f}$ in response to histamine was found. In the whole group, $\mathrm{BHR}^{+}$and $\mathrm{BHR}^{-}$, no significant changes were found in VT between control and histamine values. Histamine values of VT were significantly higher in $\mathrm{BHR}^{-}$as compared to $\mathrm{BHR}^{+}$. Mean $( \pm \mathrm{SE})$ increase in FRC after inhalation of histamine was $8.4(0.9) \%$ of FRC predicted $(0.27 \pm 0.03$ litre $)$. This increase in FRC was significantly $(\mathrm{p}<0.01)$ larger in $\mathrm{BHR}^{+}$than in $\mathrm{BHR}^{-}$.

Table 6.3 Effects of histamine on several respiratory variables for ventilatory responders and non-responders.

\begin{tabular}{|c|c|c|c|c|c|c|}
\hline & \multicolumn{3}{|c|}{ responders $(\triangle \dot{V} E>0)$} & \multicolumn{3}{|c|}{ non-responders $(\triangle \dot{V} E<0)$} \\
\hline & total & $\mathrm{BHR}^{*}$ & $\mathrm{BHR}^{-}$ & total & BHR. & $\mathrm{BHR}^{-}$ \\
\hline n & 42 & 26 & 16 & 33 & 24 & 9 \\
\hline$\Delta \mathrm{f}[/ \mathrm{min}]$ & $2.1(0.5)$ & $2.6(0.7)$ & $1.2(0.8)$ & $0.2(0.5)^{\prime}$ & $-0.1(0.7)^{\prime \prime}$ & $0.8(0.8)$ \\
\hline$\Delta V_{T}[\mathrm{ml}]$ & $76(21)$ & $66(26)$ & $91(37)$ & $-70(17)^{-3 \prime \prime}$ & $-75(20)^{\prime \prime \prime}$ & $-58(35)^{u \prime}$ \\
\hline$\Delta \dot{V} E[l / m i n]$ & $2.2(0.4)$ & $2.3(0.5)$ & $1.9(0.4)$ & $-1.3(0.2)^{60 \prime}$ & $-1.5(0.3)^{\prime \prime \prime}$ & $-0.5(0.1)^{* \cdots}$ \\
\hline hist [mg/ml] & $7.9(0.8)$ & $6.3(1.0)$ & $10.5(1.0)^{* *}$ & $5.0(0.9)^{\prime}$ & $3.5(1.0)$ & $8.9(0.9)^{\cdots}$ \\
\hline$\triangle \mathrm{FEV},[\%]$ & $-20.2(1.6)$ & $-27.3(1.0)$ & $-8.6(1.4)^{\cdots}$ & $-26.8(2.7)^{\prime}$ & $-33.5(2.6)^{\prime}$ & $-8.9(0.9)^{\ldots . .}$ \\
\hline$\triangle \mathrm{FRC}[\%]$ & $9.4(1.1)$ & $11.2(1.4)$ & $6.5(1.5)^{\circ}$ & $7.1(1.4)$ & $8.7(1.9)$ & $3.0(1.0)^{*}$ \\
\hline
\end{tabular}

Data are means $\pm S E$. $\triangle$ refers to values after histamine minus control values. Change in FEV, is expressed as percentage of control value. $B \mathrm{BR}^{+}$, subjects with hyperresponsiveness; $B \mathrm{HR}^{-}$, normal subjects. Change in FRC is expressed as percentage of FRC predicted. Asterisks indicate significant differences between $B H R^{+}$and $B H R$ ' and 'H' indicate significant differences between responders and non-responders. \#, $p<0.05 ; * *, p<0.01 ; * * *$, \#\#, $p<0.001$.

In 16 out of $25 \mathrm{BHR}^{-}$, and in 26 out of $50 \mathrm{BHR}^{+}$, minute ventilation increased in response to histamine (ventilatory responders; Table 6.3). Ventilatory responders were not different from nonresponders with regard to sex, age, height, weight, and 
control values of $f$ and VT. Significant differences, however, were found for $\Delta f$, $\Delta \mathrm{VT}, \Delta \dot{\mathrm{VE}}$, histamine concentration and histamine-induced decrease in $\mathrm{FEV}_{1}$ between ventilatory responders and non-responders (Table 6.3).
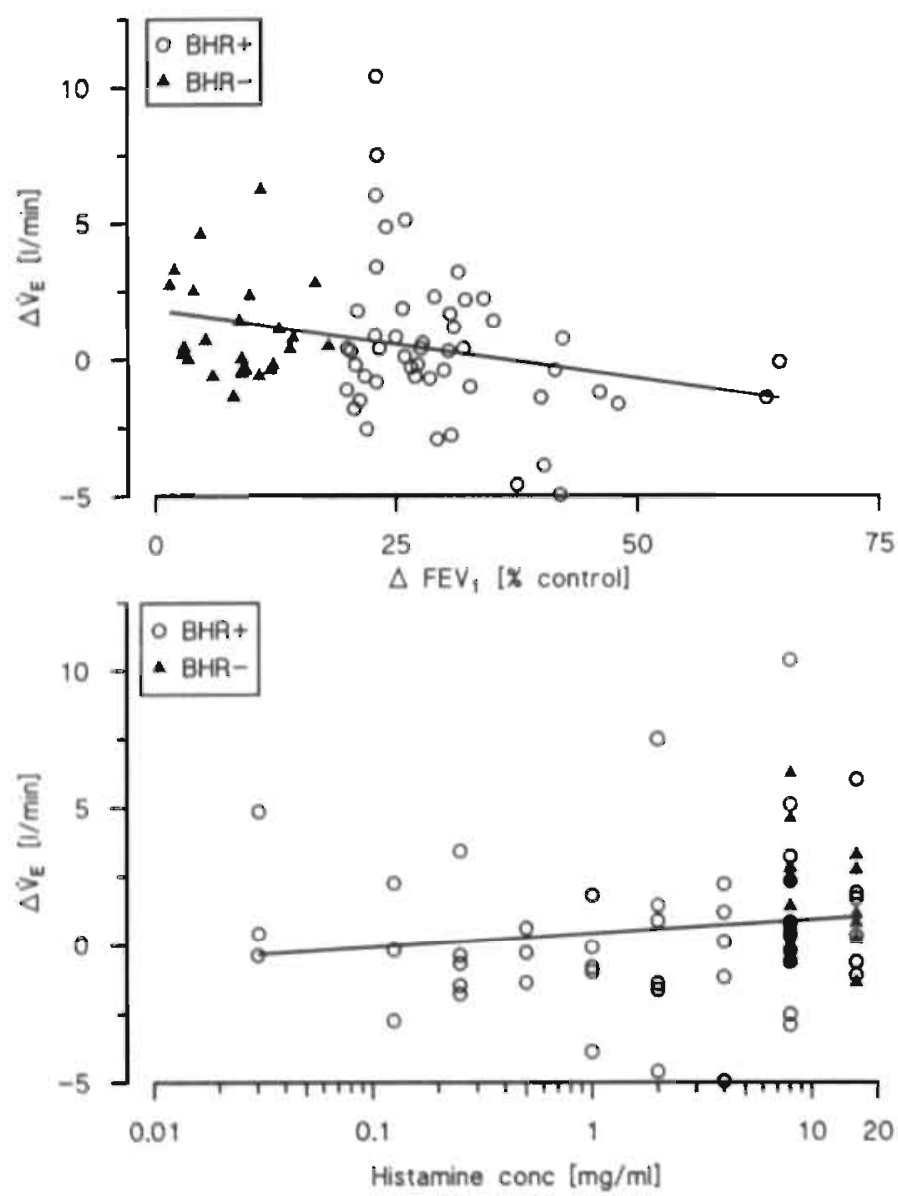

Figure 6.2 Upper panel: Relationship between change in $\dot{V}_{E}\left(\Delta \dot{V}_{E}\right)$ and change in $F E V_{1}$ $(\triangle F E V)$ in response to histamine obtained from 50 subjects with hyperresponsiveness $\left(B H R^{+}\right)$ and 25 subjects without hyperresponsiveness (BHR-). $\triangle F E V_{t}$ is expressed as percentage change from control values. For BHR $r=-0.312(p<0.05)$; for $B H R^{-} r=-0.119$ (NS, not significant); for whole group $r=-0.261$ ( $p<0.05)$. Lower panel: Relationship between $\Delta \vec{V} E$ and histamine concentration obtained from $50 \mathrm{BHR}^{+}$and $25 \mathrm{BHR}$. For $B H R^{+} r=0.202$ (NS); for $B H R^{-} r=0.031$ (NS); for whole group $r=0.199 \quad(p=0.865)$. 
In the 42 responders the increase in $\triangle \dot{V} E$ was due to an increase in $f(n=11)$ or $V T$ $(n=12)$ or both $(n=19)$. In the 33 non-responders the decrease in $V_{E}$ was due to a decrease in $f(n=5)$ or VT $(n=14)$ or both $(n=14)$.

No significant difference in $\triangle \mathrm{FRC}$ was found between ventilatory responders and. non-responders (Table 6.3). Both for responders and for non-responders $\triangle \mathrm{FRC}$ was significantly larger in $\mathrm{BHR}^{+}$compared with $\mathrm{BHR}^{-}$.

In Figure 6.2 relationships are shown between $\triangle \dot{V}^{2}$ and $\Delta F E V_{1}$ in response to histamine (upper panel), and between $\Delta \dot{V} E$ and the applied histamine concentration (lower panel). Results are presented separately for $\mathrm{BHR}^{+}$and $\mathrm{BHR}^{-}$. A significant correlation was found for the relationship between $\triangle \mathrm{V} E$ and $\triangle \mathrm{FEV}_{1}$ for $\mathrm{BHR}^{+}(\mathrm{r}=$ $-0.312, p<0.05)$ and for the whole group $(r=-0.261, p<0.05)$ but not for BHR ${ }^{-}$. Thus, it appeared that the subjects with the largest decrease in VE showed a relatively large decrease in $\mathrm{FEV}_{1}$. No significant relationships were found between $\triangle \mathrm{V} E$ and the applied histamine concentration.

\subsection{DISCUSSION}

The use of a mouthpiece and noseclip may be criticized. Effects of a mouthpiece on breathing pattern have been described in the literature, but conclusions are not consistent". In the present study we have evaluated the effects of inhalation of histamine on respiratory variables. Values after histamine were compared to control values; i.e., before starting nebulising histamine. Thus, baseline values were obtained after subjects had been connected to the mouthpiece and the nose had been clipped. Hence, the differences in breathing partern found in response to histamine may not be attributed to an effect of the mouthpiece or noseclip. It has been reported recently that ventilatory responses (i.e. $\dot{V}_{E}$ ) to inhaled histamine, measured by respiratory inductive plethysmography, were diminished when breathing through a mouthpiece whilst wearing a noseclip ${ }^{25}$. All of our subjects breathed through a mouthpiece with the nose clipped. This might explain why we found a considerable number of ventilatory nonresponders. If changes in breathing pattern induced by inhalation of histamine are masked by an effect of the mouthpiece and noseclip, responses in our study may be underestimated.

Our results indicate that in most subjects $\mathrm{VE}$ and $\mathrm{f}$ increase in response to histamine. The changes in $\dot{V}_{E}, f$ and $V_{T}$, however, were non-uniform; comparable numbers of subjects responded with increases $(n=42)$ and decreases $(n=33)$ in $\dot{V}_{E}$, and for $f$ these numbers were $n=44$ and $n=31$, respectively, and similar for VT $n=36$ and $\mathrm{n}=39$, respectively. These results are in agreement with the observations of Strom- 
berg and Gustafsson who had found that $50 \%$ of the subjects responded to histamine with an increase in $\dot{V}_{E}$ whereas in the remaining $50 \%$ VE was unchanged or tended to decrease. We think that histamine-induced increases in $\dot{V}_{E}$ and $f$ are, at least in part, due to a vagal reflex in which RARs are involved. From our previous studies in cats $^{14,15}$ we learnt that stimulation of RARs, either by negative airway pressure or by administration of histamine, led to an increase in $\mathrm{f}$.

RARs are stimulated by histamine in two ways: mechanically by histamine-induced bronchoconstriction, and chemically. The decrease in $\mathrm{FEV}_{1}$ is a measure of airflow limitation due to histamine and may be inversely related to the magnitude of mechanical stimulation of RARs. If stimulation of RARs causes an increase in $\dot{V} E$, a positive correlation between $\Delta F E V_{1}$ and $\Delta \dot{V}_{E}$ may be expected. In our experiments, however, a negative correlation was found (Figure 6.2). In several subjects opposite responses were seen for $f$ and VT; i.e. $f$ increased and simultaneously $V_{T}$ decreased. The net result was that VE did not alter much. In $\mathrm{BHR}^{+}$the change of FRC on histamine was larger than in normal subjects (Table 6.3). This can be attributed to the more pronounced airflow limitation and the possible presence of end-tidal inspiratory activity during increased activity of RARs ${ }^{14,15}$. An increase in FRC may prevent an increase in VT or even cause a decrease in VT with a concomitant decrease in VE. Also the increased airway resistance after inhalation of histamine may cause a decrease in $V_{T}$ and $\dot{V}_{E}$ in subjects with large decreases in FEV . This can explain why we found that $\dot{V E}_{E}$ was negatively correlated to $\triangle \mathrm{FEV}_{1}$ (Figure 6.2), and therefore, $\dot{V}_{E}$ decreased especially in subjects with large decreases in $\mathrm{FEV}_{1}\left(\mathrm{BHR}^{+}\right)$.

In conclusion, in our subjects non-uniform responses were observed concerning the effects of inhaled histamine on the breathing pattern, in particular tidal volume and minute ventilation. I.e., both increases and decreases in these quantities were found. These findings imply that different mechanisms are involved with opposite effects, e.g. excitation of central inspiratory activity by stimulation of rapidly adapting pulmonary stretch receptors which will promote increases in respiratory rate, tidal volume and minute ventilation, and bronchoconstriction with increased airway resistance which will promote decreases in these quantities. In that case the final results are unpredictable so that different subjects may respond differently. 


\subsection{REFTRENCES}

1. Armstrong DJ and Luck JC (1974). A comparative study of irritant and type J receptors in the cat. Respir Physiol 21: 47-60.

2. Chadha TS, Schneider AW, Birch S, Jenouri G and Sackner MA (1984). Breathing pattern during induced bronchoconstriction. J Appl Physiol : Respirat Environ Exercise Physiol 56: 1053-1059.

3. Cockcroft DW, Killian DN, Mellon JJA and Hargreave FE (1977). Bronchial reactivity to inhaled histamine: a method and clinical survey. Clin Allergy 7: 235-243.

4. Coleridge HM and Coleridge JCG. Reflexes evoked from tracheobronchial tree and lungs. In: Handbook of Physiology, The Respiratory System, Control of Breathing, Vol. II, edited by Cherniack NS and Widdicombe JG. Bethesda, MD: American Physiological Society, 1986, p. 395-429.

5. Davies A and Roumy M (1986). A role of pulmonary rapidly adapting receptors in control of breathing. Aust J Exp Biol Med Sci 64: 67-78.

6. Dixon M, Jackson DM and Richards IM (1979). The effects of H1- and H2-receptor agonists and antagonists on total lung resistance, dynamic lung compliance and irritani receptor discharge in the anaesthetized dog. Br J Pharmacol 66: 203-209.

7. Fanelli A, Duranti R, Gorini M, Spinelli A, Gigliotti F and Scano G (1994). Histamine-induced changes in breathing pattern may precede bronchoconstriction in selected patients with bronchial asthma. Thorax 49: 639-643.

8. Hargreave FE, Ryan G, Thomson NC, et al (1981). Bronchial responsiveness to histamine or methacholine in asthma: measurement and clinical significance. J Allergy Clin Immunol 68: 347-355.

9. Kassabian J, Miller KD and Lavietes MH (1982). Respiratory center output and ventilatory timing with acute airway (asthma) and alveolar (pneumonia) disease. Chest 81: 536-543.

10. Kelsen SG, Prestel TF, Chemiack NS, Chester EH and Deal EC,Jr. (1981). Comparison of the respiratory responses to external resistive loading and bronchoconstriction. $\mathrm{J}$ Clin Invest 67: 1761-1768.

11. Kesten S, Maleki-Yazdi MR, Sanders BR, et al (1990). Respiratory rate during acute asthma. Chest 97: 58-62.

12. Lougheed MD, Lam M, Forkert L, Webb A and O'Donnell DE (1993). Breathlessness during acute bronchoconstriction in asthma: pathophysiologic mechanisms. Am Rev Respir Dis 148: 1452-1459.

13. McFadden ER and Lyons HA (1968). Arterial-blood gas tension in asthma. N Engl J Med 278: 1027-1032.

14. Meessen NEL, Grinten van der CPM, Folgering HTM and Lujiendijk SCM (1993). Tonic activity in inspiratory muscles during continuous negative airway pressure. Respir Physiol 92: 151-166.

15. Meessen NEL, Grinten van der CPM, Folgering HTM and Luijendijk SCM (1995). Histamine-induced end-tidal inspiratory activity and lung receptors in cats. Eur Respir J 8: 2094-2103.

16. Millman RP, Silage DA, Peterson DD and Pack AI (1982). Effect of aerosolized histarnine on occlusion pressure and ventilation in humans. J Appl Physiol : Respirat Environ Exercise. Physiol 53: 690-697. 
17. Oliven A, Cherniack NS, Deal EC and Kelsen SG (1985). The effects of acute bronchoconstriction on respiratory activity in patients witch chronic obstructive pulmonary disease. Am Rev Respir Dis 131: 236-241.

18. Quanjer $\mathrm{PhH}$ (1993). Standardised Lung function testing. Eur Respir J 6 (suppl 16): 5-33.

19. Quanjer Phll,ed., (1983). Standardized lung function testing. Report Working Party 'Standardization of Lung Function tests'. Bull Eur Physiopathol Respir 19(suppl.): 1-95.

20. Savoy J, Allgower E, Ccourteheuse C and Junod AF (1984). Ventilatory response to bronchospasm induced by methacholine and histamine in man. Respir Physiol 56: 195-203.

21. Savoy J, Fleetham JA, Arnup M-E and Anthonisen NR (1981). Airway anesthesia and respiratory response to methacholine induced bronchoconstriction. Respir Physiol 43: 59-68.

22. Savoy J, Louis M, Kryger MH and Forster A (1988). Respiratory response to histamineand methacholine-induced bronchospasm in nonsmokers and asymptomatic smokers. Fur Respir J 1: 209-2.16.

23. Sellick H and Widdicombe JG (1971). Stimulation of lung irritant receptors by cigarette smoke, carbon dust, and histamine aerosol. J Appl Physiol : Respirat Environ Exercise Physiol 31: 15-19.

24. Sterk PJ, Fabbri LM, Quanjer PhH, et al (1993). Airway responsiveness. Standardized challenge testing with pharmacological, physical and sensitizing stimuli in adults. Eur Respir J 6: s53-s83.

25. Stromberg NOT and Gustafsson PM (1993). Ventilatory pattern during bronchial histamine challenge in asthmatics. Eur Respir J 6: 1126-1131.

26. Vidruk EH, Hahn HL, Nadel JA and Sampson SR (1977). Mechanisms by which histamine stimulates rapidly adapting receptors in dog lungs. J Appl Physiol : Respirat Environ Exercise Physiol 43: 397-402.

27. White MV and Kaliner MA. Regulation by histarnine. In: The lung: Scientific foundations, edited by Crystal RG, West JB, Barnes PJ, Cherniack. NS and Weibel ER. New York: Raven Press, 1991, p. 927-939.

28. Williams; Jr. MH (1991). Asthma: the pulse is not the paradox. Lung 168: 179-184.

29. Woolcock AJ (1988). Asthma -what are the important experiments? Am Rev Respir Dis 138: 730-744.

30. Woolcock AJ, Rebuck AS, Cade JF and Read J (1971). Lung volume changes in asthma measured concurrently by two methods. Am Rev Respir Dis 104: 703-709. 
7

General Discussion 


\subsection{PULMONARY RECEPTORS AND ETIA}

Figure 7.1 is a schematic representation of the respiratory system. The investigations presented in this thesis were concentrated on the activity of inspiratory muscles which can be derived from their electrical activity (EMG) and indirectly from changes in airway pressure, in parameters of the breathing pattern and in lung volume. Hyperinflation and the reflex activity in inspiratory muscles caused by stimulation of pulmonary receptors were the main objects of our studies.

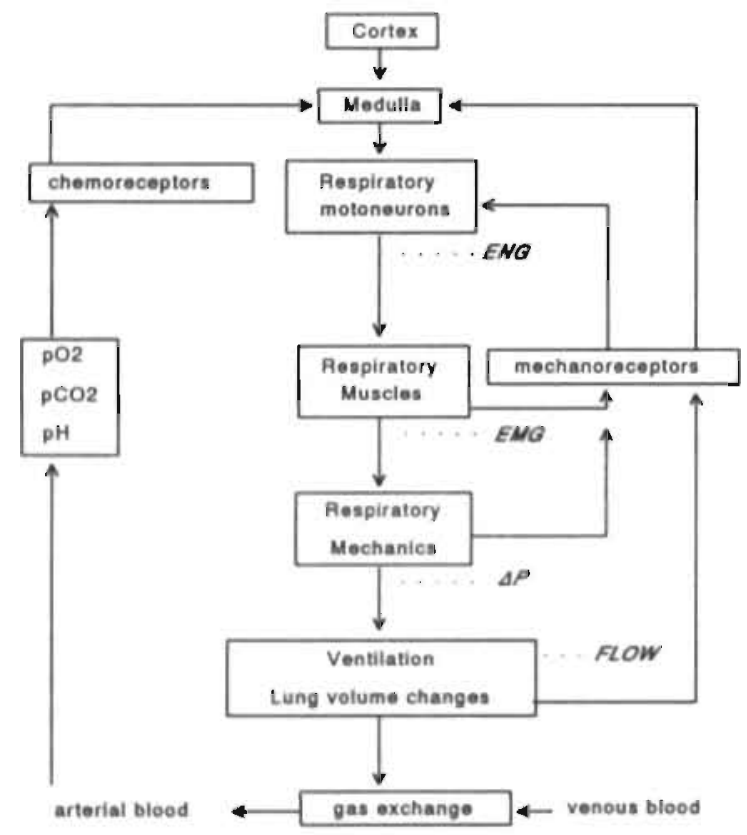

Figure 7.1 Schematic representation of respiratory system. Activity of respiratory centres in medulla can be derived from electroneurogram (ENG) of phrenic nerve, or from electromyogram (EMG) of respiratory muscles. Gas exchange is perceived by central and peripheral chemoreceptors. $\Delta P$, change in airway pressure.

There are three types of mechanoreceptors in the lungs: RARs, SARs and C-fibre endings. Reflex effects of these receptors have been extensively studied in the past ${ }^{1,220.35}$. The end-tidal inspiratory activity (ETLA) as a reflex effect has received attention only in recent studies ${ }^{3,12.28}$. In the literature several techniques have been described to differentiate between reflex effects of the three pulmonary receptors. Anodal polarisation ${ }^{13}$ and vagal cooling techniques have been used to selectively block conduction in myelinated vagal nerve fibres (i.e. afferents of SARs and RARs) while 
leaving conduction in non-myelinated $\mathrm{C}$-fibres relatively unaffected $0,11,27,34$. Vagal cooling is based on the principle 'the greater the conduction velocity, the higher the blocking temperature ${ }^{27}$. Franz and Iggo ${ }^{11}$ have shown in cats that the blocking temperature of non-myelinated axons was significantly lower than that of myelinated axons. Besides differences in conduction velocities between myelinated and nonmyelinated fibres, also differences in conduction velocities between SARs and RARs have been found ${ }^{30}$, although some overlap remained ${ }^{5,30}$. Conduction in afferents of SARs, however, is consistently faster than that in afferents of RARs ${ }^{5.30}$. In dogs it has been found that between vagal temperatures of 7-12 ${ }^{\circ} \mathrm{C}$ the decrease in activity of SARs was markedly greater than that RARs ${ }^{19.29}$. At $10^{\circ} \mathrm{C}$, the recorded activity of RARs had decreased on average by approximately $33 \%$, and that of SARs by $75 \%$, and the relative decrease of RAR activity continued to be less at each subsequent lower temperature ${ }^{29}$. At $9{ }^{\circ} \mathrm{C}$, impulse frequency in afferents of SARs during hyperinflation was only' one third of that during control ventilation, whereas RAR activity did not fall significantly below control level until the vagus nerves were cooled down to $7{ }^{\circ} \mathrm{C}^{19}$. Below 6-4 ${ }^{\circ} \mathrm{C}$ conduction in myelinated fibres (afferents from SARs and RARs) was almost abolished whereas a large fraction of the activity of non-myelinated $\mathrm{C}$-fibres was still transmitted ${ }^{19}$. Our experiments in cats, during control and during CNAP, showed that gradual cooling of both vagus nerves first affected tI (below $14^{\circ} \mathrm{C}$ ) and then tE (below $8{ }^{\circ} \mathrm{C}$ ). These effects on $\mathrm{U}$ and $\mathrm{E}$ can be attributed to reduced activity from SARs (inhibition of inspiratory off-switch) and from RARs (inhibition of facilitation of inspiratory on-switch), respectively. Our observations concerning the effects of vagal cooling on $U$ and $\mathbb{E}$ (chapter 2) confirm similar findings in dogs and indicate that vagal cooling provides a valid and useful technique to selectively block conduction in afferents of SARs and RARs in cats.

In the animal studies presented in this thesis the role of the three: types of pulmonary receptors in generating ETIA was studied. The experiments were performed in cats. Nearly all of our experimental animals showed considerably increased levels of ETIA at application of CNAP $(\geq-1.8 \mathrm{kPa})$ and this was also seen in about $40 \%$ of them after i.v. administration of histamine $300 \mu \mathrm{g}$. In none of the cats, however, was ETIA found after vagotomy. It was concluded, therefore, that ETIA is a vagal reflex activity. To differentiate between the reflex effects of RARs and SARs, the vagus nerves were cooled and the lung receptors were additionally stimulated by application of CNAP, histamine and C.PAP. Although these stimuli are not specific for one particular type of lung receptors, it is generally agreed that RARs, are stimulated by CNAP and histamine whereas CPAP mainly activates SARs ${ }^{5}$. During CNAP, RARs are stimulated mechanically while SAR activity is inhibited.

Figure: 7.2 represents a schematic diagram of the airway epithelium. Contraction of 
airway smooth muscles by histamine may be evoked in two ways; by direct stimulation of $\mathrm{H}_{1}$-receptors or by a vagal reflex evoked by stimulation of RARs.

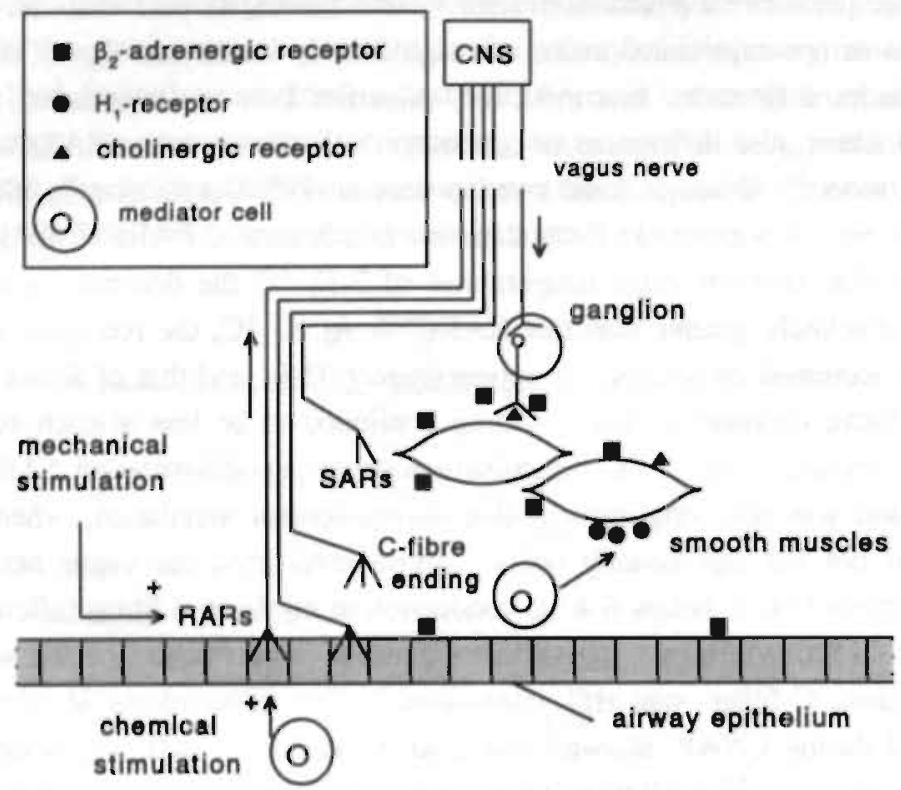

Figure 7.2 Schematic representation of airway epithelium. Pulmonary mechanoreceptors (RARs, SARs and C-fibre endings) with vagal afferents are shown, as well as ainway smooth muscles with several chemoreceptors. Ainway smooth muscles are activated by histamine (mediator cell) and via vagal reflex (by stimulation of RARs). CNS, central nervous system.

Patberg ${ }^{2 \pi}$ has also found ETLA in response to a lowered tracheal pressure in rabbits. One of his conclusions is that, with vagus nerves at normal temperature, ETIA can be increased by refiexes mediated by the vagus nerves. Further, he found at a vagus termperature of $8{ }^{\circ} \mathrm{C}$ an increase in ETIA not only at lowered but also at increased. tracheal pressure. He discussed two possible mechanisms to explain these results. Assuming that the cold block at $8{ }^{\circ} \mathrm{C}$ is complete for all myelinated fibres, the reflex effects must be due to stimulation of non-myelinated fibres. It was argued that if the cold block were not complete an increase in ETIA should be attributed to a decreased level of SAR activity. Our experiments in cats (chapters 2 and 3 ) showed that only when the vagus nerves were cooled below $4{ }^{\circ} \mathrm{C}$ no ETIA was found. This indicates that non-myelinated $\mathrm{C}$-fibres were not involved in the generation of ETIA. We agree with Patberg that at $8{ }^{\circ} \mathrm{C}$ activity of SARs is markedly reduced. However, a disinhibition of inspiratory activity due to a diminished lung volume at lowered tracheal pressure cannot explain his results sufficiently. E.g., it does not explain why ETIA disappeared after vagotomy. Patberg ${ }^{28}$ suggested that besides a reduced SAR activity 
other receptors may be involved. Our results indicate that at $8^{\circ} \mathrm{C}$ RARs may still be stimulated by deflations and inflations (CNAP and CPAP, respectively). This RAR activity together with the abolished SAR activity can explain the presence of ETIA at this temperature. Our results further show that at a normal vagus temperature increased activity of SARs may mask or reduce ETIA. This is further confirmed by our findings that in some experiments at vagus temperatures $\left(14-8{ }^{\circ} \mathrm{C}\right)$ at which SAR activity is likely to be diminished, ETIA was even enhanced by application of CPAP (Fig. 3.2).

Martin et al. ${ }^{23}$ suggested that during histamine-induced bronchoconstriction in humans inspiratory muscles are active during expiration. Muller et al. ${ }^{25}$ studied this so called 'tonic' inspiratory activity during expiration by recording EMGs of the diaphragm and ICM. Their results confirmed that there is an increase in end-tidal inspiratory muscle activity during histamine-induced bronchoconstriction. It was suggested that the persistent inspiratory activity during expiration was a determinant of histamineinduced hyperinflation. Muller et al. ${ }^{25}$ reported that if lung volume was elevated 1 litre above FRC by positive end-expiratory pressure, no 'tonic' inspiratory activity was observed any more. This is in agreement with our findings in cats where at a normal vagus temperature histamine-induced ETIA was suppressed during CPAP. This can be explained by the inhibiting effect of SAR activity on ETLA. During CPAP and if lung volume is increased above FRC, SARs are stimulated and thus ETIA will be reduced or abolished.

The model conceming the mechanism underlying ETLA that we found for cats was extrapolated to humans. Histamine and CNAP are stimuli known to activate RARs in animals $^{32,33}$. Vagal reflex effects found in animal studies are also found in humans, including the Breuer-Hering reflexes and responses to histamine and irritant agents ${ }^{5}$. Studies in humans have demonstrated that expiration is prolonged through passive lung inflation ${ }^{16,15}$. It has been shown in dogs that this reflex is mediated by the vagus nerves ${ }^{4}$. After bilateral lung transplantation expression of this Breuer-Hering reflex in humans is abolished ${ }^{16}$. This indicates that intact vagus nerves are necessary for this reflex. In humans we found that during CPAP the duration of inspiration was shortened, the duration of expiration was prolonged and FRC was increased (unpublished data from our laboratory). Further, we showed that inhalation of histamine and application of CNAP evoked ETLA in man similar to what we found in cats. Thus, as responses to these stimuli in animals and humans are similar, it is very likely that the underlying mechanisms are similar too. 


\subsection{ORIGIN OF END-TIDAL INSPIRATORY ACTIVITY}

We have studied ETIA under different conditions: at control, after i.v. administration of histamine at normal and elevated airway pressures, and during CNAP. These experiments were repeated at different temperatures of the vagus nerves and after vagotomy. RARs are stimulated by intravenous administration of histamine and CNAP. Stimulation of RARs by histamine was combined with additional stimulation of SARs by CPAP. To differentiate between reflex activities from the three types of lung receptors (RARs, SARs and $\mathrm{C}$-fibre endings) both vagus nerves were cooled. The model derived from our experiments in cats (chapters 2 and 3 ) is depicted in Figure 3.5. The primary cause for ETIA to occur in our experiments was the excitation of inspiratory motoneurons by stimulation of RARs. The amplitude of ETIA was modulated by SAR activity through inhibition of inspiratory activity. Further, our experiments with vagal cooling and vagotomy showed that $\mathrm{C}$-fibre endings are not involved in the generation of ETIA.

In the literature, end-tidal electrical activity of inspiratory muscles, just prior to the phasic increase in inspiratory activity, is mostly called tonic inspiratory activity 3.23 .25 . Initially, we adopted the term tonic inspiratory activity, to describe the phenomenon of inspiratory activity at end of expiration (chapters 2 and 4). From our analysis of the origin of histamine-induced ETIA (chapter 3) we learnt that the origin of ETIA is more complex and cannot be described fully by the term 'tonic'. It has been argued in chapter 3 that the magnitude of ETIA may also be influenced by tE and the time constant of the decay of the inspiratory activity $(\tau)$. When the ratio $\mathrm{tE} / \tau$ is decreased, the delayed decay of inspiratory activity will also affect the magnitude of ETIA. In chapter 3 , however, it was shown that the incomplete decay of inspiratory activity during expiration plays a minor role in histamine-induced and CNAP-induced ETIA.

Figure 7.3 is a schematic representation of different models which may explain the generation of ETIA. For 4 different conditions (panels I-IV) EMG activity of inspiratory muscles during expiration (e) and during the subsequent inspiration (i) is shown. In Figure 7.3 (panel I) EMG activity retums to the baseline value (BL) during expiration, thus no ETIA remains.

If the ratio $t E / \tau$ is decreased, e.g. due to decrease in $t E$, the subsequent inspiration may already start while inspiratory activity may not have reached the baseline value during the previous expiration (Figure 7.3, panel II). This will result in ETIA. It was found that this factor is not very important both during CNAP and during histamine challenge (chapter 3 ).

ETIA can be evoked if RARs are stimulated continuously (Figure 7.3, panel III). This part of Figure 7.3 reflects the situation where RARs are stimulated tonicly 

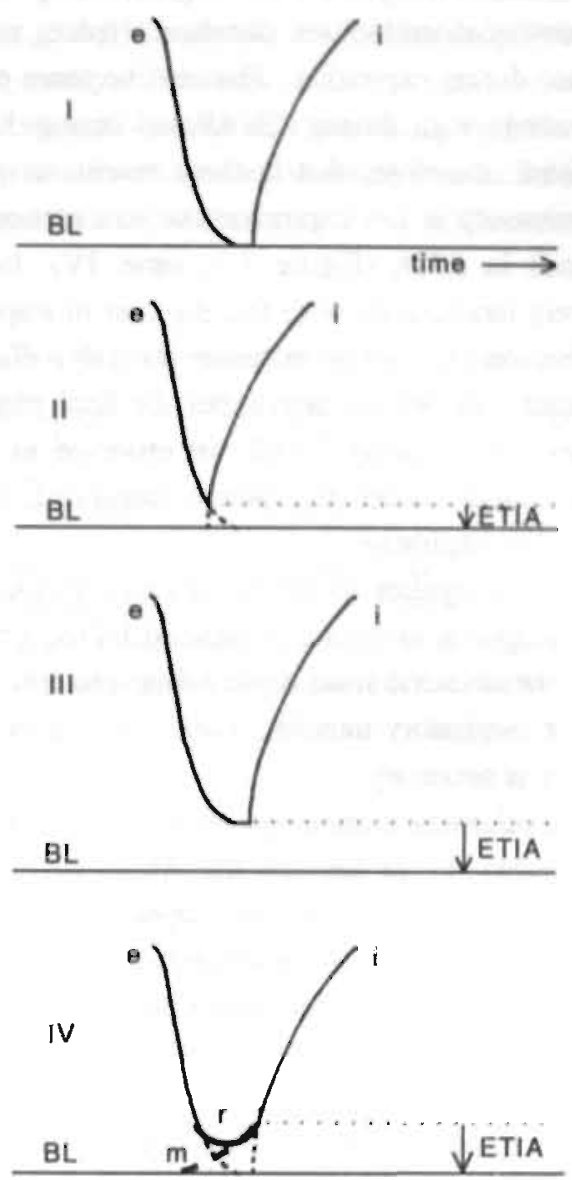

Figure 7.3. Schematic representation of different models involved in end-tidal inspiratory activity (ET/4). EMG activity of inspiratory muscles is shown during expiration (e) and during subsequent inspiration (i). Panel I: Inspiratory activity has retumed to baseline (BL) during expiration. No ETIA present. Panel II: inspiration starts before inspiratory activity reached BL during expiration. Panel III: Continuous and equal stimulation of RARs leading to 'tonic' inspiratory activity in late expiration. Panel IV: Inspiratory activity increases in late expiration due to enhanced mechanical stimulation of RARs $(m)$ leading to ETLA. r, resultant EMG. BL. refers to the electrical zero. For further explanation see text. 
throughout expiration leading to a constant level of inspiratory activity at end expiration.

It can be argued, however, that RARs do not discharge tonically during expiration. As expiration continues, airway diameter will decrease. Hence, mechanical stimulation of RARs may increase during expiration. This will be more pronounced when airways are already narrowed, e.g. during CNAP or during histamine-induced bronchoconstriction. We think, therefore, that in those conditions reflex inspiratory activity may increase progressively in late expiration due to increasing stimulation of RARs which will also result in ETIA (Figure 7.3, panel IV). In this last model stimulation of RARs is purely mechanical. Note that the start of inspiration is defined as the moment at which inspiratory activity increases abruptly. The resultant EMG activity from several different mechanisms determines the final magnitude of ETIA (Figure 7.3, panel IV, curve ' $r$ '). During CNAP we observed in some cats EMG activity which closely resembled model IV, where integrated inspiratory EMG activity actually increased in late expiration.

One could argue that model IV applies to CNAP induced ETIA whereas a combination of model III and IV applies to histamine-induced ETIA. From these models it is clear that ETIA cannot be obtained from curve fitting procedures of the descending part of the EMG of the inspiratory muscles. Therefore, the measurement of the actual end-tidal EMG activity is necessary.

ETIA can be evoked by mechanical stimulation of RARs during CNAP in cats (chapter 2) and humans (chapter 4). In humans stimulation of RARs by bronchoconstriction (i.e. mechanical stimulation of RARs) appeared to be more important than direct chemical stimulation of RARs by histamine (chapter 5). It can be concluded, therefore, that mechanical stimulation of RARs plays a more important role in the generation of ETIA than chemical stimulation of RARs.

\subsection{HISTAMINE AND BREATHING PATTERN}

It has been shown that pulmonary stretch receptors can influence the breathing pattem $^{24.31}$. Our experiments in humans and animals showed that on average breathing frequency (f) increased in response to histamine, Tables 6.2 and 7.1, respectively. It can be argued that the histamine-induced increase in $f$ and $\dot{V}_{E}$ are, at least in part, due to a vagal reflex in which RARs are involved. In about fifty percent of the cases, however, minute ventilation $\left(\dot{V}_{\mathrm{E}}\right)$ was not increased in response to administration of histamine. We think that this non-uniform response of $\dot{V}_{\mathrm{E}}$ to histamine can be explained by the histamine-induced airflow limitation and increased airway resistance. Accordingly, the occurrence of a decreased $\dot{\mathrm{V}}_{\mathrm{E}}$ was relatively more frequent in the 
subjects who showed bronchial hyperresponsiveness (Table 6.3). The non-uniform effects of histamine on $\mathrm{V}_{\mathrm{T}}$ may be explained in the same way. Increases and decreases in $\dot{V}_{E}$, therefore, may occur depending on the contribution of factors which will increase $\dot{V}_{\mathrm{E}}$ (e.g. by stimulation of RARs) and decrease $\dot{\mathrm{V}}_{\mathrm{E}}$ (e.g. histamineinduced increase in airway resistance).

The similarity of results in humans and cats concerning the effects of stimulation of airway receptors by histamine on the breathing pattern lends support to the assumption that underlying mechanisms are the same for both species.

Table 7.1 Effects of histamine on respiratory variables in cats.

\begin{tabular}{llll}
\hline & $f(/ m i n)$ & $V_{T}(m l)$ & $\dot{V}_{f}(l / m i n)$ \\
\hline Control & $37.5(4.9)$ & $41.9(3.4)$ & $1.51(0.18)$ \\
Histamine & $49.3(6.4)^{*}$ & $37.4(4.3)$ & $1.76(0.20)$ \\
\hline
\end{tabular}

Data presented are means $\pm S E$ obtained from 7 cats during control and after intravenous administration of $300 \mu \mathrm{g}$ histamine. Temperature of the cervical vagus nerves was $37{ }^{\circ} \mathrm{C}$. Asterisks refer to statistical comparison (histamine versus control) using the t-test for paired observations; **, p<0.01. For experimental protocol see chapter 3.

\subsection{HYPERINFLATION AND ASTHMA}

Hyperinflation and bronchoconstriction are characteristics of asthma. With an increased airway smooth muscle tone there is a greater tendency to airway closure, which is opposed by an increased distending force on the airways due to the recoil of surrounding lung tissue. Although airway closure probably contributes to an increase in end-tidal lung volume, the flow limitation is not the sole explanation. ETIA is considered as another factor which contributes to hyperinflation ${ }^{1721,22}$. Muller et all. ${ }^{25}$ showed a significant correlation between the increase in lung volume and ETIA. Hyperinflation is considered disadvantageous to inspiratory muscle function ${ }^{10}$. Ninane and Gorini ${ }^{26}$ showed in dogs that hyperinflation affects the action of the ICM. Rib elevating activity was decreased, whereas the action on the sternum was increased. Hence, the force to inflate the lungs was reduced. Although mechanical disadvantages of hyperinflation for ICM are less than for the diaphragm ${ }^{79.18}$ the inflationary force of both the diaphragm and ICM were reduced ${ }^{26}$.

In humans we observed an increase in FRC in response to inhalation of histamine. It was shown that both ETIA and bronchoconstriction (expiratory flow limitation) were involved in evoking hyperinflation. It was found that bronchoconstriction was the more important factor. 
ETIA is primarily evoked by stimulation of RARs. Stimulation of RARs also increases airway smooth muscle tone. The concomitant bronchoconstriction will, in turn, stimulate RARs. This suggests a positive feedback mechanism. The simultaneous occurrence of hyperinflation, however, will interfere with this mechanism because increased lung volume reduces mechanical stimulation of RARs and, in addition, increases SAR activity. These changes in RAR and SAR activity will result in decreased levels of ETIA as was shown in our experiments with cats.

Although ETIA may not be the most important factor in the generation of hyperinflation, it may contribute to muscle fatigue and thus to respiratory failure during exacerbations of asthma. We think, therefore, that the often applied therapeutical method of intentionally lengthening the duration of expiration which may reduce FRC is not indicated in asthmatics as this may result in reflex bronchoconstriction and ETIA by stimulation of RARs. On the contrary, our results indicate that it might be more useful to increase FRC, e.g. by application of CPAP. This will reduce stimulation of RARs. Thus, application of CPAP may facilitate breathing in asthmatics during exacerbations by decreasing both airway resistance and ETIA. It might be worthwhile, therefore, to evaluate this hypothesis in future investigations.

\subsection{REFERENCES}

1. Adrian ED (1933). Afferent impulses in the vagus and their effect on respiration. J Physiol (Lond) 79: 332-358.

2. Armstrong DJ and Luck JC (1974). A comparative study of irritant and type J receptors in the cat. Respir Physiol 21: 47-60.

3. Badier M, Jammes Y, Romero-Colomer P and Lemerre C (1989). Tonic activity in inspiratory muscles and phrenic motoneurons by stimulation of vagal afferents. I Appl Physiol 66: 1613-1619.

4. Breuer J (1868). Die Selbststeuerung der Athmung durch den Nervus vagus. Sitzungsber Akad Wiss Wien 58: 909-937.

5. Coleridge HM and Coleridge JCG. Reflexes evoked from tracheobronchial tree and lungs. In: Handbook of Physiology, The Respiratory System, Control of Breathing, Vol. II, edited by Cherniack NS and Widdicombe JG. Bethesda, MD: American Physiological Society, 1986, p. 395-429.

6. Coleridge HM, Coleridge JCG and Roberts AM (1983). Rapid shallow breathing evoked by selective stimulation of airway C-fibres in dogs. J Physiol (Lond) 340: 415-433.

7. Decramer M (1989). Effects of hyperinflation on the respiratory muscles. Eur Respir J 2: 299-302.

8. Decramer M. Effects of hyperinflation on respiratory muscle function. In: Chronic pulmonary hyperinflation, edited by Grassino A, Rampulla C, Ambrosino $\mathrm{N}$ and Fracchia C. London: Springer-Verlag, 1991, p. 83-89. 
9. Decramer M, Jiang TX and Demedts M (1987). Effects of acute hyperinflation on chest wall mechanics in dogs. J Appl Physiol 63: 1493-1498.

10. Demedts M (1990). Mechanisms and consequences of hyperinflation. Eur Respir J 3: 617-618.

11. Franz DN and Iggo A (1968). Conduction failure in myelinated and non-myelinated axons at low temperatures. J Physiol (Lond) 199: 319-345.

12. Grinten van der CPM, Vries de WR and Luijendijk SCM (1992). Vagally mediated modification of inspiratory activity by changes in airway pressure. Respir Physiol 90: 159-172.

13. Guz A and Trenchard DW (1971). The role of non-myelinated afferent fibres from the lungs in the genisis of tachypnoea in the rabbit. J Physiol (Lond) 213: 345-371.

14. Hamitton RD, Homer RL, Winning AJ and Guz A (1990). Effect on breathing of raising end-tidal lung volume in sleeping laryngectomized man. Respir Physiol 81: 87-98.

15. Hamilton RD, Winning AJ, Horner RL and Guz A (1988). The effect of lung inflation on breathing in man during wakefulness and sleep. Respir Physiol 73: 145-154.

16. Iber C, Simon P, Skatrud JB, Mahowald MW and Dempsey JA (1995). The BreuerHering reflex in humans. Am J Respir Crit Care Med 152: 217-224.

17. Jammes $\mathbf{Y}$ and Badier $\mathbf{M}$. Hyperinflation due to tonic activity in inspiratory muscles. In: , edited by Grassino A, Rampulla $\mathrm{C}$, Ambrosino $\mathrm{N}$ and Fracchia $\mathrm{C}$. London: SpringerVerlag, 1991, p. 75-89.

18. Jiang TX, Deschepper K, Demedts $\mathbf{M}$ and Decramer $\mathbf{M}$ (1989). Effects of acute hyperinflation on the mechanical effectiveness of the parasternal intercostals. Am Rev Respir Dis 139: 522-528.

19. Jonzon A, Pisarri TE, Roberts AM, Coleridge JCG and Coleridge HM (1988). Attenuation of pulmonary afferent input by vagal cooling in dogs. Respir Physiol 72: 19-34.

20. Karisson J-A, Sant'Ambrogio G and Widdicombe JG (1988). Afferent neural pathways in cough and reflex bronchoconstriction. J Appl Physiol 65: 1007-1023.

21. Macklem PT (1984). Hyperinflation. Am Rev Respir Dis 129: 1-2.

22. Martin JG, Habib M and Engel LA (1980). Inspiratory muscle activity during induced hyperinflation. Respir Physiol 39: 303-313.

23. Martin JG, Powell E, Shore SA, Emrich J and Engel LA (1980). The role of respiratory muscles in the hyperinflation of bronchial asthma. Am Rev Respir Dis 121: 441-447.

24. Millman RP, Silage DA, Peterson DD and Pack AI (1982). Effect of aerosolized histamine on occlusion pressure and ventilation in humans. J Appl Physiol 53:690-697.

25. Muller N, Bryan AC and Zamel N (1980). Tonic inspiratory muscle activity as a cause of hyperinflation in histamine-induced asthma. J Appl Physiol : Respirat Environ Exercise Physiol 49: 869-874.

26. Ninane V and Gorini $M$ (1994). Adverse effect of hyperinflation on parasternal intercostals. J Appl Physiol 77: 2201-2206.

27. Paintal AS (1992). Vagal afferent fibres. Ergebnisse der Physiologie 52: 75-156.

28. Patberg WR (1983). Effect of graded vagal blockade and pulmonary volume on tonic inspiratory activity in rabbits. Pflügers Arch 398: 88-92.

29. Pisarri IE, Yu J, Coleridge HM and Coleridge JCG (1986). Background activity in pulmonary vagal $\mathrm{C}$-fibers and its effects on breathing. Respir Physiol 64: 29-43.

30. Sant'Ambrogio G (1982). Information arising from the tracheobronchial tree of mammals. Physiol Rev 62: 531-569. 
31. Savoy J, Allgower E, Courteheuse C and Junod AF (1984). Ventilatory response to bronchospasm induced by methacholine and histamine in man. Respir Physiol 56: 195-203.

32. Sellick $H$ and Widdicombe JG (1970). Vagal deflation and inflation reflexes mediated by lung irritant receptors. Q J Exp Physiol 55: 153-163.

33. Sellick H and Widdicombe JG (1971). Stimulation of lung irritant receptors by cigarette smoke, carbon dust, and histarnine aerosol. J Appl Physiol : Respirat Environ Exercise Physiol 31: 15-19.

34. Sibuya M, Kanamaru A and Homma I (1993). Inspiratory prolongation by vagal afferents from pulmonary mechanoreceptors in rabbits. Jpn J Physiol 43: 669-684.

35. Widdicombe JG (1954). Receptors in the trachea and bronchi of the cat. J Physiol (Lond) 123: 71-104. 
8

Summary 
Important characteristics of acute asthma are bronchoconstriction and hyperinflation. Hyperinflation can be considered to be disadvantageous to inspiratory muscle function. Martin et al. ${ }^{i}$ have shown that during histamine-induced hyperinflation the end-tidal pleural pressure was lower than the predicted chest wall relaxation pressure at the corresponding end-tidal lung volume, indicating end-tidal activity of inspiratory muscles. Muller et al. ${ }^{2}$ observed end-tidal activity of inspiratory muscles after administration of histarnine. These authors further showed a linear relationship between end-tidal thoracic gas volume and the activity of inspiratory muscles in response to histamine. Both flow limitation and end-tidal inspiratory activity are considered to be causes of hyperinflation during exacerbations of asthma and during histamine-induced bronchoconstriction. Studies in cats and rabbits have shown that lowering tracheal pressure can also evoke end-tidal inspiratory activity. In the literature, the end-tidal electrical activity of inspiratory muscles is usually called tonic inspiratory activity.

Three types of pulmonary stretch receptors are distinguished: 'rapidly adapting pulmonary receptors (RARs), 'slowly adapting pulmonary receptors (SARs) en 'Cfibre endings' which are described in more detail in chapter 1. These receptors are connected to the respiratory centres by afferents in the vagus nerves.

The aim of the studies was to answer the following questions: What are the mechanisms underlying end-tidal inspiratory activity? What is the role of the three types of pulmonary stretch receptors in evoking end-tidal inspiratory activity? What is the contribution of end-tidal inspiratory activity to the histamine-induced increase in end-tidal lung volume? What effects have bronchodilating agents on the end-tidal inspiratory activity?

Initially we adopted the term 'tonic inspiratory activity' from the literature. During our study it appeared, however, that the origin of this so called tonic inspiratory activity is more complex than the term 'tonic' suggests. We prefer, therefore, to use the term 'end-tidal inspiratory activity' (ETLA).

The physiological mechanisms causing ETIA were largely unknown when we started this study. The roles of the three types of pulmonary receptors -RARs, SARs and Cfibre endings- in generating ETIA were studied in anaesthetized spontaneously breathing cats. Impulse conduction in the afferent fibres of these receptors can be affected selectively by cooling the vagus nerves. In this way the reflex effects of the different receptors on ETIA were studied. Roughly, this means that the reflexes of 
SARs disappear at a temperature of the vagus nerves (Tvg) below $8{ }^{\circ} \mathrm{C}$ and those of RARs below $4{ }^{\circ} \mathrm{C}$ and those of $\mathrm{C}$-fibres at $0{ }^{\circ} \mathrm{C}$. Electromyograms (EMGs) of inspiratory muscles (parasternal intercostal muscles and the diaphragm) were recorded with needle electrodes. To induce ETIA in the animals we applied two different stimuli: continuous negative airway pressure (CNAP) and intravenous administration of histamine. We have evaluated only the experiments of animals in which ETIA was observed. During CNAP RARs are stimulated mechanically whereas histamine stimulates RARs in two ways: mechanically due to the bronchoconstriction and chemically.

Effects of CNAP in cats are presented in chapter 2. It was found that CNAP is a forceful stimulus to induce ETIA in cats. CNAP is a stimulus known to activate RARs mechanically. At Tvg below $6{ }^{\circ} \mathrm{C}$ and after vagotomy CNAP did not induce ETIA any more.

In chapter 3 the effects of administration of histamine in cats are described. Histamine was used to stimulate RARs and this was combined with continuous positive airway pressure (CPAP) to further stimulate SARs. Ai a vagus temperature of $37{ }^{\circ} \mathrm{C}$ CPAP largely suppressed histamine-induced ETIA. This suppression diminished between 14 and $8{ }^{\circ} \mathrm{C}$. ETIA sharply declined for Tvg between 8 and 4 ${ }^{\circ} \mathrm{C}$, and at Tvg $=4^{\circ} \mathrm{C}$ ETIA had virtually disappeared. After vagotomy neither histamine nor CNAP evoked ETIA any more. The experiments during vagal cooling and after vagotomy showed that C-fibre endings are not involved in evoking ETIA. The experiments in cats indicated that excitation of inspiratory motoneurons by stimulation of RARs is the primary cause of ETIA. During CPAP histamine-induced ETIA was reduced or even completely abolished by stimulation of SARs. Thus, histamine-induced ETIA originates from stimulation of RARs and is inhibited by stimulation of SARs.

Evaluation of the experiments with histamine in cats indicated that the magnitude of ETIA also depends on the decay of inspiratory activity during expiration. Especially the magnitude of the ratio of the duration of expiration and the time constant of this decay is involved. It was shown, however, that this contribution to ETIA is modest.

After the underlying mechanisms of ETIA were clarified, we studied ETIA in human subjects. The experimental protocol aimed at estimating ETIA and the concomitant changes in FRC. EMGs of inspiratory muscles obtained from surface electrodes were analyzed, and the changes in the lung volume were assessed with use of a closed breathing circuit. The same stimuli (CNAP and histamine) were used as in our studies with experimental animals.

In chapter 4 the results of the experiments with CNAP in humans are presented. Also in humans CNAP appears to be a forceful stimulus to induce ETIA in the diaphragm and in ICM.

In chapter 5 the effects in humans of inhalation of histamine on ETIA and FRC are 
presented. The contributions of ETIA and flow limitation to the histamine-induced increase in end-tidal lung volume were quantified as well as the contribution of mechanical stimulation of RARs to ETIA. To that end, humans were challenged with histamine both before and after administration of a bronchodilator which should prevent mechanical stimulation of RARs. After inhalation of salbutamol $(600 \mu \mathrm{g})$ ETIA, evoked by inhalation of histamine (PC20), was reduced to about one fourth of pre-salbutamol values and the increase in FRC was about one eighth of that before salbutamol. Hence, ETIA was evoked by both mechanical and chemical stimulation of RARs. Mechanical stimulation due to contraction of bronchial smooth muscles appeared to be the more important factor. FRC increased in response to histamine due to both flow limitation and ETIA. A substantial part of the increase in FRC may be attributed to ETIA.

In chapter 6 the responses of several respiratory variables to histamine are described. Both in humans and cats administration of histamine caused an increase in breathing frequency. Only in part of the human subjects this increase in breathing frequency was accompanied by an increase in minute ventilation. Our results indicate that this may be explained by the concomitant bronchoconstriction which leads to an increased airway resistance and flow limitation.

In chapter 7 a model is presented which summarizes the main findings of this study.

End-tidal inspiratory activity may be considered to be unfavourable for inspiratory muscles. Further, ETIA limits the expiration which leads to hyperinflation. This may cause an unfavourable shift on the force-length curve of the diaphragm. As inspiratory muscles in the case of elevated ETIA contract more or less continuously, blood flow may also be diminished which may contribute to muscle fatigue and thus to respiratory failure during exacerbations of asthma. This implies that elimination of bronchoconstriction in asthma may be favourable for several reasons. Brochodilation will decrease airway resistance which, in turn, results in a decrease in mechanical stimulation of RARs with a concomitant disappearance of ETIA.

1. Martin JG, Powell E, Shore SA, Emrich J and Engel LA (1980). The role of respiratory muscles in the hyperinflation of bronchial asthma. Am Rev Respir Dis 121: 441-447.

2. Muller N, Bryan AC and Zamel N (1980). Tonic inspiratory muscle activity as a cause of hyperinflation in histamine-induced asthma. J Appl Physiol : Respirat Environ Exercise Physioll 49: 869-874. 
Samenvatting 
Karakteristieke kenmerken van een exacerbatie van astma zijn bronchoconstrictie en hyperinflatie. Hyperinflatie wordt beschouwd als ongunstig voor de werking van de inspiratiespieren. Martin et al. ${ }^{1}$ toonden aan dat tijdens histamine-geïnduceerde hyperinflatie de eind-expiratoire pleuradruk meer negatief was dan op grond van de relaxatiedruk van de thoraxwand bij een corresponderend longvolume te verwachten was. Zij schreven dit toe aan de aanwezigheid van inspiratie-activiteit aan het einde van de expiratie (end-tidaj). Ook Muller et al. ${ }^{2}$ vonden aanwijzingen voor de aanwezigheid van end-tidal inspiratie-activiteit na toediening van histamine. Tevens vonden zij een lineair verband tussen het end-tidal thoracaal gasvolume en de activiteit van inspiratiespieren. Deze end-tidal inspiratie-activiteit wordt in de literatuur tonische inspiratie-activiteit genoemd. Zowel bronchoconstrictie als end-tidal inspiraticactiviteit worden gezien als corzaak voor hyperinflatie tijdens exacerbaties van astma of tijdens histamine-geïnduceerde bronchoconstrictie.

In longen en luchtwegen bevinden zich rek-gevoelige receptoren, die via de nervus vagus verbonden zijn met de ademhalingscentra. Men onderscheidt: 'rapidly adapting pulmonary receptors (RARs), slowty adapting pulmonary receptors (SARs) en 'Cfibre endings'. Een meer gedetailleerde beschrijving van de receptoren is gegeven in hoofdstuk 1 .

Vraagstellingen van het onderzoek beschreven in dit proefschrift zijn: Wat is het mechanisme dat ten grondslag ligt aan de end-tidal inspiratie-activiteit? Wat is de rol van de verschillende typen longreceptoren bij de totstandkoming van dit verschijnsel? In welke mate draagt end-tidal inspiratie-activiteit bij tot de toename van het eindexpiratoire longvolume? Welke effecten hebben bronchusverwijdende farmaca op de end-tidal inspiratie-activiteit?

Aanvankelijk werd de term 'tonische inspiratie-activiteit' overgenomen uit de literatuur. Tijdens het onderzoek bleek dat de oorzaak van de end-tidal inspiratieactiviteit complexer is dan de term 'tonische inspiratie-activiteit' suggereert. Daarom is de voorkeur gegeven aan de term 'end-tidal inspiratie-activiteit' (ETLA).

Ten aanzien van de opheldering van het mechanisme dat ten grondslag ligt aan ETIA, werd gebruik gemaakt van een diermodel. De experimenten werden uit-gevoerd in genarcotiseerde spontaan ademende katten. Het electromyogram (EMG) van inspiratiespieren (parasternale intercostaal spieren en diafragma) werd gemeten m.b.v. naaldelectrodes. Het onderzoek naar de functie van RARs, SAR's en C-fibre endings bij de totstandkoming van ETLA vormde een essentieel onderdeel van deze studie. Door middel van koelen van de nervus vagus werden de bijdragen van de verschillende typen receptoren op ETIA selectief bestudeerd. Ruwweg komt dit erop 
neer, dat de reflexen van SARs niet meer worden waargenomen bij een temperatuur van de nervus vagus (Tvg) onder $8{ }^{\circ} \mathrm{C}$ en die van RARs onder $4{ }^{\circ} \mathrm{C}$ en die van $\mathrm{C}$ fibres bij $0{ }^{\circ} \mathrm{C}$. Om bij de proefdieren ETLA op te wekken werden twee typen stimuli toegepast: 'continuous negative airway pressure' (CNAP) en intraveneuze toediening van histamine. Alleen de resultaten van de proefdieren waarin na stimulatie ETLA. ontstond, werden geëvalueerd.

De resultaten van CNAP bij katten zijn beschreven in hoofdstuk 2. Het bleek dat CNAP een adequate stimulus is om ETIA te induceren bij katten. CNAP kan beschouwd worden als een mechanische stimulus van RARs. Bij een Tvg lager dan 6 ${ }^{\circ} \mathrm{C}$ en na vagotomie was CNAP niet meer in staat ETIA op te wekken.

De resultaten van stimulatie met histamine bij katten zijn beschreven in hoofdstuk 3 . Histamine werd toegediend om RARs te stimuleren. Dit werd gecombineerd met 'continuous positive airway pressure' (CPAP) om additioneel ook de SARs te stimuleren. Bij een Tvg van $37{ }^{\circ} \mathrm{C}$ onderdrukte CPAP de histamine-geìnduceerde ETIA terwijl deze suppressie verdween tussen 14 en $8{ }^{\circ} \mathrm{C}$. Bij Tvg tussen 8 en $4^{\circ} \mathrm{C}$ werd een scherpe afname in ETIA waargenomen en bij een $\mathrm{Tvg}=4{ }^{\circ} \mathrm{C}$ was ETIA nagenoeg verdwenen. Na vagotomie kon met histamine geen ETIA meer worden geïnduceerd. De experimenten in katten toonden aldus aan dat excitatie van inspiratoire motoneuronen door stimulatie van RARs de primaire oorzak van ETIA is. De experimenten met vagale koeling en vagotomie toonden aan dat de $\mathrm{C}$-fibre endings niet betrokken zijn bij het opwekken van ETIA. Tijdens CPAP was de door histamine geïnduceerde ETIA gereduceerd of zelfs geheel verdwenen. Dit kan worden toegeschreven aan stimulatie van SARs tijdens CPAP en hun inhiberende werking op ETLA. Uit analyse van de histamine-provocatie experimenten bij katten bleek dat de grootte van ETIA ook afhangt van het verval van de inspiratie-activiteit tijdens de expiratie-fase. Met name de grootte van de ratio van de expiratieduur en de tijdconstante van dit verval speelt daarbij een rol. Uit de experimenten met katten bleek echter, dat het niet volledige verval van de inspiratie-activiteit slechts een geringe bijdrage levert aan de grootte: van ETIA.

Naclat het mechanisme van ETIA was opgehelderd, werd ETLA bestudeerd bij de mens. Essentieel hierbij was het ontwikkelen van een methode om ETIA en de hieruit voortkomende longvolume-veranderingen te kunnen meten. ETIA werd geanalyseerd uit EMGs geregistreerd m.b.v. oppervlakte-electrodes. Veranderingen in het longvolume: als gevolg van de toegediende stimuli (CNAP en histamine) werden gemeten met een gesloten spirometersysteem.

De resultaten van de experimenten bij de mens met CNAP zijn beschreven in hoofdstuk 4. Ook uit de humane experimenten is gebleken dat CNAP een krachtige stimulus is om ETIA op te wekken in de intercostaalspieren en het diafragma.

In hoofdstuk 5 zijn de resultaten weergegeven van de experimenten met histamine bij de mens. ETIA werd waargenomen na inhalatie van histamine. De functionele 
residuale capaciteit (FRC) bleek toe te nemen als respons op histamine. Om de effecten van histamine te bestuderen zonder de aanwezigheid van bronchoconstrictie werden de experimenten herhaald na toediening van een $\mathrm{B}_{2}$-agonist (salbutamol). $\mathrm{Na}$ toediening van salbutamol was de door histamine opgewekte ETIA slechts $1 / 4$ van de ETIA voor salbutamol en was de toename in FRC ongeveer $1 / 6$ van die voor salbutamol. De toename in FRC na histamine werd veroorzaakt door ademstroomlimitatie en door ETLA. ETIA was verantwoordelijk voor een substantiële bijdrage in de toename in FRC na histamine.

In hoojdstuk 6 zijn de effecten van histamine op een aantal ademhalingsparameters beschreven. Veranderingen in het adempatroon (ademfrequentie, teugvolume en adem-minuutvolume) ten gevolge van histamine blijken niet uniform te zijn. Zowel stimulatie van RARs als de aanwezigheid van bronchoconstrictie blijken een rol te spelen bij het effect van histamine op het adem-minuutvolume.

In hoofdstuk 7 zijn bovengenoemde bevindingen in een model weergegeven. De belangrijkste kenmerken van dit model zijn dat ETIA wordt opgewekt door stimulatie van RARs en wordt geïnhibeerd door stimulatie van SARs.

ETIA kan als ongunstig beschouwd worden voor de ademhaling. Immers, ETLA limiteert de expiratie mede waardoor hyperinflatie ontstaat. Hierdoor wordt de werking van m.n. het dianagma ongunstig bemvloed door de verschuiving op de kracht-lengte relatie van de spier. Obo de doorbloeding van de inspiratiespieren kan ongunstig beïnvloed worden doordat de inspiratiespieren min of meer continu contraheren. Hierdoor treedt mogelijk eerder vermoeidheid op van de ademhalingsspieren. Het éen en ander betekent dat het opheffen van de bronchoconstrictie bij astma om meerdere redenen belangrijk is. Enerzijds zal door bronchodilatatie de luchtwegweerstand verminderen en anderzijds zal de stimulatie van RARs afnemen met als gevolg afname/verdwijnen van ETIA. Hierdoor zal dan eveneens de hyperinilatie afnemen.

1. Martin JG. Powell E, Shore SA, Emrich J and Engel LA (1980). The role of respiratory muscles in the hyperinflation of bronchial asthma. Am Rev Respir Dis 121: $441-447$.

2. Muller N, Bryan AC and Zamel N (1980). Tonic inspiratory muscle activity as a cause of hyperinflation in histamine-induced asthma. J Appl Physiol : Respirat Environ Exercise Physiol 49: 869-874. 


\section{DANKWOORD}

Graag wil ik bedanken, al degenen die op enigerlei wijze hebben bijgedragen aan de totstandkoming van dit proefschrift.

Dit geldt niet in het minst voor de patiēnten en gezonde vrijwilligers die aan dit onderzoek meewerkten.

Prof.dr. S.C.M. Luijendijk, Sybrand, de samenwerking en discussies met jouw heb ik steeds als zeer vruchtbaar ervaren. Bedankt voor je niet nalatende betrokkenheid bij dit onderzoek.

Prof.dr. H.Th.M. Folgering, Hans, dank voor de medewerking bij het onderzoek en voor de vele enthousiaste beschouwingen over longfunctie-metingen.

Dr.ir. C.P.M. van der Grinten, Chris, voor de uitvoering van de dierexperimenten en de data-acquisitie waren meer dan twee handen nodig. Dank voor jouw hulp hierbij. Sybrand, Hans en Chris, dank voor de waardevolle adviezen bij het vervaardigen van de manuscripten.

Dank aan de medewerkers van de afdeling Centrale Proefdiervoorzieningen van de Rijksuniversiteit Limburg (hoofd drs. A.J.E.M. van de Bogaard) voor de huisvesting en verzorging van de proefdieren.

Laboranten van de afdeling longfunctie van het Universitair Longcentrum Nijmegen, lokatie Dekkerswald, steeds kon ik een beroep op jullie doen. Zeer bedankt voor de prettige sfeer waarin ik bij jullie heb kunnen werken.

De medewerkers van de afdeling Medische Microbiologie van het Academisch Ziekenhuis Maastricht, in het byzonder Dr. Jan Jacobs - lotgenoot in de laatste faseben ik erkentelijk voor het interesse en de steun tijdens de afronding van het proefschrift. Paulus en Marte-Sophie, jullie wisten precies wanneer er voor de nodige afleiding gezorgd moest worden. Goed gedaan !

Sonja, bedankt voor je geduld. 



\section{CURRICULUM VITAE}

De auteur van dit proefschrift werd geboren op 4 december 1954 te Kerkrade. In deze plaats behaalde hij in 1972 het diploma h.b.s.-B. Vervolgens studeerde hij biologie aan de Katholieke Universiteit Nijmegen alwaar hij in 1979 het doctoraal examen aflegde. Van 1976 tot 1985 was hij als docent werkzaam in het middelbaar en hoger onderwijs. In 1982 begon hij met zijn studie geneeskunde aan dezelfde Universiteit, waar hij in 1989 het artsexamen aflegde. Tijdens deze studie verrichtte hij onderzoek op de afdeling Chemische en Experimentele Endocrinologie van het Radboudziekenhuis te Nijmegen. $\mathrm{Na}$ het artsexamen werd het onderzoek verricht dat tot dit proefschrift leidde. Het dierexperimentele deel van dit onderzoek werd uitgevoerd op de afdeling Klinische Fysiologie van de Ademhaling (hoofd: Prof.dr. S.C.M.Luijendijk) van de vakgroep Pulmonologie van de Rijksuniversiteit Limburg. De experimenten bij patiënten en gezonde proefpersonen vonden plaats op de afdeling Longfunctie (hoofd: Prof.dr. H.Th.M.Folgering) van het Universitair Longcentrum Nijmegen, locatie Dekkerswald. Tevens was hij werkzaam als arts assistent op de klinische afdeling en de afdeling Longfunctie van het Universitair Longcentrum Nijmegen, locatie Dekkerswald en werkte hij als klinisch beoordelaar bij de Directie College ter Beoordeling Geneesmiddelen van het ministerie van VWS. In 1995 begon hij met de opleiding tot Medische Microbioloog bij het Academisch Ziekenhuis Maastricht.

Hij is getrouwd met Sonja Lenzen. Ze hebben twee kinderen, Paulus en Marte-Sophie. 


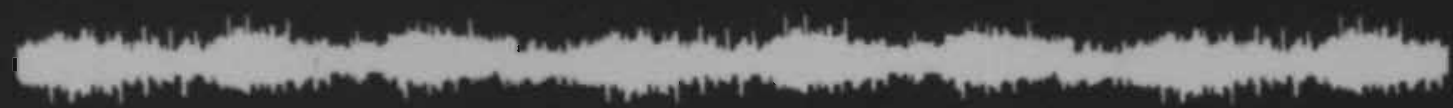

